Portland State University

PDXScholar

\title{
Writing Chinuk Wawa: A Materials Development Case Study
}

Sarah A. Braun Hamilton

Portland State University

Follow this and additional works at: https://pdxscholar.library.pdx.edu/open_access_etds

Part of the Bilingual, Multilingual, and Multicultural Education Commons, Indigenous Studies Commons, and the Modern Languages Commons

Let us know how access to this document benefits you.

\section{Recommended Citation}

Hamilton, Sarah A. Braun, "Writing Chinuk Wawa: A Materials Development Case Study" (2010). Dissertations and Theses. Paper 2875.

https://doi.org/10.15760/etd. 2870

This Thesis is brought to you for free and open access. It has been accepted for inclusion in Dissertations and Theses by an authorized administrator of PDXScholar. Please contact us if we can make this document more accessible: pdxscholar@pdx.edu. 


\section{THESIS APPROVAL}

The abstract and thesis of Sarah Althea Braun Hamilton for the Master of Arts

in Teaching English to Speakers of Other Languages were presented December 3, 2009, and accepted by the thesis committee and the department.

COMMITTEE APPROVALS:

Thomas Dieterich, Chair

Samuel Keith Walters

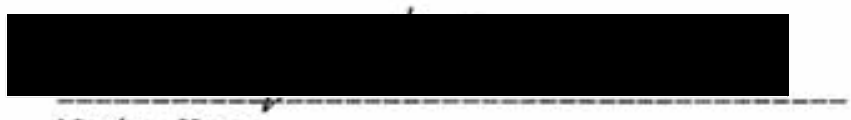

Nariyo Kono

DEPARTMENT APPROVAL:

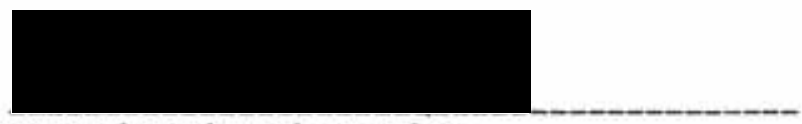

Samuel Keith Walters, Chair

Department of Applied Linguistics 


\section{ABSTRACT}

An abstract of the thesis of Sarah Althea Braun Hamilton for the Master of Arts in Teaching English to Speakers of Other Languages presented December 3, 2009.

Title: Writing Chinuk Wawa: A Materials Development Case Study.

This study explored the development of new texts by fluent non-native speakers of Chinuk Wawa, an endangered indigenous contact language of the Pacific Northwest United States. The texts were developed as part of the language and culture program of the Confederated Tribes of the Grand Ronde Community of Oregon for use in university-sponsored language classes. The collaborative process of developing 12 texts was explored through detailed revision analysis and interviews with the materials developers and other stakeholders.

Fluent non-native speakers relied on collaboration, historical documentation, reference materials, grammatical models, and their own intuitions and cultural sensibilities to develop texts that would be both faithful to the speech of previous generations and effective for instruction. The texts studied were stories and cultural information developed through research-based composition, translation from interlinear and narrative English in ethnographic sources, and editing of transcribed oral narrative.

The revision analysis identified points of discussion in the lexical development and grammatical standardization of the language. The preferred strategy for 
developing new vocabulary was use of language-internal resources such as compounding, although borrowing and loan translation from other local Native languages were also sometimes considered appropriate. The multifunctionality of the lexicon and evidence of dialectal and idiolectal usage problematicized the description of an "ideal" language for pedagogical purposes. Concerns were also expressed about detailed grammatical modeling due to potential influence on non-native speaker intuitions and the non-utility of such models for revitalization goals.

Decisions made in the process of developing texts contributed to the development of a written form of Chinuk Wawa that would honor and perpetuate the oral language while adapting it for the requirements of inscription. The repeated inclusion of discourse markers and the frequent removal of nominal reference brought final versions of texts closer to oral style, while inclusion of background information and the avoidance of shortened pronouns and auxiliaries customized the presentation for a reading audience.

The results of this study comprise a sketch of one aspect of the daily work of language revitalization, in which non-native speakers shoulder responsibility for the growth of a language and its transfer to new generations of speakers. 
WRITING CHINUK WAWA: A MATERIALS DEVELOPMENT CASE STUDY

by

SARAH A. BRAUN HAMILTON

A thesis submitted in partial fulfillment of the
requirements for the degree of
MASTER OF ARTS
in
TEACHING ENGLISH TO SPEAKERS OF OTHER LANGUAGES

Portland State University

2010 
This thesis is dedicated to the memory of the Chinuk Wawa speakers

who shared their language and their stories

and to language workers everywhere. 


\section{ACKNOWLEDGMENTS}

Over the past two years I have been privileged to learn Chinuk Wawa from my wonderful teachers Henry Zenk, Tony Johnson, Janne Underriner, Judith Fernandes, Jedd Schrock, and Evan Gardner. With their passion and care, the language is growing and flourishing. This thesis is just one small manifestation of my deep gratitude for the opportunity to become a speaker of Chinuk Wawa. I am especially grateful to Tony Johnson for his support of this research.

Tom Larsen, Henry Zenk, and Chris Doty kindly granted me permission to use and cite their unpublished manuscripts. Henry Zenk and Jedd Schrock generously shared their texts, time, energy, thoughts, opinions, and resources with me. I am grateful for their friendship, and I greatly appreciate their being a part of this project.

As I conducted this research, I greatly benefitted from the support and interest of my thesis committee, my other professors, and my colleagues in the Portland State University Applied Linguistics Department. My colleagues Lael Easton and Errin KillionBeck provided invaluable comments to a draft of this thesis. Abigail Pecore encouraged me to attend my first Chinuk Wawa class, and she debriefed with me often about this research. I also benefited from the support and enthusiasm of my Chinuk Wawa classmates, especially Ann Fulton and Thomas Thacker. This thesis was typeset in Gentium with the crucial assistance of Joel Cherney.

And, of course, none of this would have been possible without the life-giving companionship of my husband (and favorite librarian) Michael Braun Hamilton. 
TABLE OF CONTENTS

ACKNOWLEDGMENTS ......................................................................................................ii

LIST OF TABLES .........................................................................................................

LIST OF FIGURES ...............................................................................................................

1. INTRODUCTION: The case in context................................................................... 1

1.1. Setting the scene …................................................................................................ 2

1.2. Chinuk Wawa in historical context ...................................................................... 4

1.3. Chinuk Wawa revitalization at Grand Ronde...................................................... 8

1.4. Chinuk Wawa in the context of language revitalization.....................................13

1.5. Chinuk Wawa in the context of second language writing and translation..... 20

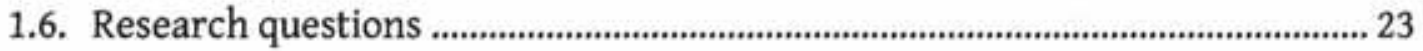

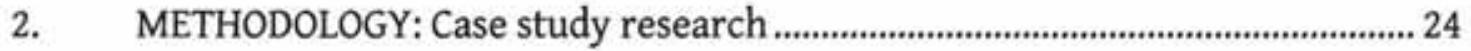

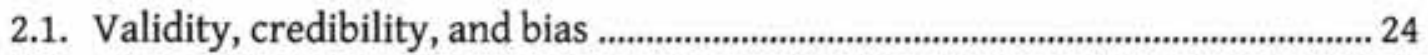

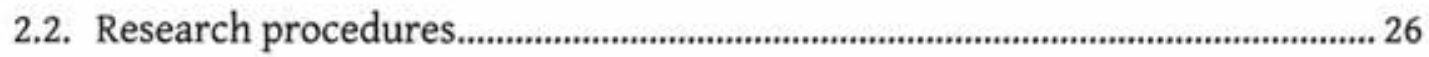

2.3. Text analysis ……............................................................................................... 27

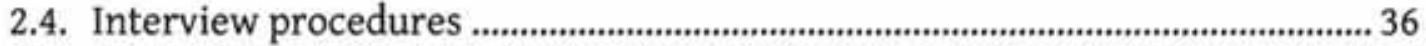

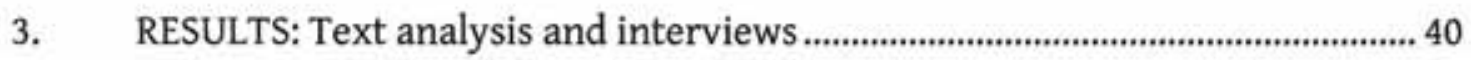

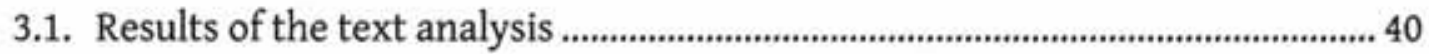




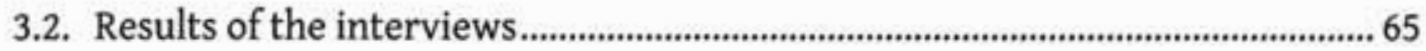

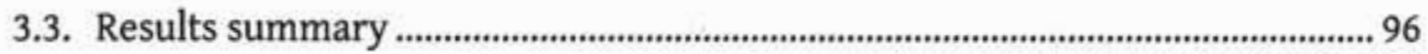

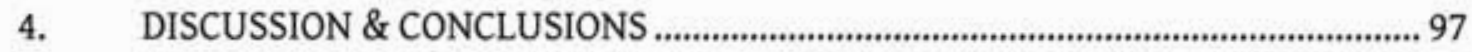

4.1. Variation, standardization, and development.................................................99

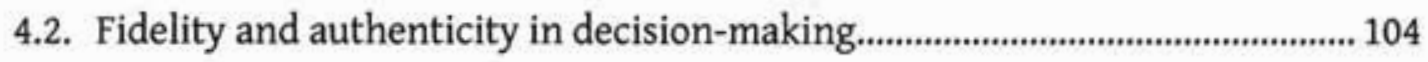

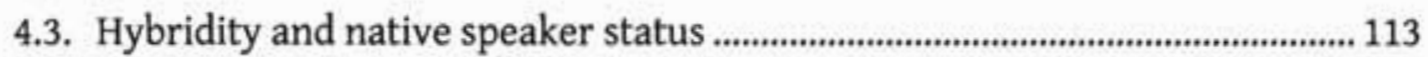

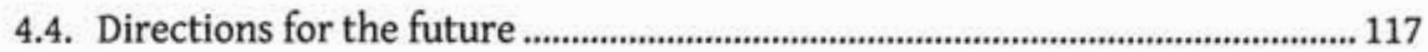

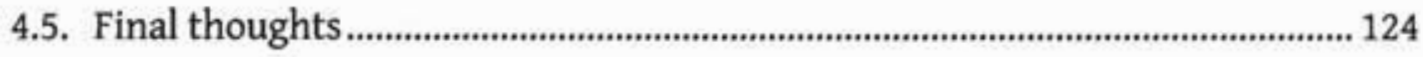

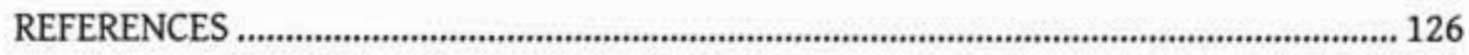

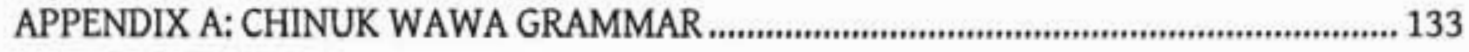

APPENDIX B: TEXTS IN THE STUDY

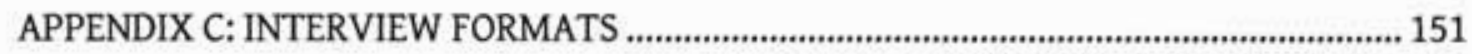

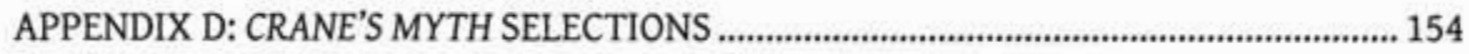

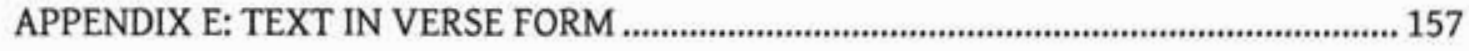




\section{LIST OF TABLES}

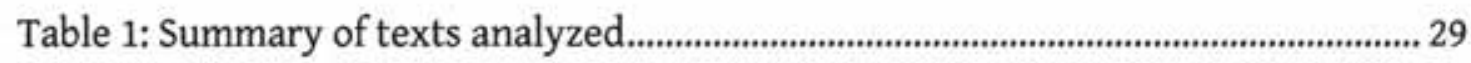

Table 2: Change categories used in text analysis ............................................................. 34

Table 3: Tabulations of changes in each category ........................................................... 41

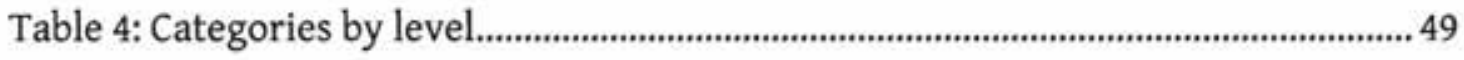




\section{LIST OF FIGURES}

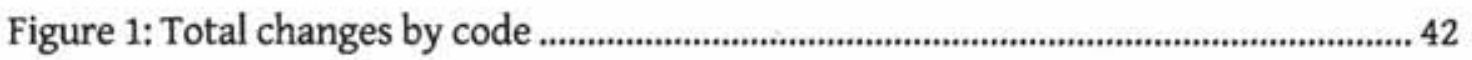

Figure 2: Net gain or loss in lexical categories ...................................................................4 44

Figure 3: Net gains and losses in lexical categories by text type ...................................... 46

Figure 4: Net gain/loss in edited texts and between independent translations ............. 48

Figure 5: Total changes by level ..................................................................................... 50

Figure 6: Change indices for each text and overall average ..............................................51

Figure 7: Changes by level: absolute and proportional .................................................... 52

Figure 8: Comparison of total changes with and without formatting...............................53 
1. INTRODUCTION: The case in context

This thesis is a case study of materials development for language revitalization. In this study I examined the collaborative development of new texts in a language with no native speakers and limited documentation. These texts have been developed by fluent second-language speakers who are also scholars of the language and its sociocultural history. I worked with these speakers to analyze the process of finalizing a selection of texts for use in university language classes. I used this analysis to uncover and explore the ongoing conversations about the lexical, grammatical, and narrative characteristics of the language. These conversations revealed the dynamics of language revitalization in the absence of fluent, authoritative native speakers both from the micro-perspective of individual second-language writing, translation, and editing decisions and from the macro-perspective of language planning and standardization.

Language communities around the world are engaged in projects to recover, rebuild, maintain, strengthen, and promote their heritage languages. This descriptive case study is addressed particularly to those communities as an example of language growth through collaborative text development. It is also, of course, directed first and foremost to those who work with this particular language, Chinuk Wawa, as a description of the current situation and a basis for future investigations. The case described here may also provide those who study translation and second language writing in general with an unusual, extreme case that may serve to elucidate the dynamics at the boundaries of their fields of study. 


\subsection{Setting the scene}

The day is Wednesday, February 4, 2009, and the time is 5:30 PM. Five people are gathered around a conference table at Portland State University in Portland, Oregon. In the center of the table sits a triangular microphone with a mute button in the center, and at the end of the room is a television on a cart. The screen is split to show two other groups around their own tables. This is the middle of AIL (American Indian Languages) 202, a videoconferenced Chinuk Wawa language class offered by Lane Community College in Eugene, Oregon in collaboration with the Confederated Tribes of Grand Ronde's language and culture education program. AIL 102 and AIL 202 are run simultaneously by five teachers: Tony Johnson at Grand Ronde, Janne Underriner and Judith Fernandes at Lane, Jedd Schrock at Chemeketa Community College in Salem, and Henry Zenk at PSU. At the beginning of each class all the classrooms meet together to discuss class business and cultural or historical topics, and then the AIL 102 classrooms at Grand Ronde and Lane split off. Now, halfway through the class period, the AIL 202 students at Lane, PSU, and Chemeketa are taking turns reading aloud from the texts in front of them. Each student reads a sentence or two and then offers an English translation.

“alta łaska łatwa khapa stik. alta xwashk'way yaka chaku-t'wax-tomtom. alta yaka iskam-hol $k^{h}$ apa stik-lima. alta yaka chaku-łax $k^{h}$ apa upkwina. uk uq'uxutt-skukum wikyaka nanich," reads one student in Portland. He translates: "Then they went to the woods. Then Heron he woke up. Then he...grabbed?...a branch? Then he came out of the basket." The student smiles. "That basket ogress, she didn't see!" 
The section of the television screen showing the group at Chemeketa increases in size as one of the students there speaks up. "What I always imagine," she says, "when I read this story, is that Heron sticks his head out of the basket and grabs onto the branch with his neck, and the basket ogress just keeps on walking, leaving Heron just dangling there by his neck." All three classes laugh at this image. For the next half hour they continue working together through the text of Crane's Myth. At some parts they stumble, at others they disagree, and at still others they digress into discussions of the desirable qualities of dried salmon, the laziness and trickiness of Coyote, the Chinookan names of different kinds of salmon, and the possibility of using -i on the ends of numerals to indicate iteration.

\subsubsection{My role in the scene}

The scene above is a recreation based on my own memory. From January 2008 through June 2009, I was a student in the teleconferenced Chinuk Wawa language classes offered at PSU. Since the summer of 2008, I have also been a contractor for the Tribes (hereinafter CTGR), providing technical support and editorial services for the production of a Chinuk Wawa dictionary based on the recorded speech of Grand Ronde community elders. When I first came to Chinuk Wawa class, I had no prior experience with the language and very little knowledge of Northwest Native culture or history. My personal heritage is almost entirely Western European, and I was raised in the eastern United States. My ancestors first came to the land of the Mohican and Munsee peoples in what is now lower New York State in 1669. In 1993 I became the 
first member of my family to "go west." Because of my interest in heritage language learning and the promotion of multilingualism, I jumped at the chance to study a Native American language in the process of active revitalization. What began as curiosity quickly became an abiding interest in and a deep commitment to Chinuk Wawa: its history, its present, and especially its future.

\subsection{Chinuk Wawa in historical context}

Chinuk Wawa is a contact language indigenous to the Pacific Northwest that became the community language of the Grand Ronde Reservation (now known as the Confederated Tribes of Grand Ronde) after the formation of the reservation in 1856. In this thesis I will follow Doty (2009) and the general practice of the CTGR language program in using the name Chinuk Wawa 'Chinook talk' to refer specifically to the variety of the language I am concerned with here: that spoken and cultivated at Grand Ronde. Chinuk Wawa is a variety of Chinook Jargon, ${ }^{1}$ which was used by non-Indians as well as by Indians ${ }^{2}$ throughout the Pacific Northwest. At its peak in the middle to late 1800 s, it was used as a lingua franca by Native peoples and European settlers throughout the Pacific Northwest as far north as Alaska, as far south as Northern

\footnotetext{
${ }^{1}$ Winford (2003) argued that the language is more accurately referred to as Chinook Pidgin, since the term "jargon" denotes "unconventional or idiosyncratic forms of interlanguage" (p.269), or a purely surface-level lexicon that speakers use with their L1 grammar (Silverstein, 1972). The term also has negative lay associations of language corruption or of exclusionary in-group vocabulary. While 1 agree with Winford, I maintain the name Chinook Jargon here in keeping with historical usage so as not to introduce further confusion into the nomenclature. thesis.

${ }^{2}$ I will use the terms "Indian," "Native American," and "Native" interchangeably in this
} 
California (Boas, 1892), and as far inland as Montana, by more than 100,000 speakers (Grant, 1998).

The pre- or post-European contact origins of Chinook Jargon and its historical status as a jargon, pidgin, or creole have been the subject of intense debate among historians and linguists (e.g. Lang, 2008; Silverstein, 1972; Thomas, 1935; Thomason, 1983; Thomason and Kaufman, 1988). This thesis, however, focuses on Chinuk Wawa as it is being cultivated today by the Confederated Tribes of Grand Ronde and does not address the historical origins debate. The CTGR refers to the language as a hybrid, and they state their position in an interactive presentation on their website as follows:

Before there was a reservation at Grand Ronde, there was a language held in common by many of our ancestors. This language is Chinuk Wawa, a hybrid indigenous language with words from local tribal languages as well as English and French. At Grand Ronde, it became the first language of many families on the early reservation. We feel that preserving the original common language of our community is an important aspect of preserving our identity. (Confederated Tribes of Grand Ronde, n.d., Ntsayka Ikanum, Our Language section, paragraph 1)

Chinook Jargon was also used by European explorers, traders, missionaries, and settlers, and much of the available published material on Chinook Jargon, especially dictionaries and reference books contemporary with the widespread use of the language (e.g. Gibbs, 1863; Hale, 1890; Shaw, 1909), is strongly associated with nonIndian pronunciation and usage. The phonologies of many pidgin languages maintain phonemes and distinctions that are shared by contributing languages, while discarding others. With Chinook Jargon, this led to Indians maintaining a variety of 
areal phonology that non-Indians in general had trouble pronouncing or representing orthographically (Thomason, 1983; Winford, 2003).

Various orthographies were developed and used by European settlers in newspapers, letters, and songs. Grant (1944) described the use of Chinook Jargon in newspaper articles and letters home from miners and other Pacific Northwest residents and listed a set of words that, at the time of her writing, were known to residents regardless of the frequency of their interaction with Native Americans. A few words, notably skookum 'strong' (skukum in CTGR orthography) can still be heard from both old-timers and teenagers in British Columbia, who use it with a meaning of 'strong, big, or good.' It has also been used as a brand name for products and businesses including coffee, power tools, and a rock band (McArthur, 2002, p. 216; Google search 7/26/2009). The role of Chinook Jargon in the construction of a Pacific Northwest identity is a fascinating topic and one strikingly pertinent to my own "immigrant" experience; however, this thesis does not directly address Chinook Jargon in non-Indian communities or in areas outside of Grand Ronde.

\subsubsection{Chinuk Wawa at Grand Ronde}

At Grand Ronde, Chinook Jargon developed the unique characteristics of the language which is now referred to as Chinuk Wawa or more specifically, Grand Ronde Chinuk Wawa. Zenk $(1984,1988)$ described this as a case of creolization, in which a pidgin language developed into a primary language of the community through use in family life. 
When the Grand Ronde Indian Reservation was formed by the US government, Chinuk Wawa was a common language of many of the people forcibly resettled there. None of the nine main "mother tongue" languages represented (Molala, Upper Chinook, Northern Kalapuya, Central Kalapuya, Southern Kalapuya, Umpqua Athapaskan, Takelma, Shasta, and Canadian French) had more than a 20\% share of the approximately 1,000 original residents, and only the three Kalapuyan languages were even close to being mutually intelligible (Zenk, 1988, pp. 110-111; Leavelle, 1998). Chinuk Wawa became the main language of the early community and especially of many homes in which parents came from different language backgrounds. Children were raised natively multilingual, with Chinuk Wawa as one of their two to three or more languages. Fluency in a tribal language, Chinuk Wawa, and English was the usual situation for older adults at the turn of the $20^{\text {th }}$ century (H. B. Zenk, personal communication, September 30, 2009). Even when community members acquired fluency in English, they often continued using Chinuk Wawa as their shared Indian language, and it was a preferred language for home use by some elders as late as the 1950's (Zenk, 1988; T. Johnson, personal communication, July 14, 2009).

It is clear that there are distinct differences between Grand Ronde Chinuk Wawa and Chinook Jargon in general. These differences were noted by Franz Boas (1933) when he reviewed Melville Jacobs' (1932) Notes on the structure of Chinook Jargon, which was based primarily on texts dictated by Victoria Howard, a speaker originally from Grand Ronde who also spoke Clackamas and Molala. Boas had used Chinook Jargon extensively to communicate with Charles Cultee, from whom he collected 
stories in Chinook (Chinook proper, not Chinook Jargon) and Kathlamet. He wrote that he had "used it with speakers of Tillamook, Clatsop, Lower Chehalis, Songish, Kwakiutl, Bella Bella, Tsimshian, [and] Haida" but that he had "never heard the forms used by Mrs. Howard" (p. 209). He attested that "neither the short form tas [Mrs. Howard's form for the third person plural pronoun taska] nor the contraction mujk [used by Mrs. Howard] for mamok, nor the reduplication of k'au [to yield Mrs. Howard's form k'au-k'au] is used by other speakers" (Boas, 1933, p 209). Those forms and others continue to distinguish Grand Ronde Chinuk Wawa today. ${ }^{3}$

\subsection{Chinuk Wawa revitalization at Grand Ronde}

There are no Chinuk Wawa educators today who learned Chinuk Wawa as a first language. Throughout its history, Chinuk Wawa has been an auxiliary language. Historically it was learned either as a lingua franca to communicate with out-group members (e.g. in trade contexts) or as a language of the home and Indian identity used to communicate with in-group members. While in the past many children were raised multilingually at Grand Ronde, there are no documented cases of monolingual adult Chinuk Wawa speakers (Zenk, 1988). In the 1930s Melville Jacobs collected Chinuk Wawa narratives from Victoria Howard and John B. ("Mose") Hudson (Jacobs, 1936, p. 1-17). After this there was no documentation until 1977, when Yvonne Hajda started working with Elmer Tom (Johnson and Zenk, 2009). In this interim, Chinuk Wawa

\footnotetext{
${ }^{3}$ Larsen (2002) contains an interesting discussion of some of the grammatical differences between Chinuk Wawa and Chinook Jargon from Kamloops, British Columbia [Kamloops Wawa] as described by Vrzić, 1999.
} 
slowly declined at Grand Ronde until there were only a few fluent elder speakers who had grown up using the language (Zenk, 1988). These elder speakers were able to share their knowledge with Hajda and with Zenk. Meanwhile, Tony Johnson, a Chinook Indian from the mouth of the Columbia River, was learning Chinuk Wawa from his elder, Tony Luscier. Those elders are now gone, but their language continues. The Confederated Tribes of the Grand Ronde Community of Oregon recognizes Chinuk Wawa as its shared heritage language and promotes its reclamation, renewal, and revitalization through their language program.

The current language program had its beginnings in 1978 when a Title IV grant allowed Eula Hudson Petite, a tribal elder and retired schoolteacher who had learned Chinuk Wawa in her family as a child, to teach Chinuk Wawa classes in the community (H. B. Zenk, personal communication, February 4, 2009): Gregry Davis (1998), a PSU student and CTGR intern, described the beginnings of formal language planning, beginning with the hiring of Tony Johnson as "Collections Curator-Language," in September of 1997 (p. 56). Johnson began gathering resources, working on orthography, and developing a lexical database that would be the precursor to the program's dictionary compiled by Henry Zenk: chinuk-wawa kakwa ntsayka tilixam taska munk-kamtəks ntsayka/Chinuk-Wawa As Our Elders Teach Us To Speak It, now in its second manuscript edition (Johnson and Zenk, 2009).

"Mrs. Petite was the daughter of John B. ("Mose") Hudson, who had dictated texts in Chinuk Wawa and Santiam Kalapuya to Melville Jacobs in the 1930's (Johnson and Zenk, 2009). 
In the summer of 1998, community language classes at Grand Ronde recommenced with the "Chinuk core group," led by Johnson and Zenk. This group was modeled on the Hawaiian "language nests," in which a small group of people commits to learning a language and disseminating it in the community. Late in 1999, Johnson and Janne Underriner, co-founder of University of Oregon's Northwest Indian Language Institute (NILI), organized "Special Studies Chinuk Wawa" classes sponsored by the University of Oregon. An immersion preschool was formed at Grand Ronde in 2001 , followed by an immersion kindergarten in 2004; these immersion programs are now supplemented by an afterschool program for grades K-8. The University of Oregon classes were redeveloped as a set of teleconferenced university classes which have been offered at four sites through Lane Community College since the fall of 2007. It is these last classes that are the focus of this study.

\subsubsection{Texts in Chinuk Wawa language classes}

There are no Chinuk Wawa textbooks yet available for the university classes, although syllabi, daily handouts, and exams have been developed for the two-year curriculum that completed its first run in Spring 2009. For the 200 level classes, most lessons included a text to be read aloud, translated orally into English, and discussed. Comprehension questions and grammar points in the lesson related to the texts; conversation topics, vocabulary items, and homework assignments were sometimes related to the week's text, but often also covered other topics. 
In the university classes, the strongest speakers (Tony Johnson, the director of the language program, and Henry Zenk, consulting linguist to the tribe) were available to answer questions and provide models for pronunciation and grammar. In class, these teachers emphasized the importance of maintaining what they referred to as the "Indian sensibility" of the language. This included the content as well as the form of speech. The phonemes, grammatical patterns, and narrative strategies that mark Chinuk Wawa as an Indian language were emphasized, and learners are discouraged from using English-like pronunciation based on orthographies in historical dictionaries (i.e. klootchman rather than tuchmon for 'woman'). This emphasis also extends to the texts used in classroom materials. The main corpus of historical Chinuk Wawa was recorded between 1928 and 1932 by Melville Jacobs and between 1977 and 1999 by Yvonne Hajda, Tony Johnson, Linda Fink, and Henry Zenk. These transcripts, along with a few texts composed in writing, are the primary data from which current knowledge of Grand Ronde Chinuk Wawa is derived, and they are an integral part of instruction in the language program. All of the illustrative examples in the main Grand Ronde section of the dictionary are drawn from them, and part of the corpus is appended to the dictionary so that learners can see the examples in context. However, instructional needs cannot be met with these texts alone. New texts have therefore been created, based on the models provided by the speech of community elders as documented in the corpus. This speech is commonly referred to as "elder Wawa." As the authors create and revise these texts, they must make decisions which, informed by their knowledge of elder Wawa, contribute to the development of the language. 
I became interested in the process of creating these new texts when we began to read the narratives dictated by Victoria Howard to Melville Jacobs in 1929 and 1930 and were instructed to write our own narratives using Mrs. Howard's text as a model. This exercise was very revealing to me because I had to ask myself what it was about Mrs. Howard's Wawa that made it "good Wawa," and how I could incorporate those features into my own writing. These are the questions that the teachers who are creating new texts for the language program must face as they write and edit, but on a scale that considers the entire canon of elder Wawa as well as the future of the language. This study explores these questions and how they were dealt with in the process of developing 12 texts for use as reading material in the Chinuk Wawa university classes.

The text that the AIL 202 class was reading in the scene that opened this section was Crane's Myth, appropriate for the winter quarter, the season in which ikanum 'myths' are traditionally told. ${ }^{5}$ The text in the students' hands had been translated into Chinuk Wawa by Jedd Schrock and edited by Henry Zenk. Schrock's source was Franz Boas' interlinear English in Chinook Texts (Boas, 1894, p. 107-112), which had been translated from Boas' transcription of Charles Cultee's narrative in Lower Chinook. Schrock's draft translation was reviewed, commented upon, and modified by Henry Zenk, who edited the Chinuk Wawa text without reference to the English source. Several drafts were exchanged, and the discussion continued into the

${ }^{5}$ According to local Native tradition, to tell these myth-age narratives from the time when animals were people and things were not yet as they are, in seasons other than winter would be to invite a rattlesnake bite or yellowjacket sting (Tony Johnson, personal communication in AIL 101). 
classroom as student interpretations elicited further revisions and suggestions for improvement. This study uses the changes and decisions made in the development of this particular text as an exemplar of the 12 texts surveyed in general.

\subsection{Chinuk Wawa in the context of language revitalization}

The project to revitalize Chinuk Wawa at Grand Ronde is unique in several ways. Chinuk Wawa is a contact language; it has several fluent second-language speakers and a reasonable amount of historical documentation but no native speakers; and it is restricted to a small population as an indigenous heritage language, although it was once the lingua franca of the entire Pacific Northwest. The case of Chinuk Wawa revitalization is similar to other language revitalization projects, however, in that there is a need to standardize orthography, expand the lexicon, codify the grammar, and teach the language.

There are other indigenous contact languages documented in the Americas, of which the best known are Mobilian Jargon, Delaware Jargon, and Eskimo Jargon (Drechsel, 1996; Winford, 2003), but they are not being revitalized at this time. Contact languages are common throughout the world, however, and many have large communities of speakers. Tok Pisin in Papua New Guinea and Haitian Creole in Haiti are two notable examples. Revitalizing Chinuk Wawa is different from projects to standardize and strengthen contact languages with many native, monolingual speakers. One such project was described for Kréyòl in Santa Lucia (Nwenmely, 1996). That project engaged in status planning to counteract views that Kréyòl was a 
degraded version of the higher status language ("broken French") and corpus planning to standardize it for official use. In this case there were many native speakers who could provide input into such planning and who might benefit from the increased status of their language. Chinuk Wawa also has faced criticism that it is not a legitimate language, and revitalizing it requires standardization. However, it tackles these issues without the benefit (or the hindrance) of a large community of speakers.

Due to its contact language nature, Chinuk Wawa has a small vocabulary and limited morphological and grammatical resources relative to other local languages. This makes it relatively simple to learn, but the multi-functionality of lexemes, the flexibility of grammar, and the demand for speaker creativity can make it difficult to control. These facts also mean that it is not genetically descended from or related to any other language (Thomason and Kaufmann, 1988), which makes it quite challenging to augment data on Chinuk Wawa with inferences from historical/comparative linguistics. The lack of morphology also limits the possibilities of inflection and derivation for lexical development.

One of the other important implications of Chinuk Wawa being a contact language is that was not originally the language of any specific people; it served to bring people together at one level rather than to differentiate them at another. Language revitalization programs often focus strongly on the interrelationship of language, culture, and identity, asserting as in the motto of the Yukon language program, "We Are Our Language" (Meek, 2009). This iconicity (Irvine and Gall, 2000), in which language directly indexes the identity of a community and its culture, is 
applicable to the case of Chinuk Wawa at Grand Ronde, but it is also somewhat problematic. Individuals and families at Grand Ronde have ties to their ancestors' other native languages, and other people throughout the region have ties to Chinuk Wawa. This thesis does not directly address these issues of identity and iconicity, but the hybridity of Chinuk Wawa is an important background to understanding the dynamics of the language development process.

The following sections situate the revitalization of Chinuk Wawa in the context of other endangered language revitalization programs. The current situation is described in terms of the general resources available and in terms of some of the basic needs of all revitalization programs: orthographical standardization, lexical development, and grammatical description.

\subsubsection{Processes and models for revitalization}

The spectrum of language revitalization programs runs from reclamation of "sleeping languages" that have not been spoken in generations, as documented by Amery (2000) for the Australian language Kaurna, to the institutionalization of preschool through graduate school education for native and second-language speakers, as achieved with Hawaiian (Wilson and Kamanā, 2001). Languages with relatively large numbers of speakers such as Hawaiian and Maori (in New Zealand) have been able to take advantage of being essentially national languages in order to gain significant government funding and support for their efforts. Other languages, such as the approximately 50 Californian languages discussed by Hinton (1996), may 
have only one or two fluent speakers and a very small heritage community. Several different systems have been devised for measuring language vitality (Fishman, 1991; Krauss, 1997 [as cited in Grenoble and Whaley, 2006]; UNESCO, 2003), and describing steps for revitalization (Hinton and Hale, 2001; Grenoble and Whaley, 2006). All of these systems strongly emphasize the importance of intergenerational transmission and language learning by children for language maintenance and revitalization. Most documentation of textbook and materials development for language revitalization focuses on the importance of native-speaker review, input, and oversight (e.g. deReuse, 1997; Palmer, 1988).

Currently, Chinuk Wawa is being taught to children and adults by fluent second-language speakers. These speakers are bridging the gap where intergenerational transmission was interrupted. Some of them learned directly from elders who had learned the language as children, and it was they who taught the others. Current speakers supplement their knowledge with narratives and other documentation from past elders. Sound recordings exist to back up phonological knowledge, and written documentation conveys information about grammar and narrative style as well as essential content.

\subsubsection{Orthographical standardization}

Writing an oral language often entails work to develop a standardized orthography (see Grenoble and Whaley, 2005; Hinton, 2001; and Hornberger, 1997 for overviews of the process). Chinook Jargon and Chinuk Wawa have been written with 
many orthographies. Those used by the few Grand Ronde elders who tried to write their language were either their own interpretation based on English or drawn from one of the historical dictionaries in popular distribution, especially Thomas (1935). The current CTGR Chinuk Wawa orthography is a modified Americanist phonemic orthography. Each lexeme in the dictionary has a standard spelling, but there are also alternate spellings of many words that represent variant elder pronunciations. The orthography used for transcription marks primary and secondary stress; stress marking is only used in everyday writing in the few cases where the stress mark differentiates lexemes: $k^{h} a p a$ 'in, at, on' versus $k^{h} a p a ́$ 'over there;' skukum 'strong' versus skukúm 'dangerous being,' and $k^{h}$ əpit 'only' versus $k^{h} ə$ pit 'stop.' Hyphenation is used in Zenk's transcriptions where the components of a compound have only one main stress, as in uk-nay-úlman 'that husband of mine' from Clara Riggs' anecdote “How We Went Up to Steal a Mattress" (Johnson and Zenk, 2009, p. 295).

\subsubsection{Developing the lexicon}

Chinuk Wawa as received from Grand Ronde elders has lexical gaps. ${ }^{6}$ This is true of many languages that are recovering from language shift. If the language is to be used for communication, new vocabulary is required, especially for technology and situations that did not exist when the language was stronger. For languages rebuilding

\footnotetext{
${ }^{6}$ For example, there are documented words from elders for spring (chxi-wam-iliii 'new warm land), summer (wam-ilifi 'warm land'), and winter ( $k^{k} u l-i l i i^{\prime}$ 'cold land'), but not for autumn. In this case there was an obvious pattern that allowed for the coining of chxi-khul iliii 'new cold land' for autumn (Johnson and Zenk, 2009, p. 31).
} 
from the knowledge of a few speakers or from archival materials alone, the lexical gaps are even more frequent.

In highly developed and highly successful language revitalization programs, there are institutions responsible for language planning at all levels. Te Taura Whiri i te Reo Māori (the Maori Language Commission) and Hale Kuamo'o (the Hawaiian Language Center), for example, were both established by legislative acts to be responsible for language standards, lexicography, and curriculum development for their languages (Hale Kuamo'o, 2009; Te Taura Whiri i te Reo Māori, n.d.). Smaller languages, such as Chochenyo, a sleeping language from California, have also implemented the model of a corpus planning committee drawn from members of the community (Grenoble and Whaley, 2005). New Chinuk Wawa vocabulary is often coined through individual innovation or brainstorming sessions, but there is currently no regular established procedure for either compiling requests or disseminating results. This type of corpus planning was an initial function of the Chinuk core group (Davis, 1998), but this function has not continued in a formal capacity.

Due to the limited lexical inventory, there are few close synonyms in Chinuk Wawa. Those that do exist usually have different etymologies, as in the case of leshaf 'egg' borrowed from French and $p^{h} a$ ? 'egg' borrowed from Santiam Kalapuya. It is therefore less likely that a writer would need to choose between close synonyms than that he or she would need to choose between options for coining a new lexeme to fill a lexical gap. Amery (2000, pp. 122-125) listed five options for restoring and building the Kaurna lexicon: borrowing, loan translations, using the language's own resources 
(derivation, compounding, and circumlocution), historical/comparative linguistics, and onomatopoeia. Grenoble and Whaley (2005) added to this list semantic extension and reclamation of words that have fallen into disuse. Vocabulary developed in Chinuk Wawa makes use of some but not all of these methods. By examining the text creation process in detail, this study examines preferences and motivations for different lexical development strategies. The possibilities of derivation and historical/comparative linguistics are limited because of Chinuk Wawa's limited morphological resources and lack of genetic connection to other languages, but Chinuk Wawa's "genius" for compounding was commented upon by many of the early recorders. In the words of Hale

It is in the faculty of combining and compounding its simple vocables - a power which it doubtless derives, in some degree, from its connection with the Indian tongues - that the Jargon has its capacity for expression almost indefinitely extended. (1890, p. 17)

Another potential method of forming new vocabulary is through the use of reduplication, a common feature of contact languages (Winford, 2003). Chinuk Wawa uses reduplication productively in some cases, but it also has several lexemes that came into Chinuk Wawa already reduplicated, without corresponding singular lexemes: musmus 'cow' and kwiskwis 'chipmunk' are two examples.' Theories of the mechanisms of creole formation are quite contentious (Winford, 2003), and although

\footnotetext{
'Interestingly, Clara Riggs, one of the elder speakers of the most recent generation, was known to treat two of these words, $k^{\prime}$ 'witk' wit 'pick' and $m a k^{h} m a k$ 'eat' as if they were productive Chinuk Wawa reduplications, also sometimes using the forms $k$ 'wit and maq. These forms were not attested from any other elders and appear to be idiosyncratic (Johnson and Zenk, 2009).
} 
it would be possible to propose new vocabulary based on knowledge of creolization processes and knowledge of local languages, this has not yet been attempted.

\subsubsection{Grammatical description}

Grammatical description is often treated more as a matter of language documentation than one of revitalization. Historical grammars are a key resource for language reclamation efforts (Amery, 2000), but the production of grammars is not a high priority for promoting language vitality. Rather, it is a part of documentation activity done to preserve the last remnants of a severely threatened language for future reclamation efforts (Fishman, 1991). Amery (2000) reported strong resistance to lexical borrowing from related languages in the Kaurna language reclamation project; however, that program did use grammatical borrowing strategies by reconstructing and fortifying Kaurna grammatical knowledge with information from related languages. Scholars of Chinuk Wawa look to the available documentation of local languages (especially Chinookan and, to some extent, local Salishan) for insight into Chinuk Wawa grammar, but because Chinuk Wawa is a contact language, the connections are more oblique than they are for languages with linear genetic relationships. A discussion of Chinuk Wawa grammar and grammatical description is provided in Appendix A.

\subsection{Chinuk Wawa in the context of second language writing and translation}

New Chinuk Wawa texts are created through composition or translation by second language speakers. Studies of second language writing have focused almost 
exclusively on writing in English and other majority languages, none of which are contact languages, undergoing revitalization, or primarily oral (Hinkel, 2002; Silva and Matsuda, 2001). These studies have found that second language learners use features of their first languages in their second language writing. It is possible, in languages with many speakers, to conduct studies in which native speakers evaluate the writing of non-native speakers and judge it against established standards of orthography, lexical semantics, grammar, and rhetoric. The writing practices of non-native speakers can also be compared to those of native speakers. In Chinuk Wawa (as in many Native American languages), there are only a very few existing written texts that were produced by native speakers; the vast majority of extant texts are transcriptions of speech. Evaluating current non-native writing by comparing it to these transcriptions would demonstrate a commitment to writing that directly represents orality, and would thus lead away from any development of a distinct written literary language. Such comparisons have not been done; however, the intuitions and standards used to develop, evaluate, and correct writing come mainly from the oral (transcribed) tradition, rather than from native-speaker writing.

Translation professionals generally translate into their native language, not into their second language. However, when no native speakers are available, translators must work into their second language. This is the case with Chinuk Wawa, complicated by the limited resources available to assure the "native-like" quality of the translation. Campbell (1998) examined the grammar of translators working into their second language (English) by using Biber's (1988) model of norms for various 
genres as a "yardstick." Biber's model was developed through a computer analysis of corpora consisting of a million and a half words of English. Chinuk Wawa has no such yardstick; even the most generous estimate of the entire historical corpus would be fewer than 20,000 words $^{8}$. Second language writing and translation is building the language.

Adab (2005) described the hybrid nature of all translated texts, which bring something unusual into the target culture as the result of deliberate translator decisions. For Adab, this hybridity is in contrast to "interference," which is the result of a lack of translator competence. When a hybrid text is accepted in the target culture, Abad argued that it is no longer hybrid, but becomes a normal targetlanguage text. This is exactly and explicitly the case with Chinuk Wawa texts created as translations: decisions made by the translators become encoded in the language as the texts are used to teach new speakers. The acceptability of the target text, which is of great concern to translators working into their second language when that language has many native speakers, is a foregone conclusion in the language classroom. Once any classroom negotiation of meaning has been completed, the texts are accepted and form a significant portion of the entire corpus of the language. The criterion for acceptance is comprehensibility, not coherence with native-speaker sensibilities. Abad suggested parameters of a restricted form of language that could be used successfully by translators in their second languages; in Chinuk Wawa,

\footnotetext{
${ }^{8}$ Although this is substantial in comparison with existing documentation of many other endangered or sleeping languages, this amounts to only about half the volume of words in this thesis.
} 
translation is an opportunity to creatively expand an already restricted language to accommodate the requirements of the source text.

\subsection{Research questions}

I am interested in processes of second language writing and translation and their implication for language maintenance and development. This study attempts to depict the process of fluent second-language Chinuk Wawa speakers developing Chinuk Wawa texts through translation, composition, and editing. Seeking resolutions to some of my own questions about the grammatical structure of Chinuk Wawa, I initially intended to focus specifically on grammatical decisions. I found almost immediately, however, that the definition of "grammar" in Chinuk Wawa was an important trope of the discussion rather than a foregone conclusion. It was therefore much more interesting not to pre-judge whether a particular change had grammatical consequences and instead to allow the data to reveal the characteristics both of the language and the decision-making that forms it. I therefore organized my research around the following two guiding questions:

1. What types of changes are made between initial drafts and final versions of new Chinuk Wawa texts created for language learners?

2. What factors contribute to the decisions made by authors and editors developing new Chinuk Wawa texts? 


\section{METHODOLOGY: Case study research}

This thesis is an exploratory single case study. Case study research is similar to historical research in that it utilizes documents and artifacts to construct a broad picture of a spatially and temporally bounded situation. Case studies are usually contemporary, and thus also have access to interviews and direct observation (Yin, 1989). Case study research uses multiple investigative techniques with the goal, as described by Gerring (2007), of "insight" (p. 7). That insight may be into only the case itself, or also into similar cases or a larger phenomenon. Schramm (1971, as cited in Yin 1989) described case study research as attempting to "illuminate a decision or set of decisions: why they were taken, how they were implemented, and with what result" (p. 23). The present case study asks is primarily exploratory, asking "what and how" rather than "why." It uses an embedded design (Yin, 1989) to consider and compare particular texts and different groupings of texts, as well as the particular experiences of individual stakeholders. I then extrapolate from these analyses to gain holistic insight into the case.

\subsection{Validity, credibility, and bias}

The quantitative research tradition emphasizes the importance of internal validity, the certainty that observed effects are attributable to the independent variables studied, and external validity, the generalizability of findings to a population (Perry, 2005). This study is exploratory and primarily qualitative (despite the amount of counting involved in the text analysis), and I attempt neither to attribute effects to 
variables nor to generalize findings to a population. That does not exempt this study, however, from concern for standards of social-scientific rigor.

Yin (1989) suggested that even an exploratory case study must concern itself with internal validity, if not in causality, then at least in the inferences made when events are described or postulated that have not been directly observed. With regards to external validity, Yin suggested that case study results be generalized not to other cases but rather to theory, which then becomes the premise for investigating other cases. Creswell (2007) presented ways in which scholars have re-interpreted or replaced the concept of validity for qualitative research. These approaches emphasize dialogue with participants, triangulation of multiple investigative techniques and data sources, acknowledgement of the situated and constructed nature of knowledge, critical consideration of the researcher's role and assumptions, and resulting interpretations that are open to reinterpretation. My main validation strategies in this research were triangulation of the text analysis and interview data to check the validity of my inferences, repeated member checking with the main participants, peer debriefing, and clear statement of my involvement and bias. I greatly hope that the interpretations detailed here will serve as a springboard for further discussion and reinterpretation.

As mentioned earlier, I am a minor stakeholder in this case. This study, therefore, is an example of participant observation. My participation in Chinuk Wawa classes and in development of the dictionary has allowed me access to this case, its artifacts, and the stakeholders. The notes I kept from my attendance at both the 
university classes at Portland State and the community classes at the CTGR Portland satellite office were a valuable resource for me as I conducted this research. Participant-observation research can be criticized for introducing bias (Yin, 1989). I hope, in this case, that my bias is clear. While I have attempted to be impartial and objective with regards to my observations and analysis, I wholeheartedly support the CTGR language program and the work of the participants in this study.

\subsection{Research procedures}

This study explores the case of 12 Chinuk Wawa texts using two primary tools: text revision analysis and semi-structured interviewing. Revision analysis is a technique of composition and translation studies that examines and taxonomizes the differences between written drafts of a document. In this case, I expanded it to also accommodate comparison of independent translations of a source document by two different authors. Faigley and Witte (1981) proposed a taxonomy for self-revision that divided changes into two basic categories: those that changed the meaning of the text, and those that did not. This taxonomy and its subdivisions have been used by other scholars to study student writing processes and the effects of peer and teacher review (e.g. New, 1999). Translation studies, such as the one conducted by Turkkonen-Condit, Mäkisalo, and Immonen (2008), tend also to focus on self-revision, categorizing changes according to whether they correct "errors" or move the final text away from "literal translation." In this study I chose not to work with a readymade taxonomy such as Faigley and Witte's, since none of the available taxonomies addressed cases 
similar to this one, and I wished to see what would be revealed by the interaction of my observations of the language and the texts themselves without explicit interference from models made for studying self-revision or revision of majority languages.

Working from the proposition that the types and frequencies of changes made to texts during revision processes should provide insight into the ways in which the language was developing, I first categorized and tabulated differences between available versions of the texts. I then used the resulting categories as a basis for general interviews with the text developers and other curriculum stakeholders. In order to investigate concrete examples of revision changes in context, I then reviewed a marked-up copy of one text, Crane's Myth, with both developers to elicit their recollections of their writing processes, their current reflections on the text, and their opinions on the issues raised by the changes. The counterpoint between my investigation of the changes to the texts and my conversations with their developers, along with the observations and perspectives of curriculum designers and students (including myself), provides a framework for discussion of this case.

\subsection{Text analysis}

\subsubsection{Selecting the texts}

The artifacts of this case are the texts used as lesson materials in the teleconferenced university Chinuk Wawa classes offered through Lane Community College from September 2007 through June 2009. I solicited the instructors and 
program director for any drafts of texts included in the lesson handouts. With their assistance, I accumulated 10 edited texts that existed in draft and final versions, and two texts that consisted of independent translations of the same source text by different writers. I used all of these texts in the analysis. The longest text was 1,169 words, and the shortest was 60 ; average length was 476 words. Complete details on all the texts selected for analysis are presented in Appendix B; a summary is presented in Table 1 below.

Eight of the texts were drafted by Jedd Schrock and edited by Henry Zenk. A ninth was one of my own homework assignments, edited by Zenk for reading in class and use with younger learners. These nine edited texts fit the model of narrative or expository texts composed or translated by a somewhat less proficient speaker and edited by a main curator of the language. The remaining three texts are different. The parallel translations were presented in an alternating line-by-line format to provide a learners with an opportunity to compare a diversity of literary styles. In both cases one of the translations is that of Zenk; the other translators represented are Schrock and Evan Gardner, teacher of community classes at the CTGR Portland and Eugene satellite offices. The final text is a derived from a transcript of Grand Ronde elders Eula Hudson Petite, Martha Hudson Mercier, and Velma Mercier collaboratively retelling a recollected folk tale in Chinuk Wawa, recorded by Zenk in 1982. This was presented to students as a narrative distilled from the raw transcript, with tangential discussions and restatements omitted and spelling standardized. An introduction was included in English that described the context of the story, followed by the transcript 
itself. This presentation allowed learners to observe how a literary text had been created from archival materials.

Table 1: Summary of texts analyzed

\begin{tabular}{lll} 
Edited texts & Parallel translations & Edited transcript \\
\hline $\begin{array}{l}\text { Translations } \\
\text { War: JS/HZ }\end{array}$ & Four Generations: JS, HZ & Black Bull of an Hour: MM, VM, EP/HZ \\
The News Precedes Coyote: JS/HZ & Good Old Days: EG, HZ & \\
Crane's Myth:JS/HZ & & \\
Coyote and the Frogs: JS/HZ & Key to initials: \\
Clackamas Marriage:JS/HZ & JS Jedd Schrock \\
& HZ Henry Zenk \\
Compositions & SBH Sarah Braun Hamilton \\
Hairdressing:JS/HZ & EG Evan Gardner \\
& MM Martha Mercier \\
Decoration: JS/HZ & VM Velma Mercier \\
Hattie Hudson: JS/HZ & EP Eula Petite \\
Red Riding Hood: $\mathrm{SBH} / \mathrm{HZ}$ &
\end{tabular}

\subsubsection{Categorizing changes}

I reviewed all the texts as Microsoft Word files in "tracked changes" format. For the parallel translation texts, Zenk's version was used as the "final" version. ${ }^{9}$ The accuracy of the change tracking was confirmed by manual comparison of the individual versions. Four very basic types of changes emerged: words added, words removed, words altered in form, and words replaced with other words. Although I attempted to address the texts with a fresh mind, this was not entirely naïve or open coding (Creswell, 2007). As a learner I had become interested in the uses of pronouns,

${ }^{9}$ Although the differences between the two translations in these texts were just that (differences), I will continue to refer to them as changes when discussed in aggregate with the edited texts. 
auxiliaries, overt subject and object NPs, and the use of the temporal adverb alta 'now, then' as a discourse marker, and this influenced me to form specific categories for these items. I did not direct this level of attention to changes involving, for example, degree and manner adverbs, which fell into a "catch all" category. My knowledge of the language and previous experience with the texts in their intended pedagogical setting allowed me to distinguish the types of changes from one another in the way that I did. I knew, for example, that the replacement of oq'óxotł with uq'uxutł was an orthographic change having to do with preferred standardized spelling of a borrowed word, while the replacement of yaka with yaxka changed the third person singular pronoun to an emphatic form, and the substitution of $k^{h}$ apá for $k^{h}$ apa replaced a preposition with a locative deictic.

Once I had annotated the "tracked changes" version of each text in hard copy, I compiled an initial list of change categories and did an initial tabulation. I was interested in counting the number of discrete decisions made, rather than multiple instantiations of the same decision, so I counted types of changes rather than tokens. Many orthographical and some lexical substitution changes were made globally, such that $A$ was replaced with $B$ throughout the text. Only the first occurrence of these global changes was counted. Individual tokens of the same change were counted when the change was applied on a case-by-case basis according to context. For example, in Crane's Myth, the spelling of Crane's name was changed from quáshquash to $q^{h}$ wash $^{h}{ }^{h}$ wash throughout the text. This change was coded once as ORTH (orthography), and the 23 subsequent instances of this change were not coded, so as to 
avoid counting 24 changes for what was essentially one decision. In Coyote and the Frogs, on the other hand, munk-mitayt 'put, cause to be located' was changed once to munk-t'lip 'insert, cause to penetrate.' This change was coded as LX, the catch-all category for lexical substitution. Any second occurrence of this change would also have been coded, since there was an instance of munk-mitayt that was not changed, and in fact there was an instance of munk-mitayt being substituted for another word (iskam 'get') in another context, showing that it was not the use of munk-mitayt per se that was being rejected (or replaced) by the editor, but its use in a particular context.

Throughout the coding and tabulation process I noted possibilities for subcategorization and I began to think of the changes in terms of three overarching categories: vocabulary, grammar, and narrative strategy. My conceptions of some categories altered over time as I considered the totality of changes in their contexts. I revised the initial categories based on my notes about possible sub-categories and category-interior trends, as well as comments from my initial interviews and discussions with stakeholders. This yielded a second working list of categories, which I used to re-code the changes using the digital files for each text so that I could easily search for and review all instances of each type of change. While coding the texts in this way I became interested in the possible semantic and grammatical categories of the words and information being added, deleted, and substituted in the "catch-all" category. I therefore added marginal comments to these codes specifying "locative," "temporal," "directional," etc. for later review. 
At this stage in the coding process I enlisted the assistance of a fellow student from Chinuk Wawa class in testing the validity of my codes and categories. She first annotated the changes in one of the short texts without knowing my codes, and then used my list of codes to code a fresh copy of the same text. We compared her annotations with my own for that file and discussed possible changes to my system of categorization. Her initial notes (before seeing my working list) included a great deal of information about the narrative strategies of the author and editor, possible motivations for changes, and the effects of changes on her as a reader. Her application of my codes was in $95 \%$ agreement with my own coding for that section, but it seemed sparse and uninformative after the richness of her autonomous notes. My working list of categories included changes to major grammatical features (pronouns, auxiliaries, overt subjects and objects, discourse markers, compounding, word order), but it was not very fine-grained in terms of changes to the amount and type of information presented or the semantics and etymologies of substituted lexemes. Our discussion led me to delve more deeply into the uncategorized lexical additions, deletions, and changes, expanding my marginal annotations and compiling them into a master list which I then sifted and sorted to determine major themes in these changes. Several of these themes, such as Location, became main codes in my final list of categories.

After finalizing my categories, standardizing codes in each category, and reviewing the codes once again with the same colleague, I completed the coding of the digital files. I revised the coding in files that had been coded previously, and spotchecked all files to ensure consistent coding of the same types of changes. Since I did 
not have an independent coder with whom to compare my work, it is possible that the codes were not entirely consistent, that changes were missed or mis-coded, or that my decisions about how to code particular changes could be questioned. I am comfortable with this possibility because the purpose of this coding process was not statistical rigor but rather an intense familiarity with the texts and the revelation of patterns that could be presented to the materials developers for discussion.

The final list used to code the changes consisted of 18 categories with 45 corresponding codes. Table 2 below shows the categories rank ordered by total number of occurrences and arranged according to the category affected by addition, deletion, alteration, or substitution. This arrangement allows for the most concise grouping of codes, with the +/-HYP code, for example, standing for two possibilities: +HYP (hyphenation added) and -HYP (hyphenation removed). The addition of parentheses, as in (+/-)AUX, indicates that the $+/$ - is optional and there are therefore three possible codes: +AUX, -AUX, and AUX. This third code indicates one auxiliary substituted for another (e.g. hayu-kamtəks 'be knowing, be perceiving' changed to chaku-kəmtəks 'come to know, learn, realize'). Two categories have additional variables specified in their codes. The code for uncategorized lexical changes includes a variable \#, representing the number of contiguous lexemes affected. The code for pronoun 
changes includes a small letter $\mathrm{s}, \mathrm{o}$, or $\mathrm{p}$ to indicate if the pronoun coded is a subject, object, or possessive pronoun, as determined by the context of the change ${ }^{10}$.

\section{Table 2: Change categories used in text analysis}

\begin{tabular}{|c|c|}
\hline Category & Codes \\
\hline Lexical changes (type unspecified) & $(+/-) \mathrm{LX} \#$ \\
\hline Demonstratives & (+/-)DEM \\
\hline Personal pronouns & (+/-)PROs/o/p \\
\hline Hyphenation & $+/$-HYP \\
\hline Word order changes & wo \\
\hline Discourse markers & $(+/-)$ DM \\
\hline Paragraph breaks & +/-PARA \\
\hline Orthography & ORTH \\
\hline Subject noun phrases & $+/$-SUB \\
\hline Rephrasing (complex changes to content or meaning) & REPH \\
\hline Punctuation & (+/-)PUN \\
\hline Locative information & $(+/-)$ LOC \\
\hline Text formatting changes (indents) & $+/$-IND \\
\hline Auxiliaries & $(+/-)$ AUX \\
\hline Prepositions & +/-PP \\
\hline Sentence split or combination & $+/-\mathrm{SS}$ \\
\hline Object noun phrases & $+1-\mathrm{OBJ}$ \\
\hline Reduplication & +/-DUP \\
\hline
\end{tabular}

\subsubsection{Tabulating changes}

When final coding was complete, I re-tabulated the numbers of each code for each text. Lexical changes were sub-categorized by number of lexemes affected: 1,2, 3-5, 5-10, and more than 10 . Types of lexical changes were not tabulated per text, but were tracked in aggregate in a separate file, with marginal annotations in each text so that per-text tabulation could be carried out at a later time.

${ }^{10} \mathrm{Chinuk}$ Wawa pronouns are not distinguished by thematic or grammatical role. For more information, see Appendix A. 


\subsubsection{Data analysis}

Once the final tabulation was complete, I began to sort and analyze the data in order to see what patterns might be revealed. Changes were totaled for each category, and aggregated categories were proposed on the basis of characteristics such as "effect on the text" (addition, deletion, change, format, restructure) and "level of change" (lexeme, sentence, text). I calculated the net gains and losses in categories with codes for addition and deletion. In order to compare the number of changes across texts, I normed the counts to changes per 100 words by dividing the total number of changes in each text by the text's word count and multiplying the quotient by 100 . Since some changes consisted of alterations of only one word, and some consisted of the addition, deletion, or reordering of many words, this normed frequency does not represent the percentage of the text that was changed, but it does give a sense of the intensity of editing or overall "changedness" of each text. I used the normed frequencies to compare the texts to each other in terms of net gains and losses, overall changedness, and changes at the lexeme, sentence, and text level. The nine edited texts were compared to the parallel independent translations, and the texts were also compared by source type, so that any differences could be seen among the four texts that had been composed from notes, the three texts that had been translated from English narrative, and the two texts that had been translated from interlinear English. 


\subsection{Interview procedures}

In addition to the text analysis, I conducted a series of semi-structured formal interviews and held informal conversations with my fellow students and with instructors. All of the possible interview participants in this study were already personally known to me at the time that the study began, and their consent, support, and interest were essential to my planning and implementation. I conducted formal interviews with Henry Zenk and Jedd Schrock (the primary developers of the texts studied) and with Tony Johnson (the primary curriculum developer and Director of the language program). Johnson was not directly involved in the development of the texts analyzed in this study, but his perspective as a primary stakeholder in the development and deployment of the language and curriculum as a whole helped broaden my understanding of the context in which these texts and the decisions they represent are operating. The formal interviews took place over the course of several months in Portland and at Grand Ronde, and were audio recorded, annotated, partially transcribed, and archived digitally. These formal interviews were supported by many informal conversations with the interviewees, both in person and via email. These conversations, my conversations with fellow students and other instructors, and my own participant observations were recorded in detailed research notes.

\subsubsection{General interviews}

The first two interviews with Zenk and Schrock, as well the interview with Johnson, were semi-structured general interviews. The original outline for the general 
interviews is provided in Appendix $\mathrm{C}$ along with the questions developed from the text analysis. The general interviews did not address any specific texts or examples, but rather sought background information, general perceptions, and thoughts about Chinuk Wawa materials development, the university classes, and "sticking points" of Chinuk Wawa grammar, vocabulary, and style. I began conducting the interviews after I had completed my first review of the texts and my initial list of change categories. I used my experience with the texts and my nascent perceptions about the changes as a way to elicit the interviewees' perspectives, but I did not present them with a detailed list to review. Due to the friendly relationship between myself and the interviewees, these interviews often wandered from the topics suggested by the outline. The relatively free-flowing nature of the general interviews led to unexpected insights that helped direct the ongoing development of the categories for text analysis and expanded my attention from my initial focus on grammatical prescription.

\subsubsection{Retrospective interviews}

Three retrospective interviews were conducted with Schrock and Zenk. These interviews addressed the specific changes made in the development of the Chinuk Wawa translation of Crane's Myth, with reference to the English and Chinookan originals (Boas, 1894).

The first retrospective interview was with Schrock, who translated the text. I first asked him to describe the process of translating the text as he remembered it, and to mention anything that he remembered being particularly challenging or 
interesting. I then provided a "tracked changes" version of the text, in which I had highlighted changes that were particularly interesting to me. We went through the changes one by one, focusing on any that brought to mind any memories of the composition process or reflections on the revisions and choices made. I asked questions when I was curious about the reasons behind a certain choice or Schrock's impressions of a particular change, but mostly I allowed the changes to act as prompts to elicit descriptions of the considerations that had gone into the creation of the text.

Several months later, I was able to conduct a similar interview with Zenk, this time using a "parallel texts" version of Crane's Myth in which the draft and final versions were compared line by line. This presentation allowed for more effective visualization of the differences between the versions for eyes unaccustomed to reading the tracked changes format. During the time intervening between these two retrospective interviews, I had become much more familiar with the texts and the types of changes, so I was able to draw attention to particular changes that were repeated throughout the document or that seemed to be emblematic of general preferences. This avoided some of the tedium of going over every change in this long text one by one.

When the text analysis was complete and I had drawn tentative conclusions, I asked Schrock and Zenk to meet with me to discuss Crane's Myth one more time. By this time they had both read and commented on the draft results of this study. We discussed their experience working on the texts in general in relation to the results I had proposed, and considered directions for applicable conclusions. I highlighted 
emblematic changes in the "parallel texts" version of Crane's Myth and asked specific questions about these changes in order to clarify questions that had arisen in the course of the analysis. As I continued to revise the analysis and refine my discussion, my informants were kind enough to continue to answer my follow-up questions by email and in person. This progression from the initial retrospective interview with Schrock early in the text analysis process, through the group discussion when the analysis was tentatively complete, and the final follow-up questions about emailed examples provided on-going feedback between the text analysis and interview components of the study. 
3. RESULTS: Text analysis and interviews

\subsection{Results of the text analysis}

In this section, I detail the results of the text analysis that I conducted in order to answer my first research question. I wished to determine the types of changes made in the process of developing texts. Because I chose to consider two texts that are parallel independent translations of the same source, this analysis also compared the editing changes made in the collaborative texts to the "naturally occurring" differences between the independent translations.

I first present the total numbers of changes ${ }^{11}$ in each of the categories described at the end of Chapter 2. In order to examine the effect of these changes on the texts, I then discuss the net gains and losses in selected categories. I compare texts developed from different sources, and I compare the proportions of changes affecting the texts at the lexical, sentence, or narrative levels. My experimentation with groupings of changes and texts during the data analysis revealed few patterns based on development process, subject matter, authorship, or chronology. I found few such patterns, suggesting that the individual differences between texts outweighed other factors. The patterns I did find are described here. In this section I also include types and examples of changes that were coded in the "catch-all" category.

The purpose of the text analysis was to suggest directions for the interviews that would help answer my second research question. In actuality, the interviews also

${ }^{11}$ As discussed in Chapter 2, revisions to the nine edited texts, changes to the transcript, and differences between the translations in the two parallel translation texts will all be referred to generally as changes. 
provided additional ideas for analysis. The initial interview concepts developed by the text analysis are outlined at the end of this section, and the results of the interviews are described in Section 2.

\subsubsection{Types of changes}

Table 3 below shows the 18 categories and 45 corresponding codes described in Chapter 2, sorted by the number of tabulated incidences. Figure 1 charts the incidences by individual code.

\section{Table 3: Tabulations of changes in each category}

\begin{tabular}{|c|c|c|}
\hline Category & Codes & Incidences \\
\hline Lexical changes (type unspecified) & $(+/-) \mathrm{LX} \#$ & 667 \\
\hline Demonstratives & $(+/-)$ DEM & 104 \\
\hline Personal pronouns & $(+/-)$ PROs/o/p & 103 \\
\hline Hyphenation & $+/$-HYP & 100 \\
\hline Word order changes & Wo & 91 \\
\hline Discourse markers & $(+/-)$ DM & 90 \\
\hline Paragraph breaks & +-PARA & 75 \\
\hline Orthography & ORTH & 70 \\
\hline Subject noun phrases & $+/$-SUB & 65 \\
\hline Rephrasing (complex changes to content or meaning) & REPH & 64 \\
\hline Punctuation & $(+/-)$ PUN & 59 \\
\hline Locative information & $(+/-)$ LOC & 51 \\
\hline Text formatting changes (indents) & $+/-$ IND & 43 \\
\hline Auxiliaries & (+/-)AUX & 39 \\
\hline Prepositions & $+/-\mathrm{PP}$ & 21 \\
\hline Sentence split or combination & $+/-\mathrm{SS}$ & 18 \\
\hline Object noun phrases & $+/-\mathrm{OBJ}$ & 17 \\
\hline Reduplication & + -DUP & 16 \\
\hline TOTAL CHANGES & & 1693 \\
\hline
\end{tabular}




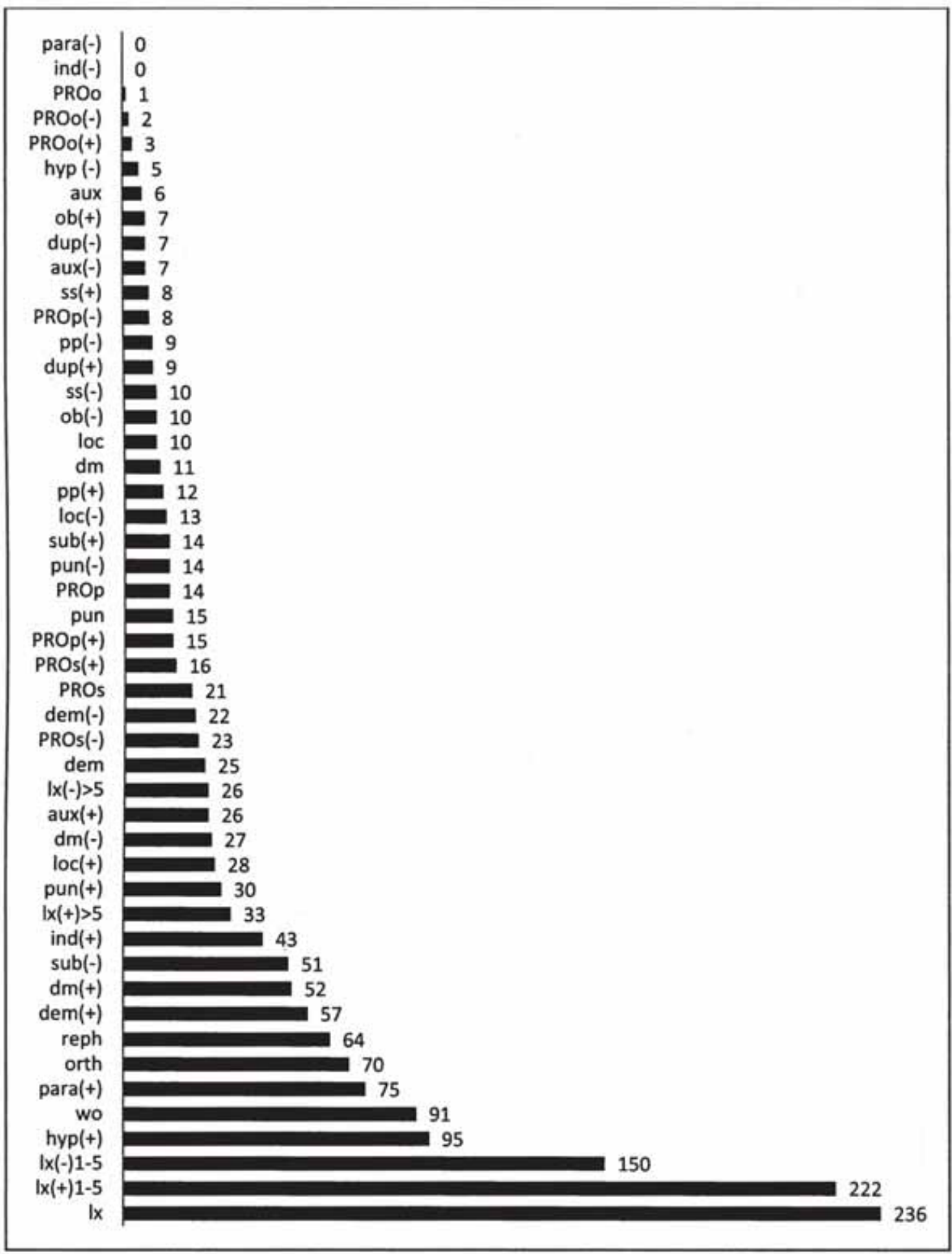

Figure 1: Total changes by code 
Almost $80 \%$ of the changes identified in these texts fit into the four broadest categories I noted in my first review of the texts: words added (29\%), words removed (21\%), words replaced with other words (17\%), and words altered in form (12\%). Although it may seem upon initial viewing of the tracked changes version of any one of these texts that it is "totally rewritten" (for an example, see the excerpt from Crane's Myth in Appendix D, Section 1), complex rephrasing comprised only $4 \%$ of the total changes marked.

Table 3 and Figure 1 show that the three "catch-all" codes (+LX, -LX, and LX) were the most common, accounting for 667 (39\%) of the total changes coded. These codes were applied to lexical additions, deletions, or substitutions in which the affected lexemes are other than the pronouns, demonstratives, discourse markers, prepositions, locatives, subject NPs, and object NPs that were assigned specific categories. The types and varieties of these unspecified lexical changes were investigated separately after the coding process; the results of that investigation are described further on page 54 below. The next five most common codes, those for the addition of hyphenation, word order changes, insertion of paragraph breaks, orthographic changes, and complex rephrasing, are similarly non-specific in that the codes could be applied in any context without requiring the presence of any specific words or grammatical roles. 


\subsubsection{Additions and deletions: net gain and loss}

Table 3 and Figure 1 track only the incidences of changes in each category, not the overall incidence of words (or punctuation, etc.) that fit those categories. Therefore, although Table 3 shows more than six times as many changes to demonstratives as changes to reduplication, the low frequency of reduplicated (or reduplicatable) lexemes proportional to demonstratives is not reflected. This information would not be accessible without a complete grammatical tagging of the corpus, which is beyond the scope of the present study. The net gain or loss in each category, however, can be calculated by subtracting the number of changes coded for deletion from those coded for addition, as shown in Figure 2.

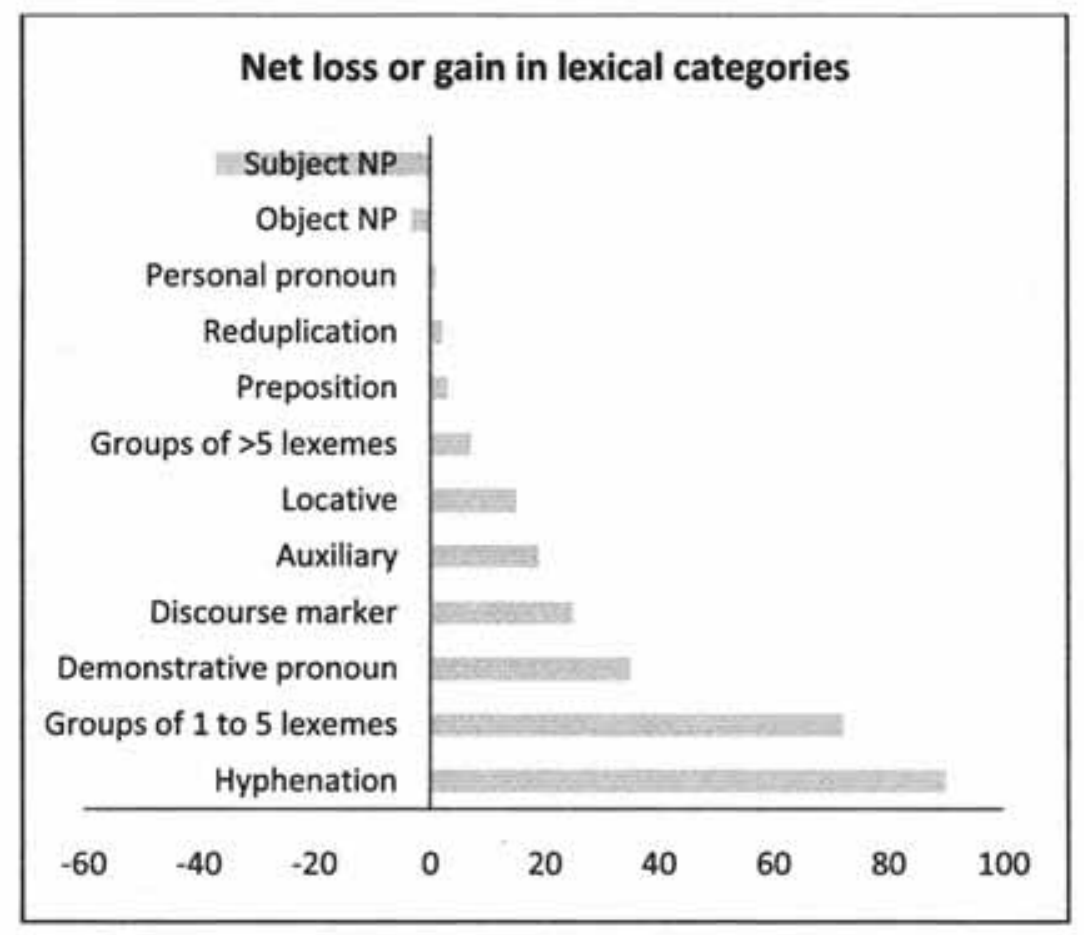

Figure 2: Net gain or loss in lexical categories 
Figure 2 shows that, overall, Zenk's versions of the texts (final edited texts and his independent translations) had fewer nominal references to participants and considerably more hyphenation than did the versions by other writers (Schrock, Gardner, and myself).The comparison also an overall net gain in unspecified lexemes in Zenk's versions. Personal pronouns showed a net gain of only 1 , showing that the numbers of personal pronouns added and removed was nearly equal; however, this was not equally distributed across grammatical roles: a net gain of 7 possessive pronouns was cancelled out by a net loss of 7 subject pronouns.

It must be noted that the net increase in the catch-all "unspecified lexemes" category does not necessarily indicate a net increase in word count, as the codes could indicate groups of one or more contiguous lexemes; however, on average the final collaborative texts were slightly longer than the drafts, although Zenk's versions of the parallel translations were both slightly shorter. Of the non-lexical categories not shown in Figure 2, punctuation showed a net increase, and formatting (indents and paragraph breaks) was only added to the texts, never removed.

\section{Comparison of net gains and losses by text type}

The texts in this study were created in four different ways: editing of a transcript (Black Bull of an Hour), translation from interlinear English glosses (How They Made War, Crane's Myth), translation from English narrative (The News Precedes Coyote, Coyote and the Frogs, Clackamas Marriage, Four Generations, Good Old Days), and composition based on English notes (Decoration, Hairdressing, Hattie Hudson, Little Red 
Riding Hood). The translations from English narrative included the two parallel translation texts (Four Generations and Good old Days). Figure 3 breaks down the net gain and loss shown in Figure 2 into these groups.

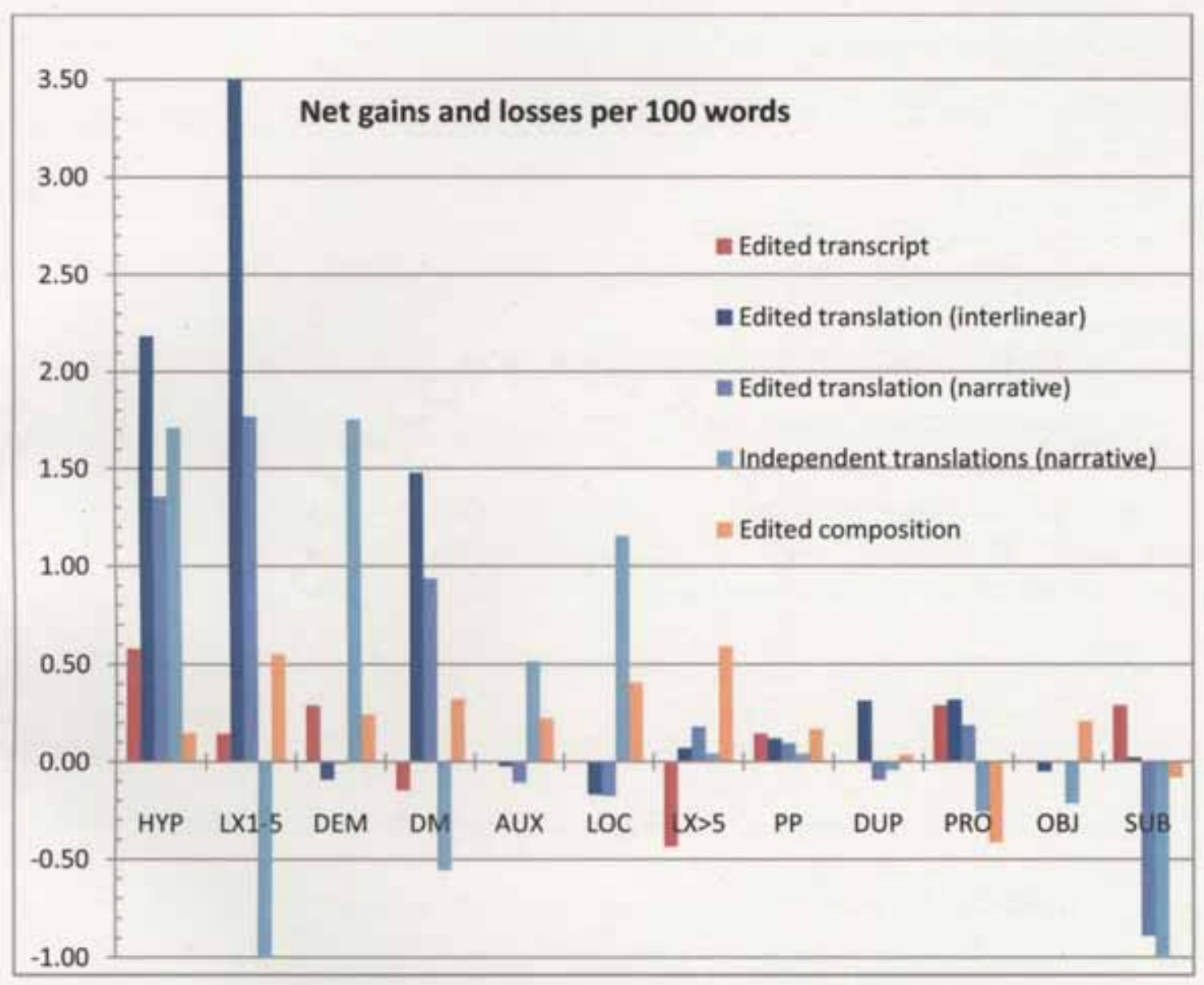

Figure 3: Net gains and losses in lexical categories by text type

This figure shows that there do seem to be differences among these five types of texts in terms of the net results of additions and deletions. Translations from interlinear glosses had the greatest net gain overall and received more net hyphenation, discourse markers, and single and small-group unspecified lexemes than the other types of texts. Edited translations from English narratives seemed to be 
similar to translations from interlinear glosses, although the net gains and losses were usually less pronounced. The strongest exception to this is in the category of explicit NP subjects, in which both types of translations from narrative showed a much greater net loss than other types of texts. This could indicate a lower number of NP subjects in the interlinear source texts, reflecting a Native narrative preference for pronominal subject reference.

The comparison of the independent translations showed a much higher net gain in Zenk's version for demonstratives and locatives, but unique net losses in discourse markers, object NPs, and groups of 1-5 unspecified lexemes. These may be signs of Zenk's personal style, as discussed below on page 48 in relation to Figure 4, which specifically compares Schrock and Zenk's collaborative and independent translations. Although all these types of texts showed a net increase in hyphenation, compositions were closer to breaking even than the others, and only compositions showed a net gain in auxiliaries and locatives. These compositions, since they were not constrained by translation processes, may be seen as the clearest indicator of Schrock's personal Chinuk Wawa style.

The source of the edited transcript was elder speech, and as such the interest was in preserving its integrity while presenting a readable text. Therefore it had very few changes, and very few words were added to it, so it shows a substantial net loss in large groups of lexemes. This represents editing that removed repetitions and artifacts of a transition between tapes. The net loss in discourse markers in the edited transcript may also represent removals of false starts. 


\section{Comparison of independent and edited translations}

In order to highlight the difference between Zenk's editing decisions and his choices in independent translation, I averaged the results from all of the texts composed by Schrock and edited by Zenk and compared them to the results from four Generations, which Schrock and Zenk both translated independently.

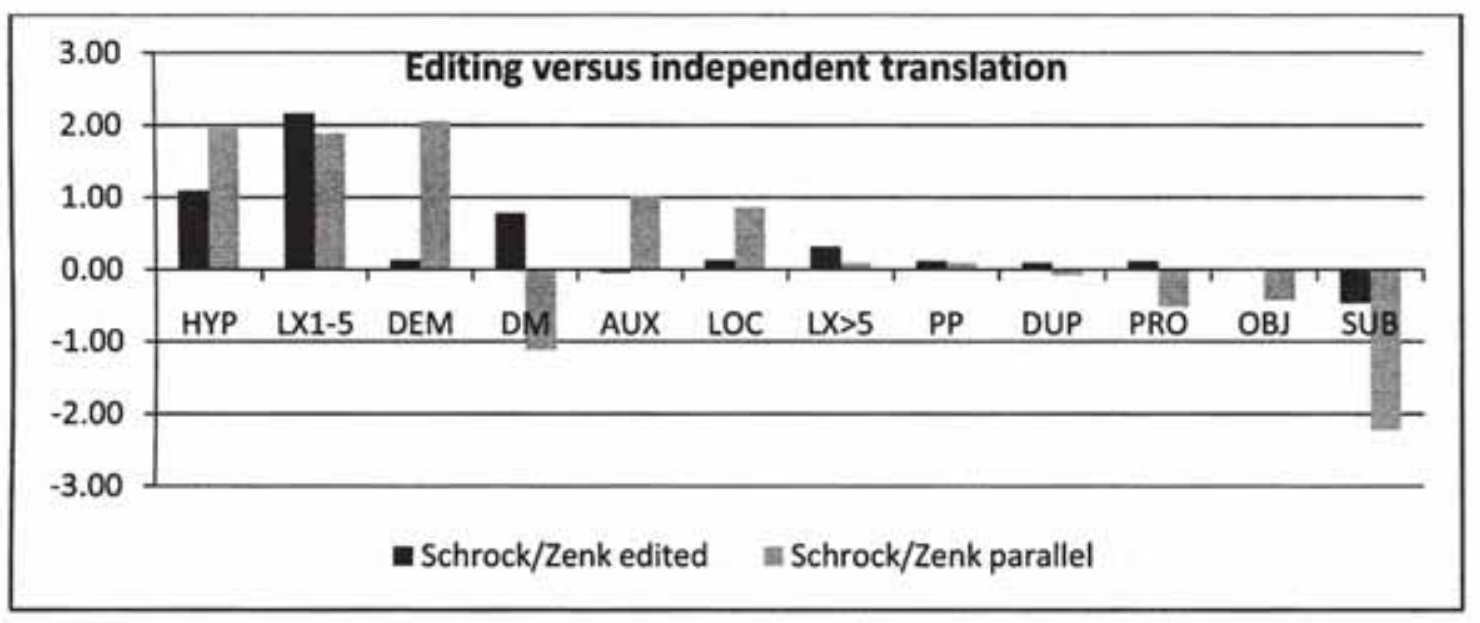

Figure 4: Net gain/loss in edited texts and between independent translations

Figure 4 shows some notable differences between the same two writers working in an editing relationship and preparing separate translations. Presuming that Schrock's writing stayed more or less constant, there is some indication here that Zenk used fewer explicit subject NPs in his own translations than he felt it was necessary to remove from Schrock's, and that he made more use of hyphenation, auxiliaries, and demonstratives in his own translations than he felt it was necessary to add. These differences may well be indications solely of the content of the Four Generations source text; however, they may also point towards fruitful inquiry into the 
characteristics of Zenk's Chinuk Wawa style and the way he deploys it as an editor and as a writer.

\subsubsection{Categorization of changes: by level}

One of the many ways the 45 codes used to analyze these texts can be sorted is by the "level" at which they take effect. In order to sort the codes in this way I asked myself the following questions: Does the change primarily affect a particular lexeme by changing its spelling or form, adding an auxiliary to it, or exchanging it for a different word? Does it primarily affect the sentence by adding or removing lexemes, adjusting punctuation, or changing the word order? Or, does it primarily affect a larger chunk of the text by adding or removing large numbers of words, restructuring the narrative, or adjusting the formatting of the document? Sorted in this way, the categories are organized as in Table 4.

\section{Table 4: Categories by level}

\section{LEXEME LEVEL}

Orthography

Hyphenation

Reduplication

Auxiliaries

Pronoun (substitute)

Demonstrative (substitute)

Discourse marker (substitute)

Locative (substitute)

Unspecified lexemes

(substitute)
SENTENCE LEVEL

Punctuation

Sentence split/combination

Pronoun (+/-)

Demonstrative (+/-)

Discourse marker (+/-)

Locative (+/-)

1-5 unspecified lexemes (+/-)

Preposition (+/-)

Subject NP (+/-)

Object NP (+/-)

Word order
TEXT LEVEL

$>5$ unspecified lexemes (+/-)

Paragraph breaks

Indenting

Complex rephrasing 
By analyzing the relative proportions of changes at these levels, it is possible to see that the majority of the changes in these texts take effect at the sentence level, as shown in Figure 5 below.

\section{Total Changes by Level}

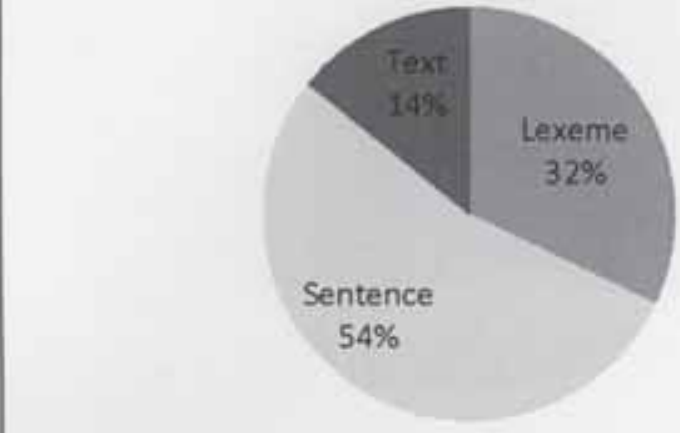

Figure 5: Total changes by level

Of course, lexical and sentence level changes can and do affect the narrative structure of the text by changing content, emphasis, and style. Figure 5 shows each code assigned to only one level, which is not reflective of the inherent interrelatedness of these levels. Discourse markers, for example, here assigned to the sentence level, also drive the narrative at the text level. The addition and deletion of discourse markers make up $5 \%$ of Figure 5 . If they were to be moved to the text level, they would increase the proportion of text-level changes to $19 \%$ and decrease the proportion of sentence-level changes to $49 \%$. It would be perhaps more realistic, however, to envision a $5 \%$ overlap between these two categories, or to understand that all the boundaries here are somewhat fuzzy and artificial. 


\subsubsection{Changes by text}

Figure 6 below shows the total changes in each text, normed per 100 words as described above.

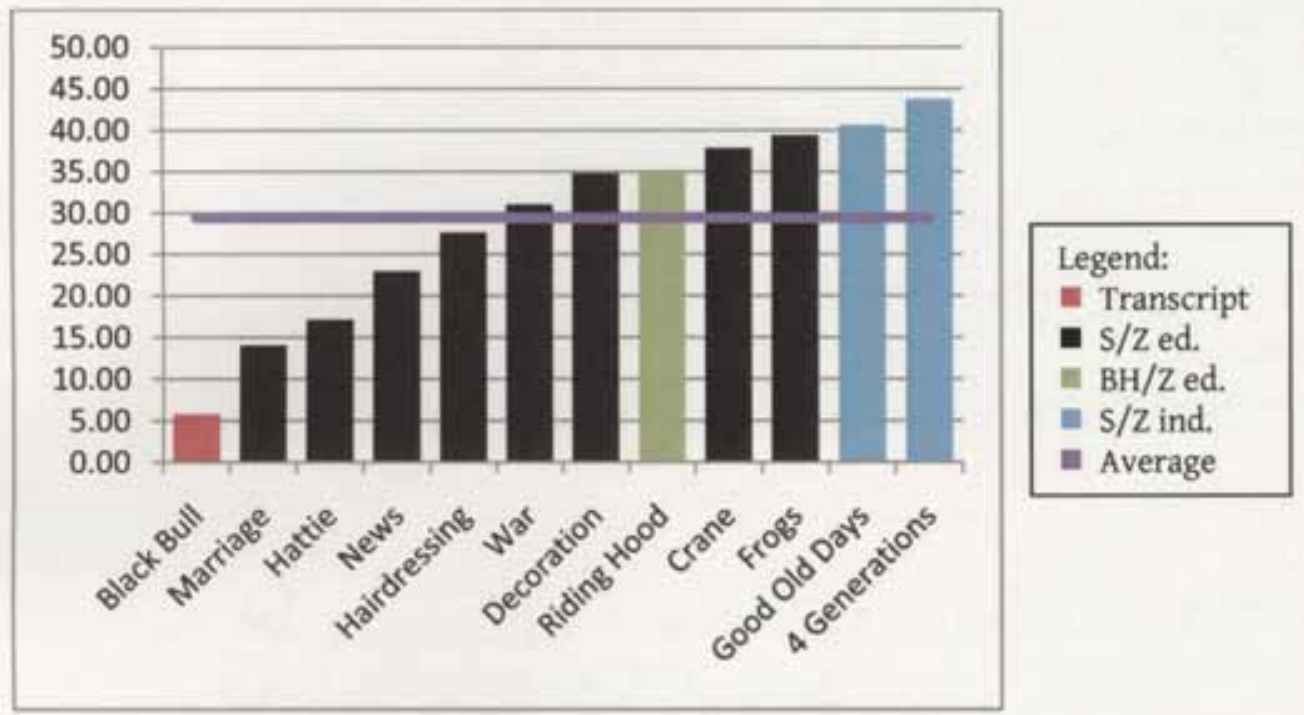

Figure 6: Change indices for each text and overall average

Figure 6 shows that the standardized transcript showed the least difference between versions while the parallel translations showed the greatest differences. The most changed edited text, Coyote and the Frogs, however, was only very slightly less changed than Good Old Days, showing that some draft and final versions of edited texts could be almost as different, overall, as independent translations, although as we see below, the changes may be of different types. The least changed edited files, Clackamas Marriage and Hattie Hudson, were also the most recently developed. Both of these texts are from Spring term of 2009; two months passed between the completion of Coyote and the Frogs and the completion of Clackamas Marriage. 
Figure 7 shows the absolute and proportional changes for each text, broken down by level as in Table 4. Changes at the sentence level were most prevalent in all of the texts. In all but one, lexeme level changes were second and text level changes third. The exception was Red Riding Hood, which had a higher proportion of textrelated changes; this was due to many formatting changes. Crane's Myth and Coyote and the Frogs, which have the highest absolute change frequencies of the Schrock/Zenk edited texts, do not have the highest frequencies of sentence level changes; their relatively high levels of lexeme and text level changes are what raise their totals above the others.

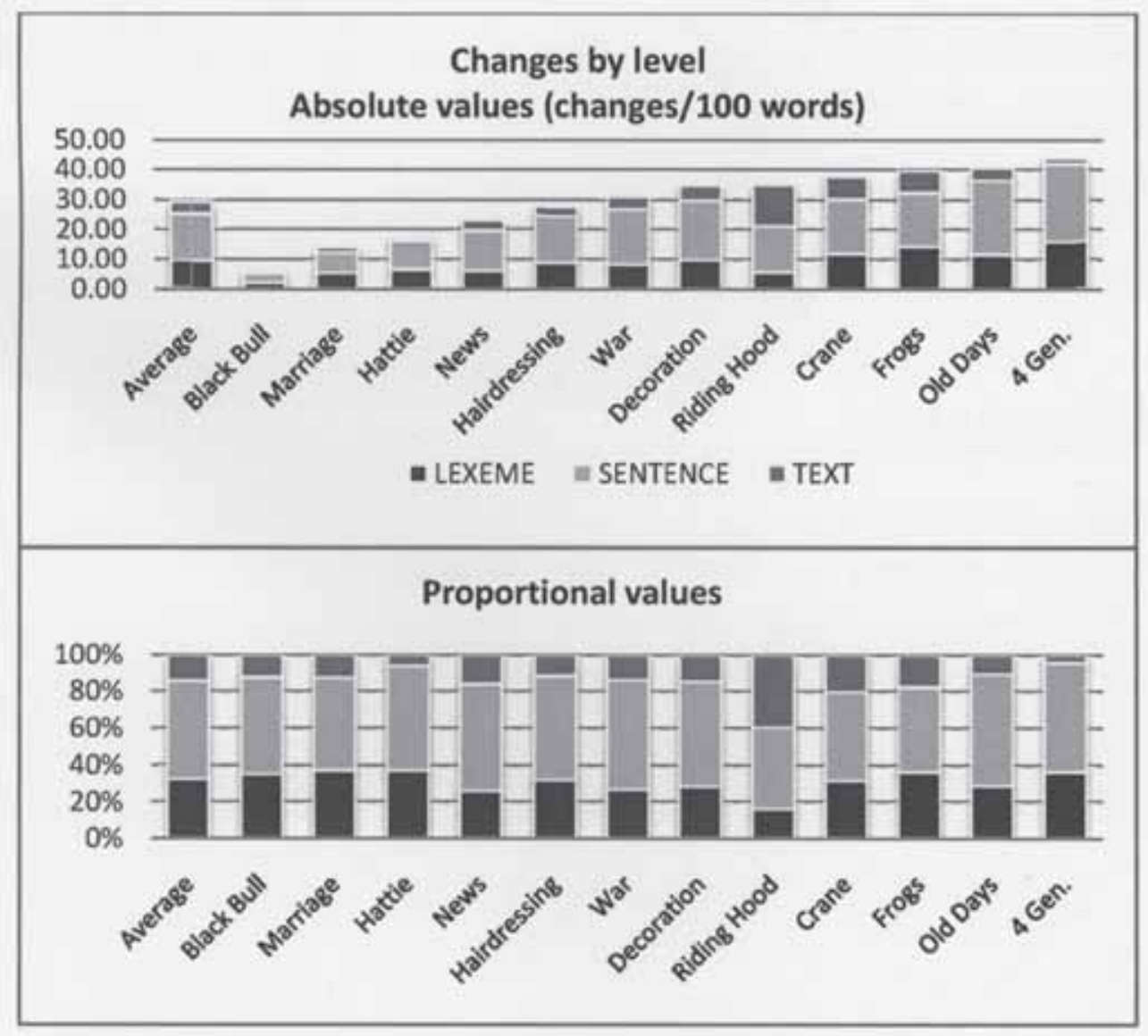

Figure 7: Changes by level: absolute and proportional 
The Red Riding Hood text is here notably different from all the others both in the proportions of changes at different levels and the high index of text-level changes. The uniqueness of this text as student work may have played a role not only in the quality of the draft composition but also in Zenk's focus while editing it. In reviewing these results he commented that in his role as a teacher (rather than a collaborating colleague) he felt more comfortable "introducing sweeping changes."

More fine-grained grouping of changes within each level showed that only four of the 12 texts had any formatting changes and that Red Riding Hood had many. This selective application of formatting changes affected the general sense of "changedness" of the various texts, even though it did not affect the content. Setting aside the inserted paragraph breaks and indents in those four texts makes the change frequency in Red Riding Hood considerably lower than many of the Schrock/Zenk texts, and shows more of a distinction between Crane's Myth and Coyote and The Frogs and the parallel translations seen in Figure 8 below.

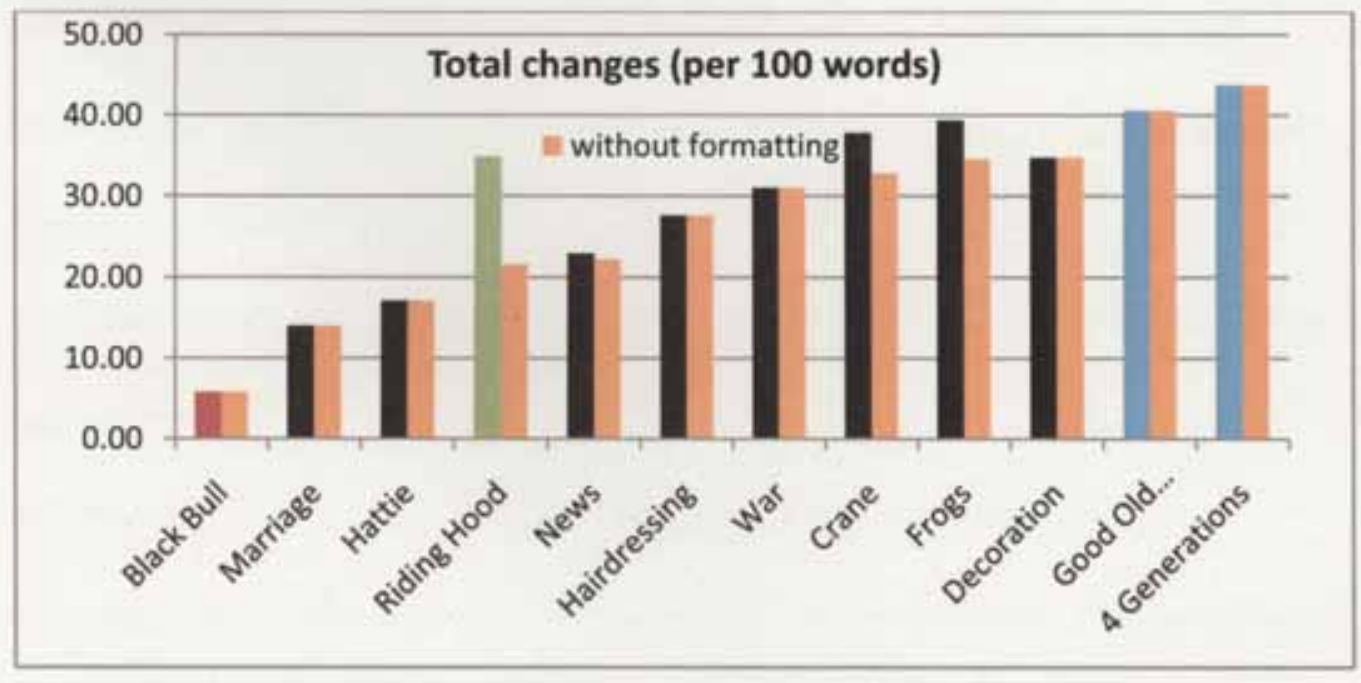

Figure 8: Comparison of total changes with and without formatting 
Crane's Myth had the highest absolute frequency of changes to orthography when hyphenation was included. Addition of hyphenation was the most common change in Crane's Myth, accounting for $12 \%$ of the total changes. This was twice the average proportion. This text was an important site of discussion about transliteration of borrowed words and the uses of hyphenation, as will be seen in section 2 of this chapter.

\subsubsection{Categories of lexical changes}

As described above, lexical additions, deletions, and substitutions not fitting any specific code were coded as (+/-)LX\#, and after coding was complete, marginal annotations were made with an aim towards classifying these changes. These annotations were collated and sorted as described below.

\section{Addition (or removal) of specificity}

Many of my annotations described lexical changes as "more specific" or, less often, "more general." At the lexical level, this type of change manifested as lexical substitutions that affected the specificity of reference, with a prototypical change being tonas 'child' $\leftrightarrow$ tonas-tuchmon 'girl.' This occurred most frequently with NPs, but also often with verbs (iskam 'get' $\rightarrow$ malyi 'marry'), adjectives (xluyma 'different' $\rightarrow$ xantq'i 'crooked'), adverbials (pus 'when' $\rightarrow$ ałqi-pus 'until'), and negation (wik 'not' $\rightarrow$ wik-qhonchi 'never'). These last two examples show the substitution of conventionalized or idiomatic compounds for unitary lexemes. The formation of nonidiomatic (transparent) compounds was another common way in which specificity 
was added at the lexical level, as in the following example from Four Generations, in which Zenk used a compound not recorded from elder Wawa to disambiguate a word with two potential meanings:

\section{Example 1}

JS: tsiltsil 'star' (tsiltsil also means 'button')

HZ: kusax-chilchil 'sky-star'

(Note: tsiltsil and chilchil are alternate spellings of the same lexeme; an orthographic difference was coded here as well as a lexical change).

On a clausal level, the addition and removal of any modifier can be seen as affecting the specificity of reference as to location, direction, time, manner, extent, quality, or degree. Frequently observed changes involving the alternation of the locative deictic $k^{\text {hapa }}$ 'over there, in that place' with locative phrases led me to include location as a specific code, as described above. In a complete re-coding, I would likely include other specific adverbial categories, as during my review of unspecified lexical changes I listed 38 additions, 19 deletions, and 9 substitutions of temporal words or phrases, as well as 26 additions of quantifier words.

On a narrative level, multiple lexemes were added that explained or gave more specific information about other words used (such as a sentence added to explain tonas-tiya?wit 'braid' (literally 'little leg') in Hairdressing); participant motivation, purpose, or goal; component actions resulting in an outcome specified in the narrative; or historical and cultural information that the reader (or writer) might not have been aware of. An example of this last type of increased specificity is information added by Zenk to the biographical text about Hattie Hudson specifying the number of 
her children who had become teachers, based on his personal knowledge of the family. Deletion of multiple lexemes sometimes reduced specificity, removing, for example, specific reference to an action implied by subsequent sentences, or information about a participant's purpose, motivation, or internal state.

\section{Specification and interpretation}

My annotations regarding extensive or back-to-back lexical changes and rephrasing often mentioned interpretation. This category overlaps somewhat with the previous one. While clarification may be seen in some cases as an example of specification, especially in cases of disambiguation, in these cases the information included in the text was altered to clarify the narrative in accordance with Zenk's interpretation of the events portrayed, either based on his reading of the Chinuk Wawa or his prior knowledge of the subject matter. In Example 2, from The News Precedes Coyote, Coyote calls to some people off shore in a boat. In the final version, Zenk inserted a sentence (in boldface below) to spell out Coyote's motivations for calling a second time.

\section{Example 2}

"ikta chxi-wawa pus msayka ya?im?" kakupus wik łaska kəmtəks yaka. alta woxt ya hala, "ikta chxi-wawa pus msayka ya?im?"

Is there any news for you to tell?" It seemed like they didn't hear him. Then again he hollered, "Is there any news for you to tell?

Zenk's marginal comment, added during the revision of the text, marks this instance of specification as an interpretation: "Again, motivations are usually implied, not explicitly stated in these stories. Seems to me though that he likely hollers again 
because they didn't acknowledge" (Zenk, annotation to News manuscript, January 23, 2009).

\section{Condensation and simplification}

Another common annotation to rephrasing, especially with substantial deletion, was that of condensation or simplification at the sentence or text level. This simplification sometimes included omission of participants' motivations or other information, but it often took the form of standard copy-editing: eliminating redundancies and smoothing the text. In translations, these types of edits may have moved the Chinuk Wawa version away from strict adherence to the original. Example 3 below, one sentence from Crane's Myth, shows the interlinear English source, Schrock's original translation, and the final version edited by Zenk. I have used the mark in quoting the source in order to show the boundaries between the Chinookan words represented by the gloss.

\section{Example 3}

Interlinear English source:

- He rose • coyote: • "Ōqō'xōL • she • comes down to the beach" •(Boas, 1894, p. 107).

Schrock's draft:

ixt pulakhli t'alapas yaka kitap. alta yaka wawa, "nanich yawál oq'óxotł yaka chaku khapa pulali-ilizi."

One night Coyote he arose. Then he said, “Look over there! Oq'óxotz she comes to the beach."

\section{Zenk's revision:}

alta ixt pulakhli t'alapas yaka kitap. alta yaka wawa, "nanich! uq'uxutt-skukúm yaka chaku!" Then one night Coyote he arose. Then he said, "Look! The uq'uxutt-monster she comes!" 
In this very short example, we see that Schrock's translation conveys more information than the source. Zenk's revision makes the final text more concise by removing directional and locational information that did not seem to be required by the narrative, some of which was included in the source text and some of which had been added by Schrock.

\section{Lexical innovation and choice}

The texts analyzed used a wide variety of the options for lexical innovation and choice described in Section 1.4.3, and often the editor suggested a different option from the one chosen by the writer. One example is Schrock's choice in Crane's Myth of oq'óxotł for the word spelled $\bar{Q} q i \bar{o}^{\prime} x \bar{L} \mathrm{~L}$ by Boas, the "basket ogress" in the myth. Zenk modified the spelling to uq'uxutł and converted Schrock's footnote ("type of skukúm ['monster']") into part of the name of the character, uq'uxutt-skukúm, so that the borrowed noun was compounded with a explanatory familiar noun. I noted a preference in the changes for Chinuk Wawa compounds over borrowings from any language, with seven borrowings from local languages and two borrowings from English replaced with Chinuk Wawa compounds or circumlocutions. This preference was discussed in detail in interviews, as will be discussed in Section 3.2 below.

The substitution of single lexemes for circumlocution in the editing process also contributed to the concision of the final text. This result is exemplified in the change made to the title of Coyote and the Frogs, shown in Example 4: 


\section{Example 4}

JS: $\quad$ 'alapasyaka munk-kakshat uk ili?i, Coyote he makes-destroyed that land, $q^{\text {ha }}$ shwiq ${ }^{h}$ iq taska munk-khoptt tsaqw where Frogs they make-stop water

HZ: $\quad$ t'alapas ya munk-hilu shwiqhiq tas tsaqw-q'alax

Coyote he makes-gone Frogs their water-corral

The circumlocutions referring to the Frogs' dam were replaced with the compound meaning dam throughout the text, resulting in a more concise text.

\section{Repeated substitution of one specific word for another}

While reviewing the unspecified lexical changes in the coded texts, I noted several instances of the substitution of pronouns for overt NPs (and vice versa). I also noted six instances of alternation of ixt 'one, a certain' with uk 'this/that,' and four instances of alternation of chaku 'come, come from' and łatwa 'go.' In addition, I listed 12 instances of deletion of conjunctions, which were often followed by the addition of the discourse marker alta, 'and then.' Zenk included a marginal note to one of these changes in The News Precedes Coyote:

There's nothing wrong with the grammar here, only pi is actually very sparingly used in our elder Wawa (though it is used more elsewhere, e.g. by the Francophone priests). Real elder Wawa style uses alta to sequence any kind of narrative; you almost can't overuse it (alta... alta... alta... ad infinitum). (Zenk, undated comment to News)

There were also several incidences of repeated rejection by the editor of productive use of a particular form derived from the historic corpus of Chinuk Wawa. The compound construction munk- 'make, do, cause' $\mathrm{X}$, where $\mathrm{X}$ is a commodity, in emulation of Victoria Howard's use of munk-lakamas to mean 'harvest camas,' was 
replaced in several texts with iskam X 'gather X;' similarly, use of the iterative numeral suffix $-i$, documented in ixti 'once' and makwsti 'twice,' with numerals higher than two, was replaced with the bare numeral.

\section{Uses of pus}

I noticed many incidences of pus 'when, if, for, in order to' being added in these texts, and a count indicated that all the final versions of edited texts have more incidences of pus than the original texts do; furthermore, Zenk's translation of Four Generations has more than twice as many incidences of pus as Schrock's does. Pus was often added in the context of indicating the purpose or goal of an action. Several examples follow in which Zenk introduced pus in various ways. It is notable that none of Schrock's versions cited below were judged by Zenk to be incorrect; his choices represent stylistic improvements rather than corrections. In Example 5, from Clackamas Marriage, pus was added in the process of combining two narrative sentences into a single sentence indicating an action and its purpose:

\section{Example 5}

JS: alta taska iskam lishol pi hayu kamusaq. alta taska munk-ixpuy uk łuchmən. Then they get shawl(s) and many beads. Then they make-be-covered that woman.

HZ: alta łaska munk-miłayt lishol pi hayu kamusaq pus munk-ixpuy uk łuchman. Then they make-be-located [place] shawl(s) and many beads in order to make-be-covered that woman.

Pus is also featured in several changes having to do with expressions of instrumentality, either adding an instrument to the sentences as in Example 6 from 
Coyote and the Frogs, or by changing the way instrumentality is portrayed, as in Example 7 from Four Generations.

\section{Example 6}

JS: alta t'alapas ya munk-kakshat.... Then Coyote he made-destroyed...

HZ: alta t'alapas ya munk ya lima pus kakshat.... Then Coyote he did [with] his hand in order to destroy...

\section{Example 7}

English source: the child played with it

JS: $\quad$ alta uk tonás yaka hihi khapa uk stun then that child he played at/on [with] that stone

HZ: uk tonas ya iskam pus hihi that child he got [it] for the purpose of play

In Example 8, from Crane's Myth, munk pus 'do in order to' (understood in the context of this case as 'try') is used to replace tiki 'want, need' in a change emblematic of the substitution of description of action for description of internal states or motivations that was noted several times in my review of unspecified lexical changes. In my annotations I hypothesized that the construction tiki + verb, which was also replaced with other constructions by Zenk a few times in Schrock's earlier texts, was changed because it seemed to show influence from English 'want to X.' In our discussions, both Schrock and Zenk confirmed that tiki + verb was an English-like construction that was best avoided. 


\section{Example 8}

JS: alta t'alapas yaka tiki q'wəł yaka. Then Coyote he wanted to hit him.

HZ: alta t'alapas yaka munk pus q'wəł yaka. Then Coyote tried to hit him.

Pus was also used in its temporal sense to replace other temporal adverbs such as ałqi 'FUTURE' and alta 'PRESENT.'

\section{Summary of unspecified lexical changes}

The many otherwise uncategorized lexical additions, deletions, and substitutions coded in these 12 texts were seen upon closer examination to affect the specificity, content, readability, and concision of the texts. These changes also showed some preferences for certain grammatical constructions (those using pus, for example) and certain words and types of lexical choices over others. These changes took effect at all levels. The list of annotations to the lexical changes ran to eight single-spaced pages; the above is only a sampling of the patterns observed. These observations were used in interviews to discuss the weight and extensibility of individual choices in the text creation process, as detailed in Section 2 of this chapter.

\subsubsection{Summary of the text analysis}

This section has presented the results of the text analysis, in which differences between available versions of each text were categorized and tabulated. The greatest number of changes was in the catch-all category of unspecified lexical additions, deletions, and substitutions. The contents of this category were explored separately, 
which revealed flux in the use of modifiers, especially adverbials, and the use of the interesting multi-functional word pus. This exploration also suggested patterns related to stylistic concepts such as specificity and clarity and elicited dialogue about lexical coining and word choice.

Approximately half of the changes in these texts were additions or deletions of one or more contiguous lexemes. Overall, the final texts showed a net loss of subject and object NPs, and net gains in all other lexical categories. Net differences were shown among texts developed from transcripts, interlinear glosses, English narrative, and notes. This suggested that these different sources, with their different amounts of constraint upon the writer's style and creativity, might be a factor in the writer's decision-making process and therefore the editor's choices might also be affected. Differences were also seen between the English narrative sources translated collaboratively and those translated independently, suggesting that the edited texts represent a compromise between the preferences of the author and the editor.

All 12 texts were compared to each other according to their relative numbers of changes. The independent translations were the most "changed," and the standardized transcript had the fewest changes by far. The two latest Schrock/Zenk edited texts, Clackamas Marriage and Hattie Hudson, were the least changed of the other texts, but no other clear chronological differences were seen. Arranging the changes into broader categories showed that the greatest number of changes took effect at the sentence level. Sub-categorizing at each level showed that formatting changes were applied only to some texts, and exclusion of these changes from the analysis showed 
that Red Riding Hood, the only edited text by an author other than Schrock, was not as different from the other texts as it had appeared.

\subsubsection{Interrelationship of interviews and text analysis}

As a result of the text analysis I developed specific topics of conversation for interviews based on my observations in the text analysis related to vocabulary choice, orthography and hyphenation, grammatical preferences, and narrative strategies. The complete list of questions is in Appendix C following the general interview outline.

As these questions were developed they were used in interviews with Schrock, Zenk, and Johnson, and their responses in turn led me to further develop the text analysis in some directions (such as considering the types of source texts) and to abandon other avenues of inquiry (such as detailed sub-categorization of change types). The results of these initial interviews as well as subsequent interviews and casual discussions with these participants and other stakeholders will be presented in the next section. 


\subsection{Results of the interviews}

This section describes the results of my interviews with Jedd Schrock, Henry Zenk, and Tony Johnson, and my conversations with other teachers and students in the CTGR language program. I relay their descriptions of the process used to develop the texts for the university classes, and present the overarching concerns that these stakeholders expressed. I then describe their specific comments according to the categories of changes described in Section 1 of this chapter.

\subsubsection{Text development process}

In order to help meet the need for reading material, Jedd Schrock joined the curriculum and materials development team in fall term of 2007 and went to work locating or drafting texts that would fit the topic-based curriculum outline. If there were no appropriate Chinuk Wawa texts from Grand Ronde elders, new texts were developed. Translation was considered to be a more efficient means of text development than composition because of the need for authenticity. In the case of a translation, authenticity could be contributed by an appropriate source text. Otherwise, creation of a culturally authentic text would require the use of multiple sources and collaboration with Johnson or other knowledgeable persons with limited availability, thereby lengthening the development process. Sometimes Schrock was directed to particular sources by Johnson or others. Other times he searched on his own, looking first through ethnographic sources containing direct dictation from local 
Natives from tribes that were relocated at Grand Ronde in order to represent the heritages of the Grand Ronde community.

Schrock's choice of texts for translation was motivated by "the idea of trying to translate as straight from what Indians said as possible" (J. Schrock, interview, April 30,2009 ), rather than translating from other people's interpretation or synthesis. He described his preference for translating from interlinear English glosses, which are available, for example, in Chinook Texts (Boas, 1894), which was the source for How They Made War and Crane's Myth:

My opinion is that the least amount of information is lost if you can translate from interlinear rather than from somebody else's ordering of things.... Funny enough, it's easier to translate that way than it is from English prose. I think word order is borrowed at some level. I haven't quantified that. I think you probably could. In order to do that, you'd have to understand Chinook better. There's something about the way it's told, you know, what strikes me as good Chinuk Wawa, somehow it translates easier from orderings of old Chinook than from English. (J. Schrock, interview, April 30, 2009)

Schrock stated that his second preference was to work from Melville Jacobs' Clackamas field notes from his work with Victoria Howard, ${ }^{12}$ as he did with Clackamas Marriage. In the ethnographic sections of these notes, Schrock said that although Jacobs was not taking verbatim dictation, "you can kind of hear what Victoria Howard said... the flavor of her voice comes through" (J. Schrock, interview, April 30, 2009). Schrock's concern for fidelity to the source voice also came through in his translation methodology. He would usually translate word by word if possible. When a word by word translation did not make sense, he would translate the sentence as a

\footnotetext{
${ }^{12}$ Victoria Howard lived at Grand Ronde, and Jacobs also collected four texts in Chinuk Wawa from her (Jacobs, 1936), which are included in the Chinuk Wawa dictionary corpus.
} 
chunk, and when a sentence by sentence translation did not make sense, only then did he paraphrase. Having composed a translation that was as close to the source as feasible, he would then give it a day of "drawer time" before reviewing it to see if it seemed garbled and revising it to improve the flow if necessary. This second draft would then be sent to Zenk for review and corrections. When the corrected draft was returned, Schrock would generally review and accept the changes, and would then integrate the text into the week's lesson if necessary.

\section{Time pressures}

Many texts and lessons were developed under intense time pressure. Johnson described the process of creating the materials for the 100 level classes, in which he would develop a first draft which was sent to both Zenk and Janne Underriner for review. Their reviews, for language and content respectively, would be brought together in "a meeting of the minds...and often that was happening on a Monday morning for class Monday night" (T. Johnson, interview, July 14, 2009).

During the time that these interviews were being conducted, the process of producing new texts under a grant for producing place-based curriculum for the immersion school had been reviewed and redesigned. The result was a formal sevenday process in which a text would be reviewed by three parties for language, classroom usability, and final approval before a final draft was authorized. This more formalized revision process might be utilized in the future for any additional texts created for the university classes. However, during the period of this study, which was 
the second and third quarters of the second year of the curriculum, there was often a "scramble" to get materials ready for class. The students' hunger for reading materials and new challenges outpaced the materials being made available for them to work with. As Zenk admitted in early May, "two classes a week, two hours a class, you kind of end up going through this stuff, and right now we actually don't know what we're going to do for tomorrow" (H. B. Zenk, interview, May 5, 2009).

\section{Collaboration}

Although producing texts collaboratively took more time than having them produced by one person, especially considering persistent technological difficulties, collaboration (or at least review) was seen as important for producing texts that would be used with learners. There was a sense that collaboration produced better results, and also that it allowed several people to share responsibility for the texts.

One of the difficulties with collaboration, especially when it occurs under time pressure, is that it can be difficult to distinguish between corrections and personal stylistic preferences. As Zenk described it, "There's kind of a gray area where [it's not incorrect but] that's just not me to say it that way, it's Jedd [Schrock]" (H. B. Zenk, interview, May 5, 2009).

Johnson and Zenk collaborated on many of the texts used in the program, although none of them met the requirements for this study. Although Johnson mentioned several points on which he and Zenk tended to disagree, Johnson expressed his satisfaction with their collaborative relationship, saying, "I'm always 
happy to defer to Henry, and Henry is really good at listening to me.... I think that the translations that he and I put together are always better than what we would have done alone" (T. Johnson, interview, July 14, 2009).

Although he agreed that collaboration and editing helped to improve texts and correct errors, Schrock expressed some frustration with the collaborative process, saying that he sometimes disagreed with changes made to his drafts and that "there are times when it's unclear. There's times when what comes back is not what's meant in the original. Multi-functionality [of lexemes] can lead to multi-interpretations" (J. Schrock, interview, April 30,2009). The time pressure involved in the production of these texts often precluded repeated email exchanges or face-to-face negotiations. In his editing of Schrock's drafts, Zenk reported attempting to focus solely on the effectiveness of the Chinuk Wawa, without interpolating his own translation preferences. This focus occasionally lead him to make changes that smoothed the narrative according to his interpretation but which did not coincide with Schrock's intended meaning.

\subsubsection{Resources and authority}

The people I spoke with discussed using various resources to assist them in developing and working with these texts. Reference materials (the dictionary and historical texts) and personal intuitions were most prominent, although consultation with knowledgeable others and secondary sources such as historical and ethnographic works were also mentioned. 


\section{Reference materials}

The dictionary (Johnson and Zenk, 2009) distributed in draft version for use in the language classes was cited as a reference by all participants, especially for orthography. The historical texts (those included in the dictionary and others) served as references for idiom and usage. In discussing Crane's Myth, Schrock mentioned that it was written just after reading Victoria Howard's story A Stingy Girl is Taken Away by Mountain People (Jacobs, 1936, pp. 6-12), and that it was an influence on his writing in terms of his lexical choice (munk-smit'aqs, for example) and his use of $u k$ and $u k u k$, which Victoria Howard used more than other elders.

The dictionary includes many examples for most lexemes (and each draft edition includes more), but it is not a complete inventory of recorded use. Schrock expressed his desire for a comprehensive database that would return every recorded instance of a queried word or phrase in context, so that he could check his usage against that of the elders:

We're all human, and we all have notions, and none of us are native speakers, so the best thing to do is to consult these old sources, and we don't have a super thorough way of doing that yet. You know, we have the dictionary, and that's mostly what we have. (J. Schrock, interview, April 30, 2009)

The question remained, however, as to which usage documented in the old sources should be considered standard. Zenk said that he recalled elders criticizing the speech of other elders, re-iterating that "elder Wawa itself is a fairly mixed bag" (H. B. Zenk, interview, May 5, 2009). Victoria Howard, as Schrock mentioned, "seems like a pretty good person to imitate" (interview, May 8, 2009), but her usage is 
perceived only as her usage and perhaps that of her family members, rather than as a representation of the speech of the community as a whole.

\section{Intuitions and memory}

Johnson and Zenk both discussed their intuitions and memories of listening to and learning from elders as a key resource. They both described a feeling for the language in which a certain way of saying something would "just sound right," and that the reasons for that "rightness" were often difficult to explain. Johnson explained the relationship between this intuition and extrapolation from the remembered past:

Undoubtedly there are many, many, many things we've never heard. So how do we cover those issues? Well in the vast majority of those cases, there's just something so similar, some context that's so related, that you are comfortable with, it just fits right in and it's good to go. In that other instance it might require a little thinking about it but generally you settle on something that just sounds right, just feels right.... I would say if there's any standard of when we all settle on something that sounds really good it's because we, both of us [Henry and I], sit and recall other people's mode of saying it. (T. Johnson, interview, July 14, 2009)

Collaborative brainstorming and comparison of intuitions was described as an effective way to decide how to fill a perceived communicative gap. Everyone I spoke with expressed some questions or doubts about their intuitions, as non-native speakers, in comparison with those of the elders. As Johnson said, "I know Henry and I'd be the first to admit that, while we think we can really use the language, I don't think either of us are going to say that we're what people before us were" (interview, July 14, 2009). Many of the recent generation of elders (with a couple of notable exceptions) said much the same thing about the superiority of the language abilities of 
previous generations. Johnson suggested that saying that one does not speak as well as one's parents or grandparents is "a sensibility that's been in place for 10,000 years."

Zenk described his intuition as his most important guide, but also expressed some uncertainty about how his Chinuk Wawa might compare to the Chinuk Wawa of the elders as it has been documented.

I've never really self-consciously examined my own Chinuk Wawa to compare it to the elders. I sort of have my own internalized sense of how this language works, you know, and I just kind of go by that usually: the speaker's intuition. On the other hand, I'm not a native speaker. But somehow I have developed my own intuition about the language, about what feels right to me. I've never compared it deliberately with the source of the language, which for me was the elders. (H. B. Zenk, interview, May 5, 2009)

\section{Language knowledge: intuition and analysis}

Continued study and analysis of the Chinuk Wawa lexicon and grammar were also mentioned as important for the improvement of available resources for learners and writers. If the source of the language for Zenk, who came to Grand Ronde without prior knowledge of Chinuk Wawa or Chinook Jargon from any of the existing written sources, was the elders, he himself has been the source of the language for many of the current speakers. This also means that he is a main informant for linguists and others who wish to know about the language, and his comments about his concern that analysis could compromise his intuitions were very thought provoking:

I remember when Tom [Larsen] was working on his "Blue Munk" paper [Larsen, 2002], and he was using me to test hypotheses, but the trouble with that is that I knew what he was doing. What I really find is that my feeling for the language works fine up to a certain point, but there is a point where I'm thinking too consciously about it, and when that happens I'm just not sure. That feeling is gone, that intuition is gone, and I'm thinking about it, and especially when Tom was really trying to make a really fine distinction 
between two different ways of saying something, and I know what he's trying to do, and I'm actually sort of trying to out-think him in a way. This is the thing that actually scares me a little bit about [grammatical models] - if I start taking [one of them] too seriously it's liable to start influencing the way I speak, and that's like the monitor: 'Oh, I better not say it that way because that would be incorrect, because....' I'm not a native speaker. A native speaker doesn't have to doubt, I guess. (H. B. Zenk, interview, May 5, 2009)

Johnson expressed his support for research on the language, especially to learn more about the indigenous sources and to develop a learner's grammar. He did feel, however, that grammatical work and consideration of grammatical models by teachers and learners could have an eventual effect on the language itself:

As a grammar further develops I'm sure there will be dozens of things that we all go 'oh, wow!' and in some way in the back of our minds modify some small portion of how we communicate with each other in Chinuk.... I expect that it's something that over time would be noticeable, I suppose that kind of stuff could affect the language in the end, but hopefully not to any detriment, you know, it's just something that you would notice. (T. Johnson, interview, July 14, 2009)

Johnson spoke strongly, however, on the uselessness, for his purposes, of

minute linguistic analyses aimed at proving some theoretical point:

It's vivisection! It kills the language. I mean, I am joking, but it's like you take language to a point of death, you know. It's like there's no... yes, there's a point to the discussion, but the point is so far from the language, and it just becomes something void of any life... taking it apart. And look, I think that's great, it's good for somebody, but I don't think it's good for the language. I'm not saying it's bad for the language, but that nuance of analysis of the language is never going to help what I care about, which is revitalization, life, of these languages. (T. Johnson, interview, July 14, 2009).

Research and analysis within the language program often leads to changes: to the orthography, to the lexicon, to the way the grammar is described. Johnson and other teachers and learners I spoke with emphasized that learners need consistency and it is important for teaching staff to have input into the implementation of changes 
to vocabulary or orthography. Changes in spoken language use in the classroom can be assimilated more easily than changes to written language. Johnson suggested that when people become confident and fluent in the language, research-based changes do not bother them in the same way that they bother learners and those working with them. Teachers and learners who were not directly involved in text development and language planning often mentioned the challenges of adapting to changing standards and rules. What was described as "bickering" between teachers about the factors weighing on points of grammar or orthography could be at best boring and at worst alienating for some learners.

\subsubsection{Vocabulary: choice and innovation}

In the interviews, we discussed strategies for filling lexical gaps in Chinuk Wawa. As the language is used, new vocabulary is often needed. As mentioned previously, there is a strong preference for analogy with remembered or documented elder Wawa. Sometimes new vocabulary is generated spontaneously, and sometimes it is generated through brainstorming or planning; some of it "sticks" and some of it does not. Johnson's first preference is for vocabulary generated through the creativity of the children in the immersion program.

We've developed vocab that just doesn't go anywhere. We've also done nothing and had kids develop vocab that went crazy. That, to me, is my very favorite way of seeing it develop, of course, that's very natural. (T. Johnson, interview, July 14, 2009) 
Other strategies included reduplication, various types of borrowing, and compounding. Each of these main strategies was a fruitful and intensive topic of discussion that often overlapped with discussions of grammar and narrative.

\section{Reduplication}

There are examples of what seems to be productive reduplication in elder Wawa, such as łatwa-tatwa 'go all over the place' (from tatwa 'go'). There was some discussion in the margins of the texts in this study as to where to use this. In The News Precedes Coyote, Zenk changed Schrock's usage of hayu-tatwa to łatwa-łatwa, stating in the margins that "hayu- is almost always durative aspect in elder Wawa; not much used for habitual or customary, though there are exceptions. (Chris [Doty, 2009] has influenced my recent thinking here.)" (Zenk, undated annotation to News manuscript). In our interviews, Schrock indicated his understanding that single reduplication in general means 'around,' while iterative or repetitive meanings were best expressed with three repetitions, such as in kuri-kuri-kuri 'runs away fast, runs and runs.'

However, I pointed out that uses like munk-k'ilapay-k'ilapay 'make-return-return' as a way to express braiding in Hairdressing do not seem to correspond exactly to this, and Schrock agreed that there seems to be room for continued exploration of the implications of reduplication and repetition.

\section{Borrowing from English}

Borrowing words from English to fill lexical gaps was discouraged, and the few suggestions for English borrowings in the texts were changed by Zenk. English code- 
switching often passes in casual conversation, but it is just as often used as an opportunity to identify a lexical gap and brainstorm possible Chinuk Wawa words or expressions that could fill that gap; the text development process seems to have worked the same way. Johnson described his discomfort with assimilation of English lexemes into Chinuk Wawa as part of the particular heritage of the community.

That's [borrowing heavily from English] something I'm not comfortable doing, because that's not something our ancestors were comfortable doing, you know? They gained this ten percent of this language that's English, and they gained it in probably ten years and that's it. It's very clear that it did not change. In places like the Puget Sound, that's not true. People seemed willing to keep taking English. But for whatever reason, the people here weren't. (T. Johnson, interview, July 14, 2009)

\section{Borrowing from outside Grand Ronde}

The preference for the Grand Ronde dialect in the language program tends to limit sources to those documented at Grand Ronde or from people who grew up at Grand Ronde. The "regional" section of the dictionary attempts to include language from the wider area in order to enrich possibilities for modern language users and to expand outmoded words into new uses. In my discussion with Schrock, we considered the possibility that many words and expressions found outside Grand Ronde, or, indeed, in other local languages, may well have been used in Grand Ronde Chinuk Wawa. Schrock cited the example of $q^{\text {hiwa }}$ 'because,' known as Chinook Jargon from Demers and St. Onge (1871) and also known in Chinookan (Johnson and Zenk, 2009). There is no evidence that this word was used in Grand Ronde Chinuk Wawa, but there is evidence that it was used by Victoria Howard in Clackamas. There is no way to know if she also used it in Chinuk Wawa but just did not happen to use it in her recorded 
interactions with Jacobs. A word meaning 'because' would be quite useful for creating texts and having day-to-day conversations in Chinuk Wawa. Since Schrock's and my conversation at the end of April, this word has indeed come into more mainstream usage in the language program.

\section{Borrowing from other local languages}

In translations done from interlinear English, there are local language words easily accessible for borrowing to fill Chinuk Wawa lexical gaps. Elders who spoke these languages certainly did this; that is part of what contributes to the different dialects and idiolects that may be observable in the historical texts. However, Chinuk Wawa developed from the intersection of several unrelated languages. The choice to borrow or adapt a word from one of those languages invites the question of why it was not borrowed or adapted from one of the others. Direct borrowing is not favored for two reasons: it detracts from the identity-building aspect of language revitalization; and, as Amery (2000) put it, "how acceptable the practice of borrowing is to speakers of the source languages [or their descendants] is unclear" (p. 123). Thomason (2001) also suggested that resistance to borrowing may be an areal feature of Pacific Northwest languages, in which case this type of self-reliance is also in keeping with a Native focus. Zenk described his commitment to using Chinuk Wawa's own resources to develop the lexicon as a stance of resistance to accusations that Chinuk Wawa is too lexically and grammatically impoverished to serve as a community language:

That's part of my philosophy about Chinuk Wawa: there's got to be a way to say it within the limits of the language as we received it, although I have 
expanded those boundaries by adding the regional dictionary to our core Grand Ronde dictionary. There's a way to do it; there must be a way to do it; I just don't trust that 'You could never say this in a language as limited as Chinook Jargon.' (H. B. Zenk, interview, May 5, 2009)

An example from Crane's Myth, however, demonstrates a decision to borrow a word from a local language even though two other options, a single lexeme and a descriptive compound, were attested from elder Wawa. Eula Petite, in her Chinuk Wawa translation of a story from Takelma Texts (Sapir, 1909, p. 18-20), introduced the

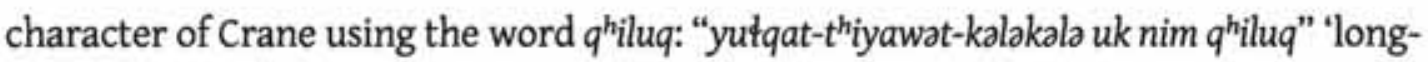
leg-bird named $q^{h i l u q}$ '(Petite, 1981, in AIL202 lesson handout, March 21, 2009). This instance seems like a straightforward "elder Wawa" justification for the use of $q^{\text {hiluq }}$ for 'crane.' However, Mrs. Petite found this word in Thomas (1935), as ke-lok in Thomas' orthography (AIL202 lesson handout, March 21, 2009). Qhiluq was cited from Bay Center by Harrington, and by Demers and St. Onge, as 'swan' (Johnson and Zenk, 2009). As there are no other citations of $q^{\text {hilu }} q$ as 'crane' from Grand Ronde elders or other sources, it seems potentially confusing to perpetuate this usage. Mrs. Petite's translation provides another alternative: a descriptive compound, yutqat- $t^{h}$ iyawatkalakala 'long-leg-bird.' Johnson and Zenk (2009) included yutqat-thiyawat as Grand Ronde Chinuk Wawa for 'crane.' In Crane's Myth, however, Schrock and Zenk chose another option: borrowing the word iqoä'cqoāc from Chinookan, the source language of the myth, transliterated as quashquash by Schrock and modified to $q^{h}$ wásh $q^{h}$ wash by Zenk. This option avoided possible confusion of Crane with Swan and allowed for parallelism with the names of other characters in the story, which are not descriptive 
compounds: t'alapas 'Coyote,' and xwáshk'way 'Heron,' another borrowing from the source Chinookan (ixoā'ckpai) for a long-legged bird not attested from elder Wawa (who could also easily be understood as a referent of yutqat-thiyawt.)

\section{Borrowing: loan translations}

Johnson described a preference for loan translations (calques), over direct borrowings from Chinookan or other local languages because of the opportunity for a cultural learning experience:

The kids all know tanas-tiya?wit for braids. In Chinookan, the translation of braids means "little legs." tonas-tiya?wit means nothing without explaining it to someone, but it has this whole cultural sensibility and context. Another one is ulq?-latet ['snake-head']. ulq?-latet-inapu ['snake-head-bug'] is a dragonfly, and he [Dragonfly] has a whole connection to Snake in mythology.... Those are really beautiful things to me, a way of really maintaining and providing the kids with something... we're not just stealing it, it gives a learning opportunity, that's the nicest thing to me, when it has some ability to teach out of it. (T. Johnson, interview, July 14, 2009)

\section{Compounds and circumlocution}

Coinings that use the language's own resources through circumlocution

(sometimes novel compounds, sometimes descriptive phrases) have the advantage, like loan translation, of being authentic. As one teacher I spoke with said, "You're still using the true language." That teacher also suggested that witnessing the process of coining would help students build confidence in their own vocabulary construction. Because of the limited vocabulary available in the dictionary, especially for modern day-to-day topics, the creativity in Chinuk Wawa composition or oral story-telling lies 
more in finding elegant ways to describe something like "skateboarding" or "Special Olympics," rather than in narrative-level expression.

\section{Hyphenation of compounds}

The text revision analysis showed that hyphenation was a major site of difference between versions of the texts, and the interviews revealed the lexical and grammatical complexities behind the choice to use (or not to use) a hyphen. Explaining the rationales and rules used for hyphenation was difficult for everyone I interviewed, and everyone admitted, with varying levels of frustration, that there was no definite agreement on prescriptive parameters for hyphen use. As Zenk said, "I can't decide what to do myself sometimes." At one point in class he admitted to having changed the way he worded something because he had not been able to decide how to hyphenate it correctly. This admission was mentioned several times to me as an indication that the rules or guidelines for using hyphens are still very much up in the air.

Johnson distinguished two types of hyphenation: lexical hyphenation (of compounds) and grammatical hyphenation (of 'auxiliary' constructions). Two related roles for hyphenation were also described: denoting the lexical status of a compound or the grammatical relationship between an auxiliary and its collocate, and denoting unitary stress. The first role was derived from the second - the phonological distinctions made by elders between compounded lexemes and non-compounded 
ones led to the use of hyphenation to make these distinctions in writing. ${ }^{13}$ As one learner said:

It was a language that wasn't written, so no elder would have been able to tell them whether to hyphenate or not, but perhaps in how it was said you would have heard the difference. (Anonymous interview, June 11, 2009)

In lexical compounds, disambiguation was a prime motivator for the use of

hyphenation: Johnson cited the common example of "a tənəs tuchman ['small woman'] versus a tənas-łuchman ['girl']."

I'll hyphenate anything that I think creates a meaning different from the two words in their own context. In my writing, the only reason I'll do that is because I want somebody to see it. Wik nayka wawa 'tush nanich uk buk,' nayka wawa 'tush-nanich uk buk' [I didn't say 'that book is good looking,' I said 'be careful with that book'], you know. (T. Johnson, interview, July 14, 2009)

Johnson described the hyphen as indicating the lexical unity of a compound. "If it's compelling me to put a dash between them, then it's its own word... that is how you make new words. Those are legitimately, you know, ulq?-latet ['dragonfly'] is its own word, period" (T. Johnson, interview, July 14, 2009).

The dictionary was seen as a resource for applying hyphenation in the absence of a productive and reliable rule. If the dictionary is referred to, at least consistency can be maintained. However, one cannot always cross-check everything with the dictionary. Johnson described his relationship with the dictionary:

There are probably things in the dictionary that Henry's hyphenating with the sensibility that he has, that are a more gray-area than what I would tend to do. I try to reflect what's in the dictionary when I'm writing, but I also, when I'm

\footnotetext{
${ }^{13}$ A hypothetical example with stress markings: munk-mifayt stik 'place a stick' versus múnk mitayt-stik 'make a horizontal stick.'
} 
freely writing, will just compound things that probably aren't otherwise. It just depends. (T. Johnson, interview, July 14, 2009)

\section{Grammatical roles of hyphenation}

Johnson said that he always hyphenates the auxiliary uses of munk, chaku, and hayu but does not see them as independent lexemes like other hyphenated compounds: "Those, that's not a stand-alone word, that's just grammar interacting" (T. Johnson, interview, July 14, 2009). In contrast, Schrock said that his understanding of the hyphenation rule was that "you hyphenate compounds that belong together as a unit," but that his conception of the unit was more at the phrasal level than at the lexical level, because he considered that the hyphen should have a single rather than a dual function. Problems arose for Zenk in determining how many hyphens to permit in compounds with internal constituencies, such as munk-hilu-mak ${ }^{\text {h }}$ ak (make none/gone food = eat all up). If only one hyphen is permitted, that forces a decision as to what, in fact, the constituencies are: munk-hilu mak ${ }^{h}$ mak (make-gone food) or munk hilu-mak ${ }^{h}$ ak (make no-food). The meaning is likely to be interpreted the same way in any case, but the use of hyphens reveals the grammatical commitments of the writer(s).

Crane's Myth was translated during a period in which Schrock was experimenting with not including hyphens in collocations with hayu(-), munk(-), or chaku(-). In the footnote to his draft, he explained it this way:

In this draft I'm taking liberties with hyphenation rules, just as an exercise. I am not hyphenating any verbal auxiliary situations with hayu, munk, or chaku. I am hyphenating all noun-noun compounds, and I am hyphenating adj-noun compounds where the adj expands the semantics of the compound i.e. saxali- 
tsaqw (high tide) versus saxali tsaqw (up river), which I would not interpret as a compound noun, but rather two words. I'm also hyphenating compounded utility idioms which I interpret as single units like wik-ikta [it's nothing, no

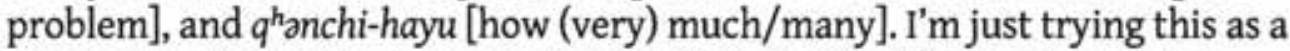
way to simplify hyphenation without losing meaning. (Schrock, undated footnote to Crane's Myth manuscript)

Zenk interpreted this as a grammatical notion that might bear discussion; however, in the interest of maintaining consistency with established practice, he added 45 hyphens in the course of his edits to Crane's Myth. Schrock's thought on the matter was that the different "intentions and notions of the purpose of the hyphen" seemed to be in conflict and that in the absence of "easy-to-comprehend reasoning," it would be "more helpful [to the learner] not to use it" (J. Schrock, interview, May 8, 2009).

In Section 1 of this chapter I noted the repeated rejection of munk + commodity to mean 'harvest X.' This usage was proposed by Schrock by analogy to Victoria Howard's use of munk-lak'amas 'dig camas' in one of her narratives. He used munksmit'aqs for Heron and Crane's clam-digging in Crane's Myth, which was changed by Zenk to tatwa-iskam smit'ags 'go-get clams. ${ }^{144}$ The discussion in the margins of the text reads as follows:

JS: If you can munk-lakamas why can't you munk-smit'ags?

HZ: Not saying you can't. tatwa-iskam is just more usual in terms of elder Wawa as we've mostly heard it. VH's munk-lakamas (contracted for munk lakamas; she

\footnotetext{
${ }^{14}$ Gardner also used munk-lakamas in his translation of Good Old Days, while Zenk again used iskam lakamas.
} 
actually also has mamuk $k^{15}$ lakamas) is kind of an unusual usage, while tatwaiskam is very common. (Schrock and Zenk, undated annotations to Crane's Myth manuscript)

Schrock was translating from the English word "gather," itself a translation of a Chinookan verb. Both of these proposals for expressing 'gather' or 'harvest' use the existing resources of the language. The compound verb tatwa-iskam is more general, in that it is used for 'go-and-get' anything. Zenk's argument is that Victoria Howard's usage may not actually be an auxiliary construction as it appears, but rather a contraction of munk (or mamuk) lakamas, meaning 'to work camas': an analogical leveling to the common phonological pattern of munk-STRESSED (H. B. Zenk, interview, September 30, 2009). In this case the hyphenation represents the stress pattern of Mrs. Howard's utterance, rather than the grammatical combination of the two elements.

\subsubsection{Grammar}

Teachers and learners that I spoke with expressed the desire for concrete, stable answers to grammatical questions. Such certainty is not always possible, as systematic description of Chinuk Wawa grammar is not yet complete, and may not provide the desired definitive answers when it is. Chinuk Wawa learners are on the proving ground of grammatical models and rules, where their need for consistency

\footnotetext{
${ }^{15}$ Mamuk was the usual form of the auxiliary in regional Chinuk Wawa, and was used as a somewhat unusual alternate form by elders at Grand Ronde; as an independent word it often had the sense 'work.'
} 
can bump up against the need to refine, improve, and test understandings of the language's structure.

\section{Models of syntax and parts of speech}

The participants in this study had different levels of personal commitment to and interest in grammatical investigation. Johnson expressed support for grammatical investigation that would promote the status of the language and assist with the development of materials such as a learner's reference grammar. However, his trust in immersion learning meant that grammar work did not concern him on a day-to-day basis. For Zenk, finding a way to accurately and usefully describe the multifunctionality of Chinuk Wawa using part-of-speech labels was an on-going concern as he continued to compile and refine the dictionary.

In the main you can separate words according to parts of speech, although some of them may participate in different parts of speech. But then there are these kind of leftover curious cases that I think to really shed light on, you just need to get all the examples you can and try to decide: is $k^{h}$ anawi ['all, every, each'] functioning as a pronoun in some of these cases? You might just have to put that in a special category, you know, that there are some words in Chinuk Wawa that can function as pronouns as well as adjectives and adverbs. If that's the way it is, that's the way it is. (H. B. Zenk, interview, May 5, 2009)

Learners and teachers also reported struggling with how to describe and explain these "shape-shifting words." Johnson remarked that people who are learning a language structure their understanding according to their expectations. He noted the way that Melville Jacob's expectations of Chinuk Wawa, which were based on his prior experiences with highly agglutinating Northwest coast languages, can be seen in his orthography and his grammatical description. 
I love that he can take na-hayu-munk-4xwap ['I am making a hole'] and just see it as what would have been a verb in Chinookan, just a single Chinookan word. That's the way he perceived it, when he was first looking at Chinuk Wawa, it's very clear: it's got its pronoun, it's got its continuative marker... even at a sentence level in Chinuk Wawa, I think the comparisons can be made with these incredibly complex verbs in Chinookan. (T.Johnson, interview, July 14, 2009)

Although Johnson, Zenk, and Schrock all indicated their interest in the possibilities of insight into Chinuk Wawa history, lexicon, and grammar through research into Chinookan, everyone I spoke with agreed that a comprehensive model of this type is still a long way off.

\section{Pronoun choice}

Johnson attributed patterns of short or long pronoun forms to dialect, stating that "there are people who are never going to use short form pronouns for any reason except economy," such as Mose Hudson and his daughters, but that those who consistently used short form pronouns would use the long forms in a marked way, "to really make the point" (T. Johnson, interview, July 14,2009$)$. Zenk pointed out that Wilson Bobb, who used short-form pronouns almost exclusively, was from the same extended family as Victoria Howard, who also had a noted preference for short forms. There may have been influence from Chinookan in this Chinookan-speaking family's Chinuk Wawa, as suggested by Boas (1933): Zenk added that he wondered about the possibility of this preference having developed as part of a desire to differentiate themselves from other speakers:

Something I really wonder about is how much of this was spontaneous or how much of this was really something motivated, that people were motivated to create a stylized Chinuk Wawa that was their thing somehow, as an identity 
thing. It seems to have influenced the Chinuk Wawa in the community. (H. B. Zenk, interview, May 5, 2009).

The CTGR language program, though it introduces all the pronoun forms, tends to use the long forms in its materials. Zenk described the reasoning behind the choice not to stress the Victoria Howard/Wilson Bobb short form style: long forms were more generic regionally, current speakers are more used to speaking long forms, and it seemed more pedagogically sensible, since elder speakers tended to use either one type or the other, to teach a complete form instead of a shortened and (distributionally) more complex one. In a later discussion, however, he and Schrock agreed that the short forms were appropriate, and often heard, in conversational contexts. Pronoun distribution in these contexts is a matter for further study.

\section{Animacy and agency in pronoun choices}

There has been some discussion in the literature and among the people I interviewed about when resumptive pronouns are required and when they are not, and what requirements there are for a person, animal, or object to be referred to with a personal rather than a demonstrative pronoun. Johnson talked with me about the way he used himself as an informant, addressing this question to his own sensibility of the language and culture:

I'm not sure that because somebody was using ukuk [demonstrative] versus yaka [3s personal] that they're trying to take the animacy out of it. I'm not sure that that's true. Even in my own brain.... I mean a long time ago I convinced myself that none of this stuff s gonna stick with me unless I'm just a believer in it. The cultural sensibilities of my ancestors. I just take it all to heart. I don't step over a salamander in the woods, you know, I just won't do it... these are just things we're not gonna do, and I think I have a certain amount of that same sensibility and... I've on occasion spent a lot of time thinking about 'okay, 
which am I using? Am I thinking about it? Do I actually care?' (T. Johnson, interview, July 14, 2009)

In Crane's Myth, both samon 'fish' and upkwina 'baskets' are referred to in object position with the third person plural personal pronoun łaska. Zenk said that use of taska was the only possible way to express the plural nature of these objects. The baskets also take the resumptive pronoun taska in subject position:

\section{Example 9}

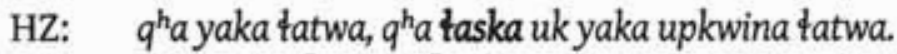
where he [Coyote] went, there they those his baskets went.

This is an unusual case, however, because the baskets are under Coyote's supernatural control, and are in fact actively moving of their own accord. The use of the resumptive pronoun here makes this clear. Without it, it would seem that Coyote was carrying the baskets, when in fact he has enchanted the baskets just so that he does not have to carry them.

In one of my interviews with Schrock, we discussed the role of resumptive pronouns in determining the semantics of a multi-functional verb. The change shown in Example 10, from Crane's Myth, changed not only the word order of the sentence, but the sense of the verb milayt.

\section{Example 10}

JS: $\quad q^{\text {ha a yaka tonas taska mitayt }}$ 'where her children they live'

HZ: $\quad q^{\text {ha }}$ mitayt yaka tonas 'where is-located her child' 
The removal of the third person plural pronoun taska, co-referential with tonas 'child(ren),' eliminated the possibility of an active interpretation of mitayt. Schrock's mental model of resumptive pronouns was that the pronoun is the subject, which is relatively closely bound to the verb, and the NP is a clarifier that is mobile within the sentence. This model is influenced by Chinookan grammar, in which obligatory bound morphemes can be amplified by mobile independent particles. Considering Schrock's explanation of the change in meaning from active 'live' to inactive 'be there' with the removal of the pronoun in this context, I would suggest that his model may be specific to participants fulfilling an agent role.

\section{Pronouns versus noun phrases}

The text analysis showed that, many times, explicit reference to the participants in a narrative was removed from the texts, leaving only the third person pronoun. One of the challenges of reading these texts was distinguishing with any certainty who was doing what to whom. This challenge was also evident in reading the historical texts, so in that sense, these changes did serve to make the texts more similar to "elder Wawa" and therefore more authentic. As Schrock mentioned in our discussion of Crane's Myth, there is a heritage reason for saying "the elders didn't do that way, so why should we?" (J. Schrock, interview, May 8, 2009). As a classroom of learners, we worked together to discuss the options in these cases of ambiguity, and we came to an agreement as to the likely intent. We also had teachers there to help us recognize any possible clues to the thematic roles of the various occurrences of the 
third person singular pronoun yaka. In thinking about the eventual creation of a textbook, especially one that would be used outside of a class environment, however, one learner suggested that "a lot of the yakas [would] have to go away, and become the people who are actually saying those things or to whom they are referring, because otherwise as a casual reader there's no way you can get the gist of the story" (anonymous interview, June 11, 2009). Schrock also commented that "that might be the style, but if it's unclear, that's one thing I think maybe we ought to change a little bit. The point of language is to make yourself understood" (J. Schrock, interview, May $8,2009)$. An increase in explicit reference to participants might be something that would begin to distinguish written Chinuk Wawa from spoken forms in which, due to the greater possibilities for contextualization, including intonation, pointing, and questions from interlocutors, explicit reference is not as necessary for comprehension.

\section{Demonstratives}

Use of the demonstrative particles $u k$ and $u k u k$ was shown to be an important site of changes in the texts reviewed. Proper and judicious use of these was also a concern of the teachers and learners I spoke with, and it was addressed specifically as a grammar point several times over the course of the two years of classes. There is functional overlap between English "the" and $u k(u k)$, and there is a concern that some learners tend to understand it as a required article in complimentary distribution with ixt 'one, a certain,' used in the same way as the English article "a/an." 
The distinction between $u k$ and $u k u k$ is still somewhat murky; they do not seem to be completely in complementary distribution. Several interviews suggested that there may be dialectal or idiolectical issues at work, as with the short and long forms of the personal pronouns. Both of them refer to a previously known referent. $u k$ is also used as a relativizer, as in Example 11 from Crane's Myth, while ukuk has not been recorded in this function. ukuk, on the other hand, serves as an inanimate third person pronoun in this example, which is a function that has not been recorded for $u k$. Both of them can be used as demonstratives before a noun phrase.

\section{Example 11}

$k^{h}$ apit pus nanich laphyush-hol-stik uk mitxwst saxali $k^{h} a p a$ ukuk. Only for see shovel-hold-stick that stood above PREP it. Only the handle that was sticking out of it [the earth] could be seen.

\section{Prepositions}

Chinuk Wawa has only one preposition. This can make it difficult to express in writing locational relations that are conveyed by a variety of prepositions in English and that are easily conveyed by gesture in speech. In the first scene of Crane's Myth, Coyote and Crane have a conversation about how many basket ogresses each of them has as lovers. Schrock's translation was unclear to Zenk, who rephrased the Chinuk Wawa without reference to the English. The resulting final version was different in meaning from the English source and still difficult for students to understand in class. When I reviewed the translation with Schrock, we discussed two factors that made the intention of his original text unclear. One was the use of a generic verb, łatwa 'go,' to refer to the action of the basket ogresses 
who wouldn't fit in the canoe following along on the bank. In retrospect, Schrock remembered the more specific verb t'aqsin 'follow.' The other factor was the use of the universal preposition $k^{h} a p a$ following pat 'full' in order to indicate what the canoes were full of. Schrock said that he had used that construction subsequently with no comprehension problems, but that also he would now use a construction developed in a latter text, Hattie Hudson: pat + FILLER + FILLED. This construction came from a change that Zenk made in that text, shown in Example 12:

\section{Example 12}

yaka ikthas chaku pat-tsaqw-ikt has

her clothing became full-water-clothing

\subsubsection{Narrative structure and strategy}

Discussions of strategies for portraying Chinuk Wawa in writing brought up a tension between the desire to maintain traditional elder Wawa narrative style and the desire to create a readable, comprehensible text. Johnson described the importance of the traditional narrative style for cultural learning: "That voice that shows up in stories is, I think, a very nice thing. It's not essential to learning the language, but I think it's very important to learning the sensibility" (T. Johnson, interview, July 14, 2009).

Johnson also described the importance of humility and respect towards the traditional stories and ancestors who perfected them.

It is very clear that that, the same way a canoe was refined over 10,000 years of time to something that became virtually perfect in the water, the stories were 
thought about that way. And they are very precise. When we're writing something ourselves now, it's like dabbling, in a sense. Like carving canoes, we're lucky if we can approximate the skills our ancestors had. So I don't expect when we're writing that we're writing what Charles Cultee had to say, you know. It's just not possible. But I hope we're not totally contradicting it either. That would be the goal, not to just blatantly contradict it (T. Johnson, interview, July 14,2009 ).

\section{Discourse markers}

As we discussed the differences between spoken and written language,

Johnson noted that he often added the clause-initial discourse marker alta in his own revision processes:

alta starts dropping away, you know, and that's something I find myself building back in, when I go back. Because I might just type whatever it is I'm typing in Chinuk, and then I go back and read it and it's totally uncomfortable because it's missing alta. (Johnson, interview 07/14/09).

Schrock mentioned that he did not yet "know rhyme or reason" for the use of alta as a discourse marker, but that it did seem to him that "you can't overuse it" (interview, 5/08/09). In a later casual discussion he remarked that clause-initial alta seems to have a temporal function only when used contrastively with other time adverbials.

\section{Text presentation}

A few of the texts in this study were presented in quasi-Hymesian verse format (Hymes, 1981). Hymes' strategy for representing oral literature in written form uses line breaks, grouping of lines into stanzas, and grouping of stanzas into acts to portray the inherent structure of narrative. A short sample of a versified text (Four Generations) is given in Appendix E. Using a verse format was seen by participants in this study as an attempt to represent the original orality of a text or to promote the understanding 
of a text as something to be read aloud. Versification requires a significant time investment, and Johnson spoke about his appreciation for the effect.

I am always happy when Henry will spend enough time to really verse something out, because while I'm not living and dying over that idea, I am a good friend of Dell Hymes. I am a believer in that, in the sense that if you ever were to have heard Dell tell one of his stories versed out, it's so obvious that that is right. It's so clear that that's a really nice, appropriate way of taking an oral literature and presenting it on paper. There's something very compelling about it. Again, though, that's the reading of it. That's the actual literal voicing of what's on the paper (T. Johnson, interview, July 14, 2009).

If there were to be no reading aloud, no future performance, Johnson suggested, Hymesian versification could be less significant. One learner I spoke with particularly liked the verse style, even though it sometimes caused reading challenges due to the unfamiliar arrangement of thought groups. This difference was seen as further cultural information that helped to situate the text in its appropriate environment. Zenk described the process of lining out texts as a useful tool for his own compositions or translations, provided that he did not go too far down the road of Hymesian analysis and become entangled in self-consciousness:

Often when I do things like compose or translate, I line things out, it's kind of quasi-Hymes, but not real Hymes, because there again if 1 start thinking too seriously about it it becomes self-conscious again. You start dividing up a text into threes and fives, you know? I do like putting a text out in lines, I think it kind of opens it up. For me that's part of trying to induce a sense of spoken Chinuk Wawa style into written Chinuk Wawa, to put it in lines like that, with a sense of hierarchy in the lines, without going all the way down that road. (H. B. Zenk, interview, May 5, 2009)

\subsubsection{Summary of interview results}

The interviews gave me a strong sense of the process of developing these texts, from selection of a topic for the curriculum to the distribution of lessons in class. The 
people I spoke with were all passionate about Chinuk Wawa: learning it, teaching it, and helping it grow. They valued collaboration in the development of new texts and new vocabulary, and struggled with time pressures and finding the best ways to reconcile the needs of pedagogy and the needs of continued language research.

Further development of comprehensive, accessible reference materials for the lexicon, grammar, and stylistic possibilities of Chinuk Wawa was considered to be important, but there was concern for protecting the intuitions of fluent speakers and the integrity of the language from over-analysis. Innovations in the lexicon were developed mainly through analogy to elder speech and novel compounds. Although there was some support for borrowing from local Native languages as a way of increasing knowledge of those languages and imitating the strategies of ancestral speakers, loan translations were seen by some as a more appropriate way to do this. The multi-functionality of Chinuk Wawa lexemes was discussed in terms of the challenges it poses to grammatical description as well as the challenges it poses to text interpretation. Hyphenation was seen to be a major point of discussion that embodied phonological, lexical, and grammatical concerns. The personal and demonstrative pronouns emerged as complex phenomena that tied into dialectal and idiolectical patterns. Opinions varied, and certainty was limited with regards to the relationship of these pronouns to concepts such as agency, animacy, activity, and control. Influences on Chinuk Wawa, and on the analysis of Chinuk Wawa, from English and other languages, were also a matter of some interest. The effects of language analysis and modeling were discussed in relation to their potential effects 
on the language in the minds of individual speakers, on the speech community as a whole, and on learner morale.

The representation of oral literature and oral style in writing and the possibilities of a developing genre of "literary" Chinuk Wawa was one thread that ran through all these interviews. The concept of authenticity and cultural appropriateness as it manifested in discussions of authentic examples versus constructed ones, cultural subject matter, lexical choice, and narrative style was strongly interwoven with the question of how to best inscribe a traditionally oral language. Underlying both of these was a theme of authority understood as responsibility to the language and its speakers: the future of the youngest learners and their descendants, and the history of the elders and ancestors.

\subsection{Results summary}

This chapter has described what I saw in the changes and differences between the versions of the texts, and what I heard in the interviews and discussions. Several important themes emerged: Chinuk Wawa is a growing language, and knowledge about Chinuk Wawa is a work in progress; authenticity of source knowledge and target production are important concerns for successful language development, and second language speakers' intuitions are a key bridge to Chinuk Wawa's future. The next chapter will describe these themes and present suggestions for future research based on the results of this study. 


\section{DISCUSSION \& CONCLUSIONS}

In this chapter, I discuss the results described in Chapter 3 and draw some conclusions about the case of Chinuk Wawa text development. The texts investigated in this study are the product of translation and editing work by non-native speakers. I investigated the process of developing them by coding and tabulating the differences between versions and by interviewing the text developers and other stakeholders about their thoughts and experiences. I also kept notes of my own experiences and observations as a student in the Chinuk Wawa classes in which these texts were used. The results of these analyses, interviews, conversations, and observations sketch a fascinating picture of a unique language in development, with implications for studies of language revitalization, translation, and second language writing.

This study is a snapshot of one facet of language revitalization in progress. The text development process I investigated mostly took place backstage of the university language classrooms, but in-class discussions and the use of the parallel translations and edited transcripts as lesson materials did occasionally serve to bring the process front and center. My research also affected the process, as once I began discussing this study with Schrock and Zenk, they became more conscious of explicitly rationalizing their writing and editing choices in footnotes, marginal comments, and email messages. By being a participant observer and by actively engaging stakeholders in discussions related to decision-making in Chinuk Wawa writing and implications thereof, I encouraged heightened awareness of the constructedness of these newlydeveloped texts and of our knowledge of the language. Attention to intuition and 
conscious processes can assist individuals in monitoring the progress of their second language development (Schmidt, 1993). I believe that this attention can be extended to a community level; this type of attention can assist a heritage language revitalization program in monitoring the progress of the language's development in the community.

While this study was in progress, one of the instructors in the program estimated that there were 33 adult Chinuk Wawa speakers who would test at ACTFL ${ }^{16}$ intermediate-mid level or above. This is a substantial increase from the small handful of speakers that began the Chinuk Wawa core group in 1998. These adults are able to converse freely, teach others, and assist with research and development activities such as transcribing archival recordings and translating materials. The main focus of the CTGR language program is on the immersion school and the hope of a new generation raised with Chinuk Wawa as one of their native languages. The success of immersion, however, is dependent upon fluent adult speakers who are able to provide continuous input to these children, so that they develop the language naturally. The adult classes, both at the community level and for university credit, serve to increase the currency of the language and build a community of successful speakers who can help raise the youth with authentic knowledge of their heritage language.

\footnotetext{
${ }^{16}$ American Council on the Teaching of Foreign Languages: The ACTFL Oral Proficiency Interview is widely used to assess language speaking ability. Intermediate mid is the fifth of ten proficiency levels and is characterized by the ability to successfully handle "a variety of uncomplicated communicative tasks in straightforward social situations" (Breiner-Sanders, Lowe, Miles, and Swender, 2000).
} 
This study showed materials developers addressing the challenges of historical and current language variation as they made decisions about vocabulary, sentence structure, information content, and narrative flow. Because the resulting texts were used as input and study materials for emerging speakers, these decisions moved the language closer to standardization. In the sections below, I will first discuss the tensions between variation, standardization, and development that were revealed in this study. I will then consider specific decisions (or lack thereof) about vocabulary building, hyphenation, and grammaticalization, and consider how they tie into commitments to fidelity and authenticity as Chinuk Wawa becomes a (natively) written language. Finally, I will conclude by addressing larger concepts of hybridity and native speaker status as they relate to language revitalization and translators working into their second language.

\subsection{Variation, standardization, and development}

Stable variation is a sign of language vitality (Amery, 2000). As the participants in this study mentioned, the Chinuk Wawa of the elders as it has been documented is heterogeneous, and the samples of speech are small enough that it is difficult to determine the amount and extent of variation among individual speakers, among speakers of different language backgrounds, or among speakers of different generations. It is also difficult to identify where characteristic contact language flexibility ends and stable variation begins. When variation is identified, such as the use by some speakers of clitic and/or truncated pronouns, it is difficult 
to determine whether it is due to idiolect (or family-lect), first language influence, or diachronic change.

Contemporary Chinuk Wawa also varies. The participants in this study sought standards and used collaboration and reference materials to limit variation, but the existing variation among speakers was sometimes a source of tension in the text development process and in comments about the language program as a whole; this tension highlights the importance of idiolect and personal style in Chinuk Wawa, where historical sources are from individuals and families, rather than a wide sample from across the speech community. Zenk's suggestion that the extensive use of clitic pronouns by Victoria Howard and other members of her extended family could have been motivated by a desire to differentiate themselves from other speakers is particularly intriguing in this light. All of the current speakers share English as a first language, but many of them speak other second languages in addition to Chinuk Wawa. The variation in their Chinuk Wawa may be attributed to different input (different educational contexts or interlocutors), to interaction with other second languages, or to different stages of interlanguage in their language acquisition processes.

Language revitalization programs sometimes report the development of a contact variety of the heritage language, in which the heritage language lexemes are used with the dominant language grammar (e.g. Goodfellow, 2003). Sometimes this is an interim goal in language reclamation (Amery, 2000; Hinton, 1996; Palmer, 1988) or even the final goal of a project in which native-like command of the language is not 
the objective of the community (Powell, 1973). In this case, however, the language is already historically a contact language, and the goal is for communicative competence that, given some explanation of newly coined vocabulary, would be effective with elders of past generations. Achievement of this goal requires vigilance against excessive change in the direction of English, even if that change seems to be internally motivated rather than an effect of contact. Since all the learners are English dominant and some are non-Indian, it is understandable that a tribally sponsored program emphasizes the pronunciation features, grammatical subtleties, and narrative patterns that mark Chinuk Wawa as an Indian language.

\subsubsection{Standardization}

Language varies, and it changes. Even in languages like Hawaiian, Maori, and Navajo that have relatively many speakers and resources, monolingual elder speakers have admitted to having trouble understanding the speech of young bilingual speakers (NeSmith, 2009; Zuckermann, 2006; Peterson, 1997). This study did not compare the new texts to the historical texts in any way. The categories developed here could provide a starting place for that analysis. Decisions would need to be made, however, about which historical texts to analyze, and what weight to give to each. Should the "standard" against which new texts are compared be an amalgamated average of all the historical texts available? If so, should the average be weighted somehow to give equal representation to the various speakers regardless of the volume of language documented from each? Or should certain speakers, or even one 
speaker, be selected? Should dialectal differences be teased apart and presented to learners, or should one standard language be forged in the crucible of the CTGR language program? For many learners, the latter is preferable. The former, however, may be more faithful to the linguistic reality of the elder speakers.

Although learners have access to many of the historical texts in lessons and in the back of the dictionary, and to examples from many speakers in the dictionary examples, there is a sense in which their access to the variation in elder Wawa is already tempered by having passed through the language acquisition process of their teachers. The teachers are both bearers and curators of the language, and it is on their authority that decisions are made about what to present to students, and what to teach them. The changes made to vocabulary in the edited texts analyzed here are essentially small-scale brainstorming sessions or negotiations between the writer and editor that resulted in standardization, at least for the learners in the university classes. (The parallel translations, on the other hand, are negotiations waiting to happen either in the mind of the reader or in class assignments.) In the lessons, each text was prefaced with a list of new vocabulary drawn from the text. This list was generated by the person responsible for compiling and distributing the lesson materials, who read the finalized text to identify unfamiliar terms. ${ }^{17}$

Several other standardizing decisions were revealed by this study. In the interest of reducing learner confusion, the decision was made to focus on teaching the

\footnotetext{
${ }^{17}$ This process sometimes did not identify all of the vocabulary that would be unfamiliar to students, as compounds assumed to be semantically transparent sometimes were not listed.
} 
long form personal pronouns and to treat the use of short forms (both clitic and truncated) as a dialectal feature, advising against the use of short forms in writing in general, and against the alternation of short and long form pronouns in the same document. The decision to consistently hyphenate auxiliary constructions and compounds also entailed the decision to consistently pronounce those compounds with unitary stress, usually on the final component of the hyphenated string. Clauseinitial alta '(and) now/then' was promoted as a more appropriate way to structure sequential narratives than the use of the conjunction pi 'and, or.' It was also decided that certain innovative patterns, such as munk INSTRUMENT pus to express instrumentality, and pat-FWLER-FILED to express something being filled with something else, could be used productively, while others, such as munk-соммовrry for 'harvest,' should not be.

\subsubsection{Standardization vs. research and development}

There is a tension between the desire for standardization and the desire for ongoing research and development, as research could lead to changes that would contradict existing materials. Development of new structural models, or the discovery of more accurate or authentic lexical resources, could have serious pedagogical implications should they require learners to "re-learn" what they know. For some learners, being on the front lines of language revitalization is thrilling; for others, however, that same dynamism is highly frustrating. Johnson's comment that more fluent speakers were more adaptable to research-based changes was echoed in Zenk's 
suggestion that it might be appropriate to teach the short-form pronouns to more advanced students after they had built up a foundational competence in the language using the long forms. Written materials for pedagogical purposes should be consistent with historical texts, but with less variation, and they should be consistent with each other and other pedagogical materials. Oral input, on the other hand, is much less easily controlled and is thus bound to be more variable. Oral language is open to negotiation and discussion in a way that written language is not, especially outside of the classroom.

\subsection{Fidelity and authenticity in decision-making}

The participants in this study were strongly concerned with developing the language in a way that was faithful to the memories of the elders and sensitive to CTGR culture and heritage. In his translation practice, Schrock emphasized fidelity to the original voice of the Native speaker inscribed in the source text, while Zenk emphasized fidelity to his internalized sense of the rhythm and style of Chinuk Wawa native speakers. The combination of these two approaches, with Schrock drafting and Zenk editing the translations, is similar to the common translation industry practice of collaboration between a translator who translates from his or her native language into the target language and a trusted editor who is a native speaker of the target language. This practice is designed to result in a target text that is as authentic as possible in both content and style. 
Examination of the text development process revealed attention to cultural and linguistic authenticity at all levels. The curriculum design and text selection focused on culturally relevant topics such as ancestral customs, local geography and history, myths and traditional stories, biographies of elders, and traditional crafts. Schrock and Zenk both looked to Tony Johnson as a cultural consultant to provide guidance on appropriate topics for texts and appropriate ways to convey cultural sensibilities in instruction. The reference materials used by the developers centered on the documented language use of Grand Ronde elders, which is inherently authentic, although opinions may have differed (and may still differ) as to whose language was "best." Preserving and promoting the distinctive (non-English-like) pronunciation, phrasing, syntax, and narrative style of Grand Ronde Chinuk Wawa is key to the mission of maintaining authenticity and remaining faithful to the heritage of the language as it was taught and used by the elders. Of course, as was mentioned several times by participants in this study, each elder speaker was different, and the most recent generation of speakers practiced extensive code switching and code mixing with English. The target of the CTGR language program is an ideal, and it errs on the side of emphasizing non-English-like characteristics in order to compensate for the inevitable influence of English on the Chinuk Wawa of modern speakers. Similarly, the topics and focus of instruction are on the stories, traditions, history, and lifeways of local Native people before and after the formation of the Grand Ronde Reservation. The texts that are read in class reflect this focus, as do classroom activities and homework assignments; for example, an assignment after a lesson on elk hunting 
might be for students to write about their own experiences hunting elk (real or imagined).

\subsubsection{Lexical development}

The process of revising the texts in this study often resulted in the replacement of borrowings from other local languages and English with Chinuk Wawa coinings. Although fluent elder speakers may have borrowed from other languages shared with their interlocutors to fill lexical gaps in Chinuk Wawa conversation or narrative, this practice seems to be seen as a privilege of native speakers that should generally be avoided in writing intended to teach and expand Chinuk Wawa. This study showed a preference for compounding, re-purposing, or extending existing lexemes, or using circumlocution, over borrowing directly from other languages. What borrowing did take place was from non-English languages, usually for names of mythical persons (such as Crane), places, or flora and fauna. Borrowing is a contact phenomenon, so in a sense, borrowing from the local Native languages that were L1s of early Grand Ronde residents not only serves to revitalize Chinuk Wawa, but also revitalizes the linguistic context of Chinuk Wawa: contact especially with Chinookan, Kalapuyan, and Molala, the L1s best represented by materials known to Zenk, Schrock, and Johnson. ${ }^{18}$

\footnotetext{
${ }^{18}$ Other principal Grand Ronde L1s were Takelman, Umpqua Athapaskan, Shastan, and nonstandard Canadian French.
} 
Since the CTGR language program does not have a standing lexicon development committee or a regular system for generating and standardizing new vocabulary, outside of collaborative materials development, the language is developing organically through creative use in conversation and writing. This is how previous speakers must have done it. It does mean, however, that speakers in different spheres (such as the conversation classes at the CTGR Portland office and the students and staff of the immersion school at Grand Ronde) may duplicate each others' efforts, leading to increased variation and even perhaps the beginnings of different dialects. Some individuals keep lists of coinings that they develop or overhear, and there are many words that have become common usage in the immersion school that were developed either by teachers or by the children themselves in response to communicative needs. Johnson's mention of the loan translation ulq'-latet 'dragonfly' is one example of this type. There is no definitive list, however, of newly coined (as opposed to historically attested) vocabulary that can be used as a reference by speakers (and writers) seeking to fill lexical gaps. The focus has been on the development and future publication of the dictionary of "Chinuk Wawa as our elders teach us to speak it" (Johnson and Zenk, 2009) with a strong interest in maintaining the purity of this source as a document of the historical language of the community.

\subsubsection{Hyphenation at the intersection}

Hyphenation has been widely used in writing Chinuk Wawa, but this study showed that its use and meaning is still being debated. My understanding of this 
debate relates it to hyphenation's multiple roles at the intersection of orality and literacy, and the emergence of "literary" Chinuk Wawa. Jacobs used hyphens in his transcriptions to represent the tendency he saw for Chinuk Wawa words to adhere or cluster tightly together in fluid speech (Jacobs 1932, pp. 33-38); sometimes a whole sentence could be represented in this way. In the final text of Crane's Myth, hyphens are used to join non-transparent/idiomatic compounds (4ush-kakwa 'good thusly = never mind,' tonas-tuchman 'small female = girl'), transparent compounds (kalayton-

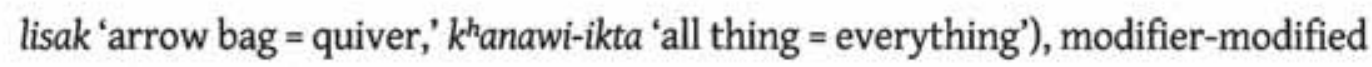
collocations (dret-k'was 'very afraid,' skukum-stik 'strong stick,' manak'i-hayu 'more many = even more,' tatwa-saya 'go far away'), compound or serial verbs (tatwa-iskam 'go and get,' łatwa-mitxwit 'go and stand,' iskam-hol 'get and hold = grab on to'), and the components of reduplicated lexemes (k'aw-k'aw 'tied up,' k'ilapay-k'ilapay-kakwa 'backand-forth-thus = wound around'). Hyphenation was also used, after Zenk's edits, to join munk and chaku to their right collocates (munk-qhata 'make messed-up = disturb,' munk-pilton 'make a fool = trick,' munk-miłayt 'make be-located = put,' chaku-kəmtəks 'come know = realize,' chaku-twax-tomtəm 'come light mind [awake] = wake up'). Shrock's suggestion that the transitive verbalizing function of munk and the changeof-state verbalizing function of chaku could be intelligible in collocation without hyphens was set aside in order to follow the existing standard and to maintain the prosodic representation of the assimilation of stress to the head word.

There is a desire, from a pedagogical point of view, for hyphenation to have a clear and simple meaning. In transcription, the meaning is prosodic. The auxiliaries 
are usually unstressed (or receive at most a light secondary stress). They may also be stressed for emphasis, however, or to indicate exceptionally careful enunciation. This distinction can be conveyed in transcription by inserting a hyphen or not: e.g., munkipsat [munk-ípsat] 'make-hidden; hide [it]' versus munk ipsat [múnk ípsat] 'HIDE IT.' In the second case, munk would still be understood in its auxiliary sense due to its collocation with an adjective and the context of the sentence or utterance. Writing directly in Chinuk Wawa, however, is not transcription, and as Chinuk Wawa gains new literate speakers, they are writing it in domains ranging from homework assignments to text messages. The prosodic function of the hyphen, then, becomes a "chicken or egg" question. Does the hyphen indicate lack of stress, or does it indicate lexical or grammatical unity of which lack of stress is a possible effect?

In writing, the function of the hyphen has been extended from an indication of prosodic unity to an indication of lexical or grammatical unity. Both components of serial verb constructions such as łatwa-iskam 'go and get' often received stress in elder Wawa (Doty, 2009), and reduplications such as k'ilapay-k'ilapay-kakwa 'back-and-forththus = wound around' receives stress on each component in current pronunciation. This extension leads to confusion between the new lexical and grammatical functions. If hyphenation serves to indicate lexical compounds that are "greater than the sum of their parts," that would seem to indicate that munk-mitayt 'make + be-located; put' is a single lexeme, rather than the grammatical interaction of an auxiliary verb and a main verb, or of a verbalizing morpheme and an adjective. If the hyphen indicates "grammar interacting," on the other hand, that would seem to indicate that $k^{h}$ anawi 
'all, every' in khanawi-ikta 'everything' has a grammatical function which is applied to the noun $i k t a$. Either one of these options would require a major restructuring of the current understanding. This issue has not yet been resolved either descriptively or prescriptively. However, it is clear that, as the written language develops, the authenticity of the hyphen's descriptive prosodic function cannot be maintained for lexical or grammatical contexts that are not attested in elder Wawa.

\subsubsection{Grammaticalization}

Contact languages undergo diachronic change just like all other languages, and it can be impossible to determine which observed changes come from contact and which come from inside the language (Thomason, 2003). Thomason noted that the verbalizing function of munk arose in Chinook Jargon in the middle of the nineteenth century, after the pidgin had already been in stable use for some time. It is possible, then, that this is the result of a natural process of grammaticalization, in which the independent lexeme munk 'make, do' is becoming a bound morpheme, rather than the result of influence from contact with Chinookan or any other language. Zenk documented further shortening of chaku-to chaw- and even ch-in speakers of the most recent generation. It is not entirely clear whether this is evidence of grammaticalization or of the occasional condensing of single high-frequency lexemes in rapid speech. What is clear is that these forms, even more than the clitic pronouns, although they are listed in the dictionary and would be discussed in class if they were to occur in historical transcripts, are not taught as part of the standard (written) 
language. The variation present in elder speech is described and presented, but it is the less syntacticized (Givon, 1979) full forms of the auxiliaries and the pronouns that are written in new texts that will be used pedagogically. In my opinion the choice not to promote the more syntacticized forms reflects both a connection to the broader regional Chinuk Wawa and a desire to let any grammaticalization that happens as the language expands to more speakers and domains occur as a natural process of the language, rather than engineering based on the speech of a few.

\subsubsection{Emergence of a "literary language"}

This discussion has already mentioned differentiations made between oral and written language in terms of the use of shortened forms of pronouns and auxiliaries, as well as in spontaneous versus researched development of new vocabulary. I have also discussed the relationship between stress patterns in oral language and hyphenation in written language. Written language is more planned, and more permanent, than oral language. The changes made in the preparation of the Black Bull transcript for use in class exemplify some of the differences: assimilation of idiosyncratic pronunciation to a choice of standardized alternate spellings, deletion and streamlining of false starts and negotiations, and insertion of elided words. Written materials developed by Eula Petite exemplify another type of change: Mrs. Petite systematically dropped resumptive pronouns from her written texts (even though she used them freely in speech) because of their frequency in 
local non-standard English ${ }^{19}$ and her efforts to promote Standard English usage in her students (H. B. Zenk, interview, September 13, 2009). When these texts were read in the university classes, resumptive pronouns were added in parentheses so that they would conform to current standards, which are based on fidelity to the elders' spoken language.

Written texts are an idealized model of language, while speech is language in action. Narrative performance is somewhere in between. Myth narratives are oral literature, repeated and refined over generations. Narrative texts in this study were adapted to match the narrative style of recorded performances from elders: using Coyote's typical pronouncements, using alta extensively to move the narration along, referencing participants primarily with pronouns, and repeating phrasal patterns from other myths. ${ }^{20}$ Even in the myth texts, however, revisions were made that increased the specificity of the narratives in various ways. These alterations compensated for the reduced cultural and communicative context of the current audience. As Schrock pointed out: "There needs to be a little bit of leeway that, this [specification] is allowed in literary Chinuk Wawa, because you can't point, or nod your head, or whatever (J. Schrock, interview, April 30, 2009)."

${ }^{19}$ E.g. "My old man, he rides with the angels."

${ }^{20}$ Zenk's phrase describing the movement of Coyote's baskets in Crane's Myth ( $q^{\text {h }}$ a yaka tatwa, $q^{\text {h a }}$ taska uk yaka upkwina tatwa 'where he went, where they those baskets of his went') echoes Victoria Howard's "Stingy Girl" narrative, in which a girl magically travels long distances by stepping in the footsteps of the mountain women: $q^{h} a$ a las mítxwit khapá y a mítxwit 'where they stood there she stood.' 
Chinuk Wawa is expanding into new domains, and it is developing a literature that begins with the historical transcribed texts. As new texts are developed, decisions must balance the desire for fidelity to tradition with the demands of new contexts and the desire for the language to develop authentically, using its own resources, without undue planning and engineering. Chinuk Wawa, as a hybrid language that has always existed in multilingual contexts, is perhaps uniquely situated to embrace this challenge.

\subsection{Hybridity and native speaker status}

All of the participants in this study emphasized their non-native speaker status. Most would likely agree with Watahomigie and Yamamoto (1992, quoted in McCarty, Watahomigie, Yamamoto and Zepeda, 1997, p. 89) that "language and literature can be taught most effectively by teachers who are native speakers of the language and are trained to teach... with language materials and literature produced by native speakers." It is essential to ask, however, what exactly constitutes a native speaker of a language, especially a language like Chinuk Wawa that developed and was primarily used as an auxiliary language. Childhood acquisition seems to be a prime criterion for native speaker status, but some scholars have argued that, with difficulty, it is possible for people to become native speakers of a language after puberty (Davies, 2004).

According to Davies, native speakers "carry the tradition [and] are the repositories of 'the language'" (p. 434). In this sense, in the absence of fluent speakers 
who learned the language in childhood, Johnson and Zenk fill the role of native speakers for the CTGR language program and the community of learners that has developed. Graddol (2003) described the "cult" of the native speaker as relating to the privileged information residing in a native speaker's intuitions, "a much richer source of data than a researcher could discover by studying a speaker's actual utterances" ( $p$. 165). The data available to the CTGR language program are speakers' actual (recorded and transcribed) utterances, conclusions drawn from studying them, and intuitions developed by means of extended exposure to them. These data bridge the gap between past and future generations of native speakers. Davies (2004) suggested that individuals who have achieved native-speaker status in their second language "are prepared to accept the fragility of the knowledge they have so carefully acquired" (p. 433). In this study, this acceptance was seen in Johnson and Zenk's humility about their language abilities in comparison to those of the elders, and in their concern for the susceptibility of their intuitions to outside influences.

Zenk's statements about the dangers posed to his intuitions by "grammars that do too much" give rise to concern about the possible side-effects of programs to train native speakers of endangered languages in linguistics so that they might better document and teach their languages. Norris (1988), a Yurok linguist who has taught in these programs, observed that trainings were more effective if linguistic concepts and terminology were introduced after the phenomena had been isolated in the speakers' language, rather than provided as a model to look for. This ordering reduced "interference from external sources of confusion" (p. 321). The effect of the 
introduction of grammatical models on linguistic intuition may be a matter for investigation by those specializing in psycholinguistics and cognitive science. The introduction of "interference" or doubt into the minds of "naïve" native speakers of endangered languages who wish to document and teach their languages, however, is a matter that should be addressed carefully by specialists in language revitalization. Zenk is not a native Chinuk Wawa speaker, so his intuitions are more malleable (or "fragile," as he described it) than those of a native speaker, and Chinuk Wawa is a contact language, the subtleties of which are difficult to pin down. Still, the comments of Johnson and Zenk in this study about overanalysis seem to me to recommend careful consideration of the balance between internal language knowledge and the development or utilization of external models.

Native speakers are often able to make quick and confident grammaticality judgments, but they sometimes are unsure, and they do not always agree. Non-native speakers make such judgments more slowly and with less immediate certainty, which leads them to make use of resources outside of their own intuition, such as reference materials and collaboration with other speakers. This reliance on outside resources works to the advantage of fidelity to the breadth of the language. The process of revitalizing Chinuk Wawa is contributing to the continuation of the creolization (in terms of a pidgin becoming a language with native speakers) that began with the resettlement at Grand Ronde (Zenk, 1988). This continued creolization is occurring from the top down with decisions that lead to standardization and increased stability, 
and from the bottom up with speaker creativity, especially among the young learners in the immersion school.

Chinuk Wawa has always been a hybrid language. The process of building it into a language that is used on a daily basis by members of its heritage community is likely to further hybridize it. Zuckermann (2006), in discussing the nature of Israeli Hebrew, asked the question "whether or not it is possible to bring a no longer spoken language back to life without the occurrence of cross-fertilization with the revivalists' mother tongue(s)" (p. 59, emphasis removed). He argued that revival of a language will create a hybrid even in the best case scenario because of the borrowing, whether overt or "camouflaged" as in the case of loan translations, that is necessary to fill lexical (and, I would add, grammatical) gaps (p. 61). The first native Israeli Hebrew speakers based their speech on the non-native speech of their revivalist parents and teachers. The new native Chinuk Wawa speakers are doing the same. There are several important differences, however. First, the young Chinuk Wawa speakers in the immersion school are at most a generation removed from the native Chinuk Wawa speakers who taught Johnson and Zenk. They have access, albeit mediated, to phonological knowledge and intuitions, although they don't have access to an extensive written tradition as young Hebrew speakers did. Second, although instructing children in Chinuk Wawa may in some cases be motivated by ideologies of Native sovereignty, there is no unified ideological movement that is comparable to the nation-building project of Zionism. Finally, the target of the revival is already a hybrid language, developed by the ancestors of the modern Grand Ronde community to meet 
the needs of their multi-cultural world. Extensive further hybridization is undesirable in terms of maintaining fidelity to the language as received from elders, but continued hybridization that encourages use of culturally authentic resources is, in my opinion, faithful to the history of the language. I feel that recognition of Chinuk Wawa as a hybrid language and proud use of it as a heritage language is an important validation of the hybrid nature of the Grand Ronde community.

\subsection{Directions for the future}

This study has identified several areas for future work that could be useful in developing Chinuk Wawa pedagogy and knowledge of Chinuk Wawa's past, present, and future. Continued analysis of the historical texts could yield information about patterns that could be extrapolated with confidence to guide new speakers as they develop their repertoires and creativity in the language. Continued documentation and analysis of the language as it develops could provide feedback about the relationship of current language use to documented elder Wawa; documentation could also help to standardize the developing lexicon, and it could well reveal the "genius" and "sensibility" of the language continuing to develop through active use, especially by the newest native speakers.

\subsubsection{Development of elder Wawa-based standards}

The dictionary is the most important compilation of Chinuk Wawa reference material for the language program; however, it is also a work in progress, and while each subsequent draft version includes more examples, more reference information, 
and more detailed lexical and grammatical analysis, it also includes more refinements, or changes from the previous version. Finalization and publication would create an official standard. (This potential standardization, of course, is why the project must be completed without undue haste and with the utmost care.) A finalized dictionary could also serve as a jumping-off point for more specialized reference materials; it would be a resource for determining lexical gaps that could be addressed by a vocabulary development team, and for raising questions about our knowledge of elder Wawa that could be addressed by continued analysis.

\subsubsection{Continued analysis of existing historical and modern texts}

A detailed computerized corpus analysis of the historical corpus of Chinuk Wawa could yield important insights into patterns of elder Wawa usage that are not immediately visible. For example, a preliminary analysis of the texts appended to the dictionary using the concordancing tool AntConc (Anthony, 2007) revealed the following possible patterning of the third person plural pronouns tas and taska (which occurred 208 and 210 times respectively in the corpus):

The long form [taska] occurs much more frequently as the antecedent of relative clauses ('...they who live across the river,') and the subject of complement clauses ('....so that they could eat') than does the short form, even in texts where the short form is predominant. Conversely, the short form appeared much more frequently as the subject of a relative clause ('... the thing they liked to eat.') (Braun Hamilton, 2009, p. 13)

With such a small corpus, the statistics generated by corpus analyses such as

the one cited above can only suggest directions for deeper inquiry; conclusions cannot be drawn from them. If these patterns are visible in the modern texts as well, that 
would be a good indication that it is strong enough to have been absorbed by today's speakers through exposure to these texts. That would then provide a basis for teaching the use of the long and short pronoun forms to learners. This type of analysis could also shed light on the distribution of the demonstratives uk and ukuk, and the collocations of munk, chaku, hayu, tatwa, and any other lexemes that seem to be (or to have been at one time) in the process of developing grammatical functions. The work of this study could be expanded upon by using the categories I established as an initial basis for examining Chinuk Wawa stylistics through comparison of texts by different authors and comparison of collaborations to independently authored texts.

The inclusion of all existing Chinuk Wawa texts into a comprehensive database, as suggested by Schrock, would allow for instant review of all examples of a certain word or phrase. This database would be a useful tool for research and a reference for writers. Semantic and grammatical tagging of the texts would allow for analysis of the overall frequency of individual lexical items in their various functions, perhaps yielding insight into the prevalence of multi-functionality and the prevalence of certain functions over others. Of course, tagging of this corpus would have to be done manually, and the work would involve many difficult decisions. It is likely that these decisions would reveal even more about the ambiguities and complexities of Chinuk Wawa; it could be useful for this reason alone. Etymological tagging of this hypothetical database could reveal the density of lexemes of different sources in the speech of individuals or groups, as well as the functions of those groups of lexemes. 


\subsubsection{Continued study of Chinuk Wawa's historical context}

Chinuk Wawa came into being and thrived in a context of intense societal and individual multilingualism, but the languages that were in contact at that time have not been thoroughly described. All the participants in this study made reference to the importance of Chinookan to the lexicon, grammar, and sensibility of Chinuk Wawa. Chinookan languages were an important part of Chinuk Wawa's historical context, even for those speakers who did not also speak a Chinookan language. Schrock's observation that, for him, translation into Chinuk Wawa is easier from interlinear glosses from Chinookan and his suggestion that, at some level, word order may be borrowed would be illuminated by further investigation into Chinookan languages, especially as they relate to Chinuk Wawa. This knowledge would be especially valuable for gauging the influence, for example, of Clackamas on the Chinuk Wawa of Victoria Howard. There are several stories that Mrs. Howard told to Melville Jacobs in both Chinuk Wawa (Jacobs, 1936) and Clackamas (Jacobs, 1959). A detailed comparison of these stories could yield valuable information about Mrs. Howard's multilingualism and the relationship between the lexical inventory, grammatical structure, and narrative style in those two of her languages.

It may seem that little needs to be said about English and French as languages in contact with Chinuk Wawa, but the local, non-standard versions of these languages have not been thoroughly described in terms of their relationship with Chinuk Wawa. Transcription of the recordings collected by Zenk of Grand Ronde elders speaking Chinuk Wawa and English is still underway. These recordings offer rich evidence of 
code-switching and code-mixing by the most recent generation of elder speakers, which is a wonderful source of information about their bilingualism and the dynamics of language attrition. They also contain many stories and conversations in English. Analysis of the English spoken by these elders would be interesting in its own right and could also permit more accurate analysis of the influence of their (as opposed to our modern Standard Academic) English on their Chinuk Wawa, and perhaps reveal the influence of Chinuk Wawa on their English.

\subsubsection{Continued documentation of current use}

Now that a Chinuk Wawa discourse community has developed, the opportunity exists to document Chinuk Wawa in modes that have not previously been well-documented, such as conversation, and current recording technology makes it possible to document more thoroughly than was ever possible before. It is my belief that current language use, especially by children in the immersion school and by instructors and other adult speakers with strong intuitions, should be recorded and archived.

Such documentation would raise the issue of the status of current language relative to "elder Wawa." At this point, no transcripts, edited or otherwise, of speech from current speakers has been used for reading materials in the language program, but of course writing by current speakers has been included, and conversation activities are an important component of each lesson. As the language program develops, audio or video recordings of speech in different genres, such as 
conversation, song, or formal speech-making, may become a larger component of lessons, especially those that reach out to learners through distance education. Transcribing and editing these audio and video recordings for use as language learning materials, as was done with The Black Bull of an Hour, would be an interesting study of the requirements of "literary" Chinuk Wawa.

Documentation of current language use could also provide for the compilation of a reference for newly developed (as opposed to historically attested) vocabulary. This reference could also include a guide for coining new lexemes as the need arises, based on the mechanisms observed in the usage of child and adult speakers and writers. Such a reference would allow for expansion of Chinuk Wawa use by relieving some of the pressure for creativity at the lexical level, thereby freeing mental energy for creativity at the level of discourse.

Analysis of current language use could be used to provide feedback to the language program, should they desire it, on the similarities and differences between emerging Chinuk Wawa and the usage of the elders. It could also be used to examine developing genres as the language expands into new domains and to continue looking at the developing differences between oral and written language. It may also be possible to see the emergence of dialectal and idiolectical features, for example, among speakers with different first languages, different other second languages, or different varieties of first language English, or among speakers of different ages, or among those who learned primarily from different speakers or in different contexts. 


\subsubsection{Continued materials and lesson development}

Now that a curriculum and lessons for the university classes have been developed and piloted, they can be refined through continued use and eventually developed into a textbook or other materials for wider distribution. In addition to the texts included in this study, the lessons include a variety of the texts from the historical corpus as well as compositions on many topics that did not exist in draft form; texts in English to be translated, paraphrased, or discussed in Chinuk Wawa; and audio and video recordings. These materials can be expanded upon through additional conversation and oral performance exercises, grammatical exposition related to the texts, writing assignments, and participation by interested learners in the ongoing analysis of the language. Audio recordings of the texts by the instructors would be an excellent resource for learners without access to regular classes where pronunciation is modeled; students could also produce their own recordings and compare their pronunciation to models from elders and current fluent speakers.

One of the effects of presenting the two parallel translations (Four Generations and Good Old Days) to learners was to provide learners with direct access to acceptable variability in the language. Both translations presented were "correct," but their different authorships gave them different styles. I find that there is a great deal of potential in this as a pedagogical exercise, especially if learners first develop their own translation of the English text and compare it to two (or more) expert translations. One of the strengths of translation as a language learning method is that it demands meta-linguistic awareness, increasing the knowledge of the source 
language as well as of the target language, and encouraging learners to explicitly compare the lexical and grammatical resources of the two. Translating from elders' English or interlinear English glosses as Schrock did for some of the texts considered here also has tremendous potential to raise awareness of the sensibility of Chinuk Wawa in its multilingual context.

Encouraging learners to consider the variation of Chinuk Wawa as well as the process of standardizing and creating new texts will encourage deep consideration of the nature of the language, and the meaning of authenticity and culturally sensitive curriculum in this context. It may also encourage learners to feel that they are part of the dynamic process of language revitalization, rather than passive recipients of a traditional artifact from a distant past.

\subsection{Final thoughts}

This thesis has considered a broad range of topics, from the interrelatedness of phonology and orthography to the implications of transparent text (and language) development processes on pedagogy. There are many ways in which the case of Chinuk Wawa elucidates issues of language revitalization and translation, and calls into question the concept (and roles) of the native speaker. The semantic and syntactic mysteries of contact languages are complex and still poorly understood. Hopefully this work has shown that analysis of collaborative writing is one way to identify points of flexibility in a contact language as it transitions into a new role in its community. Continued analysis and documentation of Chinuk Wawa, past and 
present, will continue to affect the Chinuk Wawa of the future. There is still much to learn, and many implications of knowledge about Chinuk Wawa for studies of contact languages, language revitalization, heritage language development, second language acquisition, and bilingualism are undoubtedly yet to be seen. 
Adab, B. (2005). Translating into a second language: Can we, should we? In Anderman, G. M., \& Rogers, M. (Eds.), In and out of English: For better or worse? (pp. 227-241). Clevedon, UK: Multilingual Matters.

Amery, R. (2000). Warrabarna Kaurna! Reclaiming an Australian language. Lisse, The Netherlands: Swets \& Zeitlinger B.V.

Anthony, L. (2007). AntConc (Version 3.2.1). [Computer software]. Retrieved 5/29/2009 from http://www.antlab.sci.waseda.ac.jp/antconc_index.html

Boas, F. (1892). The Chinook Jargon. Science, 19(474), 129. doi: 10.2307/1766921.

Boas, F. (1894). Chinook texts. Smithsonian Institution, Bureau of American Ethnology Washington, D.C.: Govt. Printing Office. Accessed from http://books.google.com/books?id=kVkSAAAAYAAJ\&ots=gm2FkI6msY\&dq=Bo as\%20Chinook\%20Texts\&pg=PA3

Boas, F. (1933). Note on the Chinook Jargon. Language, 9(2), 208-213. doi: $10.2307 / 409271$.

Braun Hamilton, S. (2009). Design, compilation, and use of a Chinuk Wawa corpus. Unpublished manuscript, LING 576: Corpus Linguistics, Portland State University.

Breiner-Sanders, K. E., Lowe, P., Jr., Miles, J., \& Swender, E. (2000). ACFTL Proficiency Guidelines-Speaking. Foreign Language Annals, 33(1), 13-18. Retrieved October 1, 2009, from http://www.actfl.org/i4a/pages/index.cfm?pageid=3349

Campbell, S. (1998). Translation into the second language. London: Longman.

Confederated Tribes of Grand Ronde. (n.d.). Ntsayka Ikanum (Our Story). Retrieved April 11, 2009, from http://www.grandronde.org/culture/ikanum/.

Creswell, J. W. (2007). Qualitative inquiry and research design: Choosing among five approaches. Thousand Oaks, CA: Sage.

Davies, A. D. (2004). The native speaker in applied linguistics. In A. D. Davies \& C. Elder (Eds.), The handbook of applied linguistics (pp. 431-450). Malden, MA: WileyBlackwell. 
Davis, G. M. (1998). šawaš ili'i--šawaš wawa = Indian country--Indian language: A participant observation case study of language planning by the Confederated Tribes of the Grand Ronde Community of Oregon. Unpublished MA thesis, Portland State University, Oregon.

Demers, M., Blanchet, F. N., \& St. Onge, L. N. (1871). Chinook dictionary, catechism, prayers and hymns: The missionary's companion on the Pacific coast. Montreal: [s.n.] Retrieved December 1, 2008, from http://www.canadiana.org/ECO/mtq?doc $=04222$

deReuse, W. J. (1997). Issues in language textbook development: The case of Western Apache. In J. Reyhner (Ed.). Teaching Indigenous Languages. Selected Papers from the Annual Symposium on Stabilizing Indigenous Languages (4th, Flagstaff, Arizona, May 1-3, 1997) (pp. 116-128). Center for Excellence in Education monograph. Flagstaff: Northern Arizona University. (ERIC Document Reproduction Service No. ED415058)

Doty, C. S. (2009). What's in a word (class)?: Internally-motivated word classes in Chinuk Wawa (Chinook Jargon). Manuscript in preparation, University of Oregon.

Drechsel, E. (1996). Native American contact languages of the contiguous United States. In S. A. Wurm, P. Mülhäusler, \& D. T. Tryon (Eds.). Atlas of Intercultural Communication in the Pacific, Asia, and the Americas: Vol. II.2 (pp. 1213-1240). New York: Mouton de Gruyter.

Faigley, L., \& Witte, S. (1981). Analyzing revision. College Composition and Communication, $32(4), 400-414$.

Fishman, J. (1991). Reversing language shift: theoretical and empirical foundations of assistance to threatened languages. Clevedon, UK: Multilingual Matters.

Gerring, J. (2007). Case study research: Principles and practices. Cambridge, UK: Cambridge University Press.

Gibbs, G. (1863). A dictionary of the Chinook Jargon, or trade language of Oregon. Washington, D.C.: Smithsonian Institution. Retrieved December 1, 2008, from http://chinookjargon.home.att.net/gibbs.htm

Givon, T. (1979). On understanding grammar. New York: Academic Press.

Goodfellow, A. (2003). The development of "new" languages in Native American communities. American Indian Culture and Research Journal 27(2), pp. 41-59. 
Graddol, D. (2003). The decline of the native speaker. In G. M. Anderman \& M. Rogers (Eds.) Translation today: Trends and perspectives (pp. 152-167). Clevedon, UK: Multilingual Matters.

Grant, A. (1998). Chinook Jargon and its distribution in the Pacific NW and beyond. In S. A. Wurm, P. Mülhäusler, \& D. T. Tryon (Eds.). Atlas of Intercultural Communication in the Pacific, Asia, and the Americas: Vol. II.2 (pp. 1213-1240). New York: Mouton de Gruyter.

Grant, R. V. (1944). The Chinook Jargon, past and present. California Folklore Quarterly, 3(4), 259-276. Retrieved August 14, 2009 from http://www.jstor.org/stable/1495783

Grenoble, L. (2006). Saving languages: An introduction to language revitalization. Cambridge, UK: Cambridge University Press.

Hale, H. (1890). An international idiom: A manual of the Oregon trade language, or "Chinook Jargon." London: Whittaker. Retrieved December 1, 2008, from http://www.canadiana.org/ECO/ItemRecord/05327?id=c29febaf1ce19fe6\&Lang uage $=$ en

Hale Kuamo'o. (2009). Overview: About Hale Kuamo'o. Retrieved October 4, 2009, from http://www.olelo.hawaii.edu/khuok/hk.php.

Hinkel, E. (2002). Second language writers' text: Linguistic and rhetorical features. Mahwah, NJ: Erlbaum.

Hinton, L. (1996). Flutes of fire: Essays on California Indian languages. Berkeley, CA: Heyday Books.

Hornberger, N. (1997). Indigenous literacies in the Americas: Language planning from the bottom up. Berlin: Walter de Gruyter.

Hymes, D. (1981). In vain I tried to tell you: Essays in Native American ethnopoetics. Philadelphia: University of Pennsylvania Press.

Irvine, J. T., \& Gal, S. (2000). Language ideology and linguistic differentiation. In P. V. Kroskrity (Ed.), Regimes of language (pp. 35-84). Santa Fe, NM: School of American Research Press.

Jacobs, M. (1932). Notes on the structure of Chinook Jargon. Language, 8(1), 27-50. doi: $10.2307 / 409299$.

Jacobs, M. (1936). Texts in Chinook Jargon. Seattle: The University of Washington. 
Jacobs, M. (1959). Clackamas Chinook texts. Bloomington: Indiana University Research Center in Anthropology, Folklore, and Linguistics.

Johnson, T. \& Zenk, H. B. (2009). Chinuk wawa kakwa ntsayka ulman-tilixam taska munkkamtoks ntsayka -pi waxt-hayu chinuk-wawa waxt khapa "ul chinuk-ili?i". [Chinuk Wawa as our elders teach us to speak it -and in addition-More Chinuk Wawa from the general lower Columbia ("old Chinook country"). (Revised 2nd ed.). Manuscript in preparation, Language Program of the Confederated Tribes of Grand Ronde.

Lang, G. (2008). Making Wawa: The genesis of Chinook Jargon. Vancouver: University of British Columbia Press.

Larsen, T. W. (2002). Blue munk: Towards an analysis of causatives and the like in Chinuk Wawa. In Proceedings of the $50^{\text {th }}$ Anniversary Conference of the Survey of Califormia and Other Indian Languages, June 8-9, 2002. Berkeley: University of California.

Larsen, T. W. \& Zenk, H. B. (2007). Chinuk Wawa grammar. Manuscript in preparation.

Leavelle, T. N. (1998). "We will make it our own place": Agriculture and adaptation at the Grand Ronde Reservation, 1856-1887. American Indian Quarterly, 22(4), 433456. doi: $10.2307 / 1184835$.

Meek, B. A. (2009). Language ideology and aboriginal language revitalization in the Yukon, Canada. In P. V. Kroskrity \& M. C. Field (Eds.), Native American language ideologies: Beliefs, practices, and struggles in Indian Country (pp. 172-189). Tucson: University of Arizona Press.

McArthur, T. (2002). The Oxford Guide to World English. Oxford: Oxford University Press.

McCarty, T. L, Watahomigie, L. J., Yamamoto, A. Y., and Zepeda, O. (1997). Schoolcommunity-university collaborations: The American Indian Language Development Institute. In J. Reyhner (Ed.), Teaching Indigenous Languages. Selected Papers from the Annual Symposium on Stabilizing Indigenous Languages (4th, Flagstaff, Arizona, May 1-3, 1997) (pp. 84-104). Center for Excellence in Education monograph. Flagstaff: Northern Arizona University. (ERIC Document Reproduction Service No. ED415058)

NeSmith, R. K. (2009). Tūtū's Hawaiian and the emergence of a Neo Hawaiian Language. (Revised version). Öiwi: A Native Hawaiian Journal, 3. Retrieved from www.traditionalhawaiian.com.

Norris, E. J. (1988). Language awareness and linguistic training in American Indian bilingual programs. Human Organization, 47(4), 317-321. 
Nwenmely, H. (1996). Language reclamation: French Creole language teaching in the UK and the Caribbean. Clevedon, UK: Multilingual Matters.

Palmer, G. B. (1988). The language and culture approach in the Coeur d'Alene Language Preservation Project. Human Organization, 47(4), 307-317. Accessed at http://sfaa.metapress.com/openurl.asp?genre=article\&eissn=19383525 \& volume $=47 \&$ issue $=4 \&$ spage $=307$

Perry, F. L., Jr. (2005). Research in Applied Linguistics: Becoming a discerning consumer. Mahwah, NJ: Erlbaum.

Peterson, L. C. (1997). Tuning in to Navajo: The role of radio in native language maintenance. In J. Reyhner (Ed.), Teaching Indigenous Languages. Selected Papers from the Annual Symposium on Stabilizing Indigenous Languages (4th, Flagstaff, Arizona, May 1-3, 1997) (pp. 214-221). Center for Excellence in Education monograph. Flagstaff: Northern Arizona University. (ERIC Document Reproduction Service No. ED415058)

Powell, J. V. (1973). Raising pidgins for fun and profit: A new departure in language teaching. Proceedings of the Pacific Northwest Conference on Foreign Languages 22, 40-43.

Sapir, E. (1909). Takelma Texts. Philadelphia: The University Museum. Accessed at http://books.google.com/books?id=HQoTAAAAYAAJ\&ots=nbju5PKGu8\&dq=Sa pir\%20Takelma\%20Texts\&pg=PA1\#v=onepage\&q=\&f=false.

Schmidt, R. (1993). Awareness and second language acquisition. Annual Review of Applied Linguistics 13, 206-226.

Shaw, G. C. (1909). The Chinook jargon and how to use it. Seattle, WA: Rainier Printing Company. Accessed at http://books.google.com/books?id=8bUUAAAAYAAJ\&ots=eBhXMLfQ7\&dq=Shaw\%20Chinook\%20Jargon\&pg=PR5\#v=onepage\&q=\&f=false.

Silva, T. \& Matsuda, P. K. (Eds.) (2001). Landmark essays on ESL writing. Mahwah, NJ: Hermagoras.

Silverstein, M. (1972). Chinook Jargon: Language contact and the problem of multilevel generative systems. Language, 48(2, 3), 378-406, 596-625. doi: $10.2307 / 412141$.

Te Taura Whiri i te Reo Māori [Māori Language Commission]. (n.d.). Staff-About us. Retrieved September 14, 2009, from http://www.tetaurawhiri.govt.nz/english/about_e/about.shtml. 
Thomas, E. H. (1935). Chinook: A history and dictionary of the Northwest coast trade jargon; the centuries-old trade language of the Indians of the Pacific. A history of its origin and its adoption and use by the traders, trappers, pioneers and early settlers of the Northwest Coast. Portland, OR: Metropolitan Press.

Thomason, S. G. and Kaufman, T. (1988). Language contact, creolization, and genetic linguistics. Berkeley: University of California Press.

Thomason, S. G. (1983). Chinook Jargon in areal and historical context. Language, 59(4), 820-870.

Thomason, S. G. (2001). Language Contact. Washington, D.C: Georgetown University Press.

Thomason, S. G. (2003). What motivates changes that occur in emerging pidgins and creoles? Journal of Pidgin and Creole Languages, 18(1), 107-120.

Turkkonen-Condit, S., Mäkisalo, J., \& Immonen, S. (2008). The translation process: Interplay between literal rendering and a search for sense. Across Languages and Cultures 9(1), pp. 1-15.

UNESCO Ad Hoc Expert Group on Endangered Languages. (2003). Language vitality and endangerment. Presented at the International Expert Meeting on UNESCO Programme Safeguarding of Endangered Languages, Paris. Retrieved from www.unesco.org/culture/ich/doc/src/00120-EN.pdf.

Vrzić, Z. (1999). Modeling pidgin/creole genesis: Universals and contact influence in Chinook Jargon syntax. Unpublished doctoral dissertation, New York University.

Wilson, W. H. \& Kamanā, K. (2001). "Mai loko mai o ka 'i'ini: Proceeding from a dream": The "Aha Pūnana Leo connection in Hawaiian revitalization. In L. Hinton \& K. Hale (Eds.), The green book of language revitalization in practice (pp. 147-176). San Diego, CA: Academic Press.

Winford, D. (2003). An introduction to contact linguistics. Malden, MA: Blackwell.

Yin, R. K. (1989). Case study research: Design and methods. Revised edition. Applied Social Research Methods Series, Volume 5. Newbury Park, CA: Sage.

Zenk, H. B. (1985). Chinook Jargon and Native Cultural Persistence in the Grand Ronde Indian Community, 1856-1907: A Special Case of Creolization. Unpublished Doctoral Dissertation, University of Oregon. 
Zenk, H. B. (1988). Chinook Jargon in the speech economy of Grand Ronde Reservation, Oregon: An ethnography-of-speaking approach to an historical case of creolization in process. International Journal of the Sociology of Language, 71, 107124.

Zuckermann, G. (2006). A new vision for Israeli Hebrew: Theoretical and practical implications of analyzing Israel's main language as a semi-engineered SemitoEuropean hybrid language. Journal of Modern Jewish Studies, 5(1), 57-71. 
APPENDIX A: CHINUK WAWA GRAMMAR

Chinuk Wawa does not yet have a completely standardized prescriptive grammar. Neither does it have a completely accepted descriptive grammar. This appendix is not an attempt to satisfy the need for either of these; instead, I aim only to provide materials that may enable the reader to better understand the issues discussed in this thesis. I include here a general introduction to the characteristics of the language, a comparison of proposed slot grammars, and notes towards a description of the parts of speech which will be used as introductory material in the next edition of the dictionary. Citations for examples in this appendix give the initials of the speaker and the text and line number from Johnson \& Zenk, 2009.

\section{Contact language characteristics}

Chinuk Wawa developed historically as a contact language that is perhaps best described for grammatical purposes as an extended or elaborated pidgin (Winford, 2003). Winford defined pidgin languages as "those contact vernaculars characterized by highly reduced vocabulary and structure [relative to the languages in contact], which are native to no one, and serve as lingua francas for certain restricted communicative functions such as trade" (p. 270). Like other pidgins, Chinuk Wawa has no inflectional morphology, and its derivational morphology is limited. It has few

function words, question words, and pronouns, and the sentence structure is primarily analytic. Like other pidgins, Chinuk Wawa has a restricted lexical inventory, in which lexemes, as described by Dreschel (1996, cited in Winford, 2003, p. 276), are "semantically and grammatically ambiguous, as well as polysemous" and the lexicon 
is expanded by compounding, metaphor, and borrowing to meet communicative needs. Unlike many other pidgins, however, Chinook Jargon was used historically not only for "restricted communicative functions." Considering the linguistic density and traditional exogamy of the area, was probably used in political associations, gatherings of relatives, and marriage negotiations prior to European contact. After contact, it was certainly used in these ways and also in exploration, missionary work, ethnographic research, labor relations, and entertainment (Winford, 2003). When the Grand Ronde reservation was formed, it became the shared Native language of the community, and it was part of the linguistic repertoire of children raised there, especially those in multi-ethnic families (Zenk, 1988; Lang, 2008).

\section{Multifunctionality and ambiguity}

Most Chinuk Wawa lexemes are highly multifunctional. Chinuk Wawa words come from a variety of different languages that were in contact while Chinuk Wawa was developing. These languages were often much more grammatically complex than Chinuk Wawa. With the exception of singular and plural personal pronouns, Chinuk Wawa words are not marked for number, gender, case, tense, aspect, directionality, etc. Words such as wawa can be verbs ('speak, talk, say') or nouns ('speech, word'). Others, such as $k^{h}$ anawi 'all, every, entirely, each, all of them' seem to defy traditional Western part-of-speech classification altogether, serving as adverb, adjective, or pronoun as required by context. Words derived from Chinookan verbal particles (such as t'sax, 'split'), are ambiguously adjectival ('split') or verbal ('to split, chop') in 
meaning. The Chinuk Wawa phrase "yaka t'sox stik" could mean either 'he chops wood' or "his split wood." In Chinookan, verbal morphology would distinguish these meanings. Johnson and Zenk (2009) suggest using the compound munk-t'sox for the verbal meaning in order to avoid this ambiguity in Chinuk Wawa. This verb-deriving function of unstressed munk 'make, do' will be discussed further below. The demonstrative pronoun ukuk can also be used to support an adjectival meaning, as in "ukuk yaka t'sox stik" 'that chopped wood of his' or "yaka t'sox stik ukuk" 'that's his chopped wood.' Intonation, context, collocation and word order are the principal tools with which functions are determined and ambiguities are resolved.

\section{Sentence structure}

Early descriptions of Chinuk Wawa grammar (Hale, 1890; Jacobs, 1932) focused mainly on word order, the pronoun system, and compounding. Later work has specifically explored the derivational characteristics of certain productive compounds (Larsen, 2002; Doty, 2009). To begin discussion of Chinuk Wawa word order I have used a comparison of the "slot grammars" proposed by Jacobs (1932, p. 37), Larsen \& Zenk (2007), and Doty (2009) $)^{21}$ to distill a summary model of Chinuk Wawa word order and to elucidate areas of disagreement.

${ }^{21}$ There is also a preliminary draft of a grammatical model prepared by Terrence Kaufman in 1968 that can be reviewed in the special collections of the Multnomah County Library; unfortunately this is not currently available for citation. The model, however, is in general agreement with the other models cited below. 

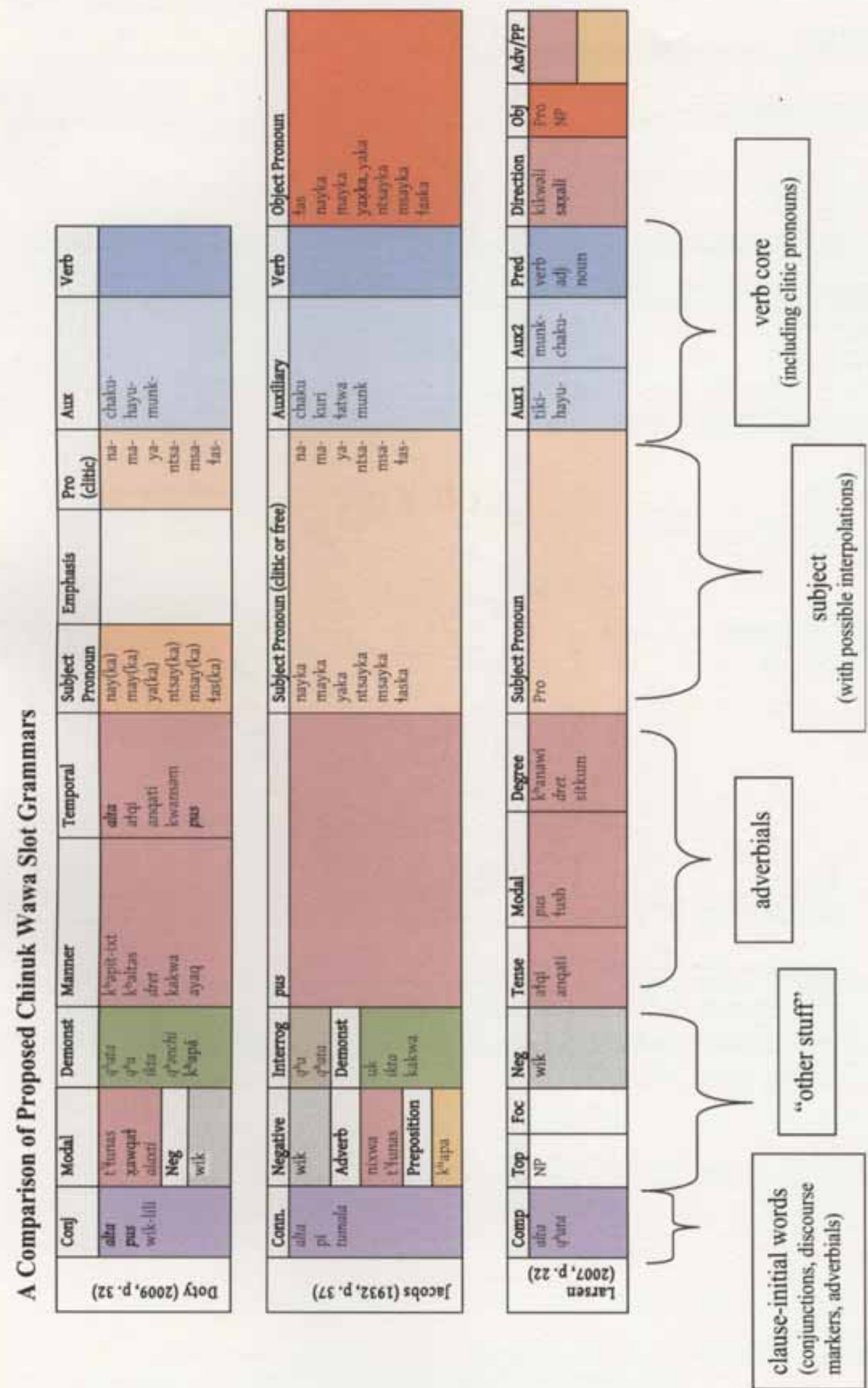
These three models of Chinuk Wawa grammar show the following main areas of agreement: the usual transitive word order is SVO; subject pronouns, especially the short clitic forms, immediately precede the verb core; the verb core may include "auxiliaries;" negation and adverbials precede the subject pronoun; and certain words are common clause-initially. This yields the following very basic transitive clause structure:

$$
\begin{aligned}
& \text { ("connector") + (negation/adverbial) + subject pronoun + verb + object. } \\
& \text { alta tas lulu yaxka (VH 13:70) } \\
& \text { then they carry her } \\
& \text { alta waxt ya munk- txwap ili?i (VH 13:125) } \\
& \text { then again she cause hole earth }
\end{aligned}
$$

Intransitive clauses normally also follow this structure:

$$
\begin{aligned}
& \text { alta waxt yaka } \\
& \text { then again (JH 3:13) } \\
& \text { he ran }
\end{aligned}
$$

Clauses with non-verbal predicates usually have VS order:

$$
\begin{array}{ll}
\text { mashachi-shawash } & \text { mayka. (WB 18:7) } \\
\text { bad-Indian } & \text { you. 'You are a bad Indian. }{ }^{22 *}
\end{array}
$$

Since many Chinuk Wawa lexemes can be used as either adjectives or verbs, word order can serve to distinguish these functions: mimalust yaka 'he's dead' versus yaka mimalust 'he died.'

\footnotetext{
${ }^{22}$ The stress patterns in this sentence, masháchi-shawàsh 'mayka, yields Zenk's translation: 'a miserable excuse for an Indian YOU are!' (Johnson and Zenk, 2009, p. 263).
} 
Although these are the basic word order patterns, fronting of objects or verbs for emphasis or topicalization is permissible and common, as is post-verbal repetition of subjects.

\section{Pronouns}

The complete set of personal pronouns in Chinuk Wawa is as follows:

\begin{tabular}{|l|l|l|l|l|}
\hline & LONG FORMS & TRUNCATED & SHORT (CLITIC) & FOCUS/EMPHASIS \\
\hline & & & $\begin{array}{l}\text { Preverbal subject \& } \\
\text { possessor only }\end{array}$ & \\
\hline 1SG & nayka & nay & na & nayka \\
\hline 2SG & mayka & may & ma & mayka \\
\hline 3SG & yaka & ya & ya & yaxka \\
\hline 1PL & ntsayka & ntsay & ntsa & ntsayka \\
\hline 2PL & msayka & msay & msa & msayka \\
\hline 3PL & taska & tas & tas & taska \\
\hline
\end{tabular}

(adapted from Larsen, 2002)

All of these pronouns are used in subject and noun possessor roles; all but the clitic forms can also be used in object roles. The long and truncated forms typically are unstressed or only lightly stressed when serving as preverbal subjects or noun possessors, while they receive more stress as objects or post-verbal subjects. The clitic forms are usually unstressed, and the emphasis forms usually receive strong stress. Neither the clitic nor the truncated forms were used by all of the elder speakers. Those who used the truncated forms tended to use them just as they did the long forms, while the clitic forms seem to be "tied" (Jacobs, 1932) tightly to the possessed nouns or the verbs that they precede.

These personal pronouns rarely represent inanimate objects, although they are occasionally pressed into service as possessors, for example: ya t'zap uk lakamas ya 
Although these are the basic word order patterns, fronting of objects or verbs for emphasis or topicalization is permissible and common, as is post-verbal repetition of subjects.

\section{Pronouns}

The complete set of personal pronouns in Chinuk Wawa is as follows:

\begin{tabular}{|l|l|l|l|l|}
\hline & LONG FORMS & TRUNCATED & SHORT (CLITIC) & FOCUS/EMPHASIS \\
\hline & & & $\begin{array}{l}\text { Preverbal subject \& } \\
\text { possessor only }\end{array}$ & \\
\hline 1SG & nayka & nay & na & nayka \\
\hline 2SG & mayka & may & ma & mayka \\
\hline 3SG & yaka & ya & ya & yaxka \\
\hline 1PL & ntsayka & ntsay & ntsa & ntsayka \\
\hline 2PL & msayka & msay & msa & msayka \\
\hline 3PL & taska & tas & tas & taska \\
\hline
\end{tabular}

(adapted from Larsen, 2002)

All of these pronouns are used in subject and noun possessor roles; all but the clitic forms can also be used in object roles. The long and truncated forms typically are unstressed or only lightly stressed when serving as preverbal subjects or noun possessors, while they receive more stress as objects or post-verbal subjects. The clitic forms are usually unstressed, and the emphasis forms usually receive strong stress. Neither the clitic nor the truncated forms were used by all of the elder speakers. Those who used the truncated forms tended to use them just as they did the long forms, while the clitic forms seem to be "tied" (Jacobs, 1932) tightly to the possessed nouns or the verbs that they precede.

These personal pronouns rarely represent inanimate objects, although they are occasionally pressed into service as possessors, for example: ya t' tap uk lakamas ya 
skin (VH 13:8), 'she found that camas its skin,' or in situations in which inanimate objects have active qualities, such as this example in which an old woman is turning pitch into a monster to chastise her disobedient granddaughter (VH 3:24): chaku-tax ukyalakum, chaku-lu?lu? $q^{\text {ha }}$ uklakum ${ }_{1}$ ya $a_{1}$ tatwa $k^{\text {hapa }}$ became- thather became- where that it went to earth out pitch, round pitch 'that pitch of hers came out, it accumulated where the pitch went to ground.'

\section{Resumptive pronouns}

A subject pronoun is almost always used when the subject has an active or agentive role in the clause, even if there is a full NP subject. This is known as a resumptive or pleonastic pronoun.

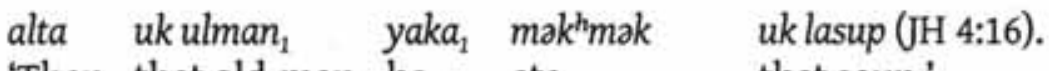
'Then that old- $\operatorname{man}_{1} \mathrm{he}_{1}$ ate that soup.'

Resumptive pronouns do not seem to be required, however, in stative or change-of-state clauses, or with non-verbal predicates:

alta uklilu yaka tonas chaku-sik (JH 5:5). then that Wolf his child became-sick.

Grammatical theories differ as to whether resumptive subject pronouns are subjects, with any nominal subjects occupying a topic position (Vrzić, 1999; J. Schrock, May 5, 2009), or whether they are verbal agreement markers, with any nominal subject occupying the subject position (Larsen, 2002). 
Since yaka can be male or female, subject or object, in narratives it often becomes a bit difficult to tell who is doing what to whom. In this case some speakers, use the special emphasis form yaxka $a^{23}$ to draw attention to a change of referent. alta ya tatwa. ya kuri. ya kuri łatwa. 'Then she [the little girl] went. She ran. She went running.' alta yaxka uk lamiyay ya iskam uk ya skin lup ya munk k'aw-k'aw ya k'watin. (JH A2) 'Then she, that old lady, she got that leather thong of hers and she bound up her stomach.'

As a subject, this form acts as a noun-phrase subject in that it requires a pleonastic pronoun.

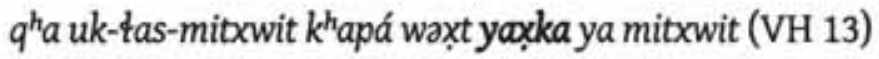
'Where it was they stood, there also she she stood.'

However, it can also occur with an explicative noun-phrase subject, as in the first example above. As an object, it can stand alone.

\section{"Auxiliaries"}

Several of the Chinuk Wawa lexical verbs have quasi-morphological functions that have been described in many ways. The CTGR language program tends to refer to them as auxiliaries, although they are not parallel to English auxiliary verbs such as "have" and "be." The three main words that have been described in this way are munk 'make, do,' chaku 'come,' and hayu 'many.'

The basic conceptualization of the functions of these three main auxiliaries is that munk-forms transitive verbs, chaku-forms intransitive change-of-state verbs, and

${ }^{23}$ This form is from the Chinookan independent pronoun iaxka which is the masculine third person focus form. In Chinookan person is marked morphologically on the verb stem, but independent pronouns can also be used to indicate emphasis (Johnson and Zenk, 2009). 
hayu- forms progressive or imperfective verbs. Doty (2009) used the ability of other lexemes to form compounds with these three auxiliaries as a basis for identifying Chinuk Wawa word classes.

When unstressed and bound to its right collocate, munk- means roughly "cause X." Depending on the collocate, this can be seen as deriving a verb from a noun (munk\&xwap 'dig,' from \$xwap 'hole') or as deriving a transitive change-of-state verb from an adjective (munk-ixpuy lapot 'close the door' from ixpuy 'closed'). With other verbs, munk- can form causatives such as taska munk-kuri yaka 'they made him run' (EJ 22 in Johnson \& Zenk 2009, p. 80). Larsen (2002) described situations in which munk- is used with other verbs in a non-causative sense, when instead it lends a reflexive meaning (as in yaka munk-ham 'he stinks') or draws focus to the action because it is particularly sudden or forceful (as in alta yaka munk-komtaks yaka 'then he [finally] recognized her') (examples from Johnson \& Zenk, 2009, p. 78).

Adding chaku- to a noun or adjective means roughly "become X;" it indicates that the subject changes to the named form or state: alta ya chaku-taxayam 'now he becomes poor' (WB, 17:7). Doty's (2009) analysis identified an inceptive meaning of chaku-when it is bound to verbs of cognition and perception (kamtaks 'know' and nanich 'see' -> chaku-kamteks 'realize;' chaku-nanich 'notice').

Unlike munk and chaku, hayu as an independent (stressed) word is not a verb, but an adjective, meaning 'many,' that can also be used as an indefinite pronoun. When it is attached to an active verb, it adds a progressive or imperfective aspect: alta yaxka uk hayash-hayash ya hayu-mək ${ }^{h} m ə k$ (VH 13:11) 'then SHE those big ones she is- 
eating.' hayu- can be added to verbs formed with munk- (e.g. ya hayu-munk-phlum 'she is-sweeping' from phlum 'broom').

\section{Short forms of awxiliaries}

Several shortened forms of chaku- (chaw-, chu-, ch-) were used frequently by Wilson Bobb and were also documented from Victoria Howard (recall that these speakers are from the same family). In Wilson Bobb's usage, the shorter forms could always be substituted for the full forms, but at least in one familiar phrase (ikta chaw-

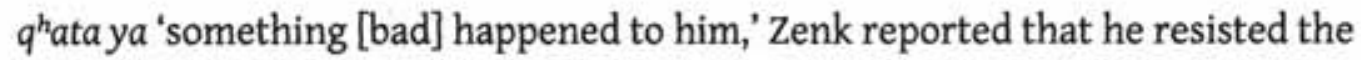
substitution of chaw- with chaku-. The examples of these short forms of chaku-seem to indicate, according to Zenk, that for these speakers "the short forms are especially appropriate when change is to be viewed as a whole or as something completed" (Johnson \& Zenk, 2009, p. 24). A shortened form of hayu-, hay-, was also documented from several speakers, although there does not seem to be any evidence for a different meaning in this case.

\section{Combining verbs}

Other verbs can collocate with verbs, such as tatwa 'go,' kuri 'run,' and tiki 'want.' These do not always lose stress in collocation, and are usually semantically transparent; therefore they are probably best understood as serial or combining verb constructions. The three main combining verbs are łatwa 'go,' kəmtəks 'know,' and tiki 'want.' Each of these are productive in combination with other verbs, but they each have conventional combinations. 
tatwa in combination with other verbs means 'go and V.' It is often used in combination with nanich 'look at, look for,' as in tas tatwa -nanich mawich 'they hunt (literally 'go look for') deer' (VH A2.88), and with iskam 'get, take,' as in khanawi nisay [ntsayka] tatu-iskam ulali 'we all go get berries' (ET 24.6). kamtəks in combination means 'know how to V' or 'be good at V,' as in yułqat-q'walan kwansum yaka hayash khəmtəkskuri 'Rabbit always he [was] very good at running' (JH 3.1). tiki in combination means 'want to $\mathrm{V}$ ' and can also be used to indicate incipient action, meaning 'show indications of V,' as in examples from John "Mose" Hudson using the alternate form tq'it: chxi tq'i-tuwax 'it's just know showing signs of dawn' and alta tq'i $k^{h} u l-i l i ? i$ 'it's getting on wintertime now'.

\section{MODIFIERS: Adverbials and adjectives}

Many Chinuk Wawa modifiers can be used to modify verbs or nouns, taking the cue for their semantic character from the word they are modifying. When words have an adverbial function they usually appear before the subject, while adjectival functions are indicated by placement directly before the noun they modify, either as a predicate adjective describing the subject of a sentence: yudqat yaka 'she is tall,' or as a modifier to the subject or object of a verb clause: alta tas munk-k'aw-k'aw $k^{h} a p a$ yuuutqat lup 'then they tie them into a loooong rope' (VH 11.2).

\section{Temporal adverbs}

Chinuk Wawa indicates temporal information through the use of three adverbs: angati 'in the past,' alta 'now,' and ałqi 'in the future.' Usually, however, time 
is not marked and is left up to context. Use of atqi can indicate expectation, intention or compulsion, rather than just simple future time:

tumala atqi na mək ${ }^{h} m 2 k$ ukuk (WB 21:26) tomorrow ałqi I eat that 'The next day I am to eat that one.'

As a temporal adverb, alta is used to contrast present to past or future time. More frequently, however, it is used as a clause-initial conjunction that I have called a discourse marker, with the meaning 'and now' or 'and then.' Other words with temporal senses such as chxi 'new, newly,' waxt 'more, again,' may also have aspectual functions. There is one intriguing example of pus 'if, when' used in a past imperfective sense by Victoria Howard (11:1):

na mama pus ya ya?im nayka $q^{\text {hata }}$ anqati pus tas hihi 1SG mother PUS 3SG tell 1SG how PAST PUS 3PL play 'my mother used to tell me how they would play long ago.

The full extent of the grammatical functions of pus for expressing conditionality, instrumentality, and aspect has not yet been described.

\section{Modals}

Chinuk Wawa has several words that seem to have modal functions: tush 'good, well' is used as a modal of suggestion or obligation, as in the common phrase tush mayka munk-kakwa 'It'd be good if you would do thus.' Thomason (2001, p. 122) mentions this type of "periphrastic imperative" as a possible Pacific Northwest areal construction. Uncertainty and possibility are indicated by $t^{\prime}$ tunas and alaxti, while impossibility is indicated by xawqał. These modals are usually clause-initial, preceding 
temporal adverbs when they occur with them, as in t'funas alta y a munk-mimalust na chach 'Perhaps now he's killed my grandmother' (VH A2.46).

\section{"Intensifiable" manner and degree adverbs}

Other lexemes have been categorized as adverbs of manner or degree when they modify a verb. Adverbs usually precede the subject, but the placement of several common "manner and degree" adverbs, hayash 'in a big way, vigorously,' dret 'really, truly,' ayaq 'quickly,' and łush 'well' can be altered to produce different effects. These adverbs can be intensified by placing them directly before the verb, rather than before the subject, as in alta yutqat-q' walan yaka hayash kuri 'then Rabbit ran really really hard' (JH 3.15), as opposed to the unmarked position alta yułqatq'wolan hayash yaka kuri 'then Rabbit ran vigorously (but not as vigorously as in the first example.) Speakers would also sometimes intensify the effect of these adverbs by placing them in between repetitions of the subject pronoun, as in tas tush tas wawa wawa wawa 'they're good for talking and talking and talking' (WB 19.25).

\section{Negation}

Chinuk Wawa has one main negation word: wik. It is used as a negative interjection, and as an adverbial. It is almost always positioned quite early in the clause, certainly before the subject, and is often clause initial, preceding temporal adverbs:

wik ałqi misayka ata nakya.

NEG FUT 2PL wait 1SG

'You won't have to wait for me' (JH 4.41) 
It is very productive in forming compounds (such as wik-lili 'not long = soon,' wik-qhanchi 'not when = never,' wik-tush 'not good = bad'), however, that may then be more mobile according to their function in the clause.

\section{Demonstratives and question words}

The demonstratives $u k$ and $u k u k$ are both used with nouns to mean 'this, that, those, the.' However, they do not seem to be completely in complementary distribution. Both of them refer to a previously known referent. $u k$ is also used as a relativizer, as in alta taska uk hayu-nanich mawich tas chaku 'then they who were hunting deer they came' (VH 12.36), while ukuk has not been recorded in this function. $u k u k$, on the other hand, can be used independently as an inanimate third person pronoun, as in tumala ałqi na mək ${ }^{h}$ mak ukuk 'tomorrow I will eat it' (WB 21.26), but it has not been recorded as the subject of an active verb. This pronominal function has not been recorded for $u k$. Both of $u k$ and $u k u k$ can be used as demonstratives before a noun phrase.

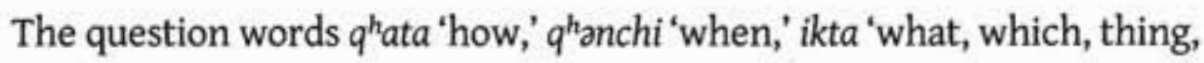
something,' $q^{h} a$ 'where' can also be used as relativizers and subordinating conjunctions. These interrogative/relatives are often clause-initial, unless they are preceded by a conjunction. One example is the following sentence from Elmer Tom, which illustrates both the pronominal function of $u k u k$ and the subordinating function of $i k t a:$ 
nay t'sipi ukuk ikta na tiki-p'u.

I missed it what I tried to shoot (ET 23.8).

This sentence can also be interpreted with $u k u k$ as a demonstrative and ikta as an indefinite noun: 'I missed that thing I wanted to shoot.' In that case it would be ukuk that would be the subordinator. Both words would be able to assume that role.

There was an interrogative particle, $n a$, that is attested from some early speakers, but it did not survive at Grand Ronde, probably due to competition with the short form pronoun na and interference from English question formation. Some of the

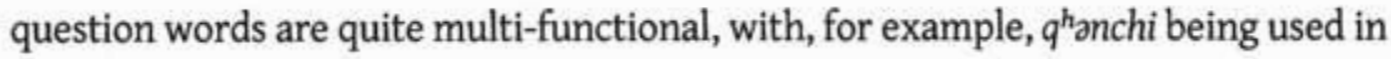
compounds to mean 'how many, how much, how long, how far, etc.' and as an

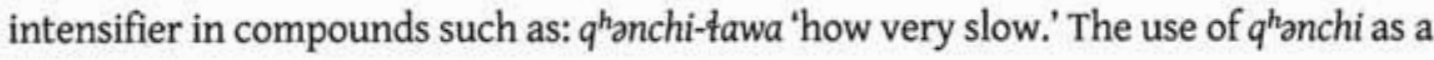
relativizer and subordinator is focused on these quantitative meanings, rather than being used as an equivalent to the English 'when,' as in "I'll see you when I arrive." In Chinuk Wawa the multi-functional word pus fills that role, as in laxw-san pus tas q'u? k'iilapay 'it would be afternoon when they got back home' (VH 13.86).

\section{Conjunctions}

Chinuk Wawa conjunctions all have very different functions. pi, most similar to English 'and,' is used to conjoin two noun phrases either additively ('and') or contrastively ('or'). It is not generally used to conjoin verb phrases or to sequence narrative. That role is filled by alta for declarative or narrative sentences ('and then...') and by pus when there is a relationship between the two verb phrases in which one action is completed in order to facilitate the second. pus is also used to set 
up conditional actions: pus ya q'u? ałqi na uma? yaxka 'when (if) he comes then I will feed him' (VH A2.21). bat is used as is English 'but.

\section{The Noun Phrase}

Chinuk Wawa noun phrases have not received much attention from scholars. The basic structure of the noun phrase is (demonstrative) + (modifiers) + (possessor/pronoun) + noun. The format DEM PRO N, as in ukya chech 'that 1SG grandmother $=$ that grandmother of hers' is very common .

\section{Directions for Research}

This brief sketch has attempted to summarize what is known about Chinuk Wawa grammar. It is still quite incomplete. It is clear that this is a language in which syntax and semantics are very interdependent. The structure of compound and complex sentences in Chinuk Wawa and the manner in which ambiguities are resolved has not been described. Many questions remain regarding the conditions for fronting and topicalization, as well as interpolation of words between the subject and the verb or between a nominal and pronominal subject. Collocation and compounding are powerful tools of Chinuk Wawa grammar, and should provide fruitful ground for inquiry into word classes and semantic relationships, especially with highly multifunctional words. 


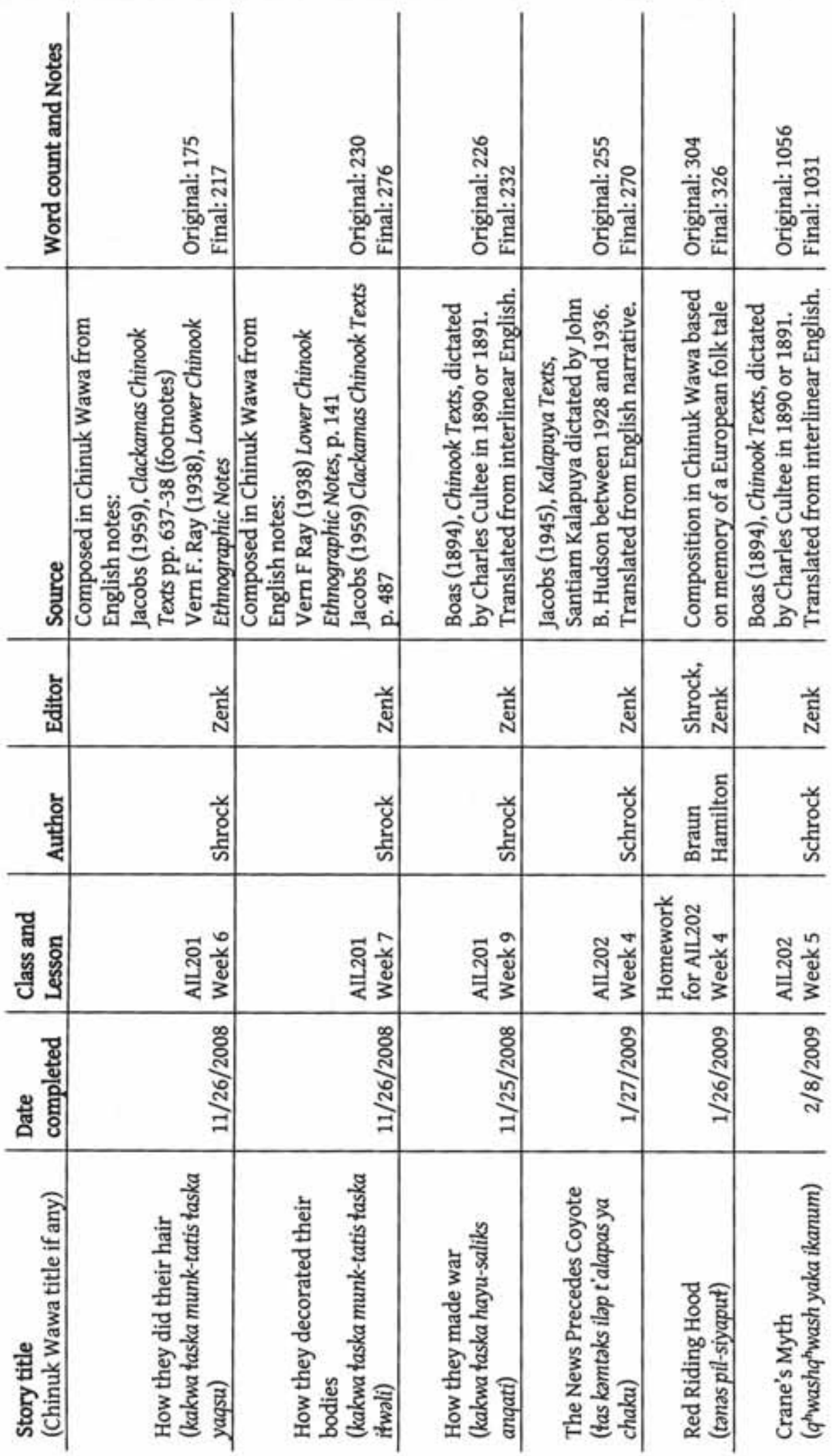




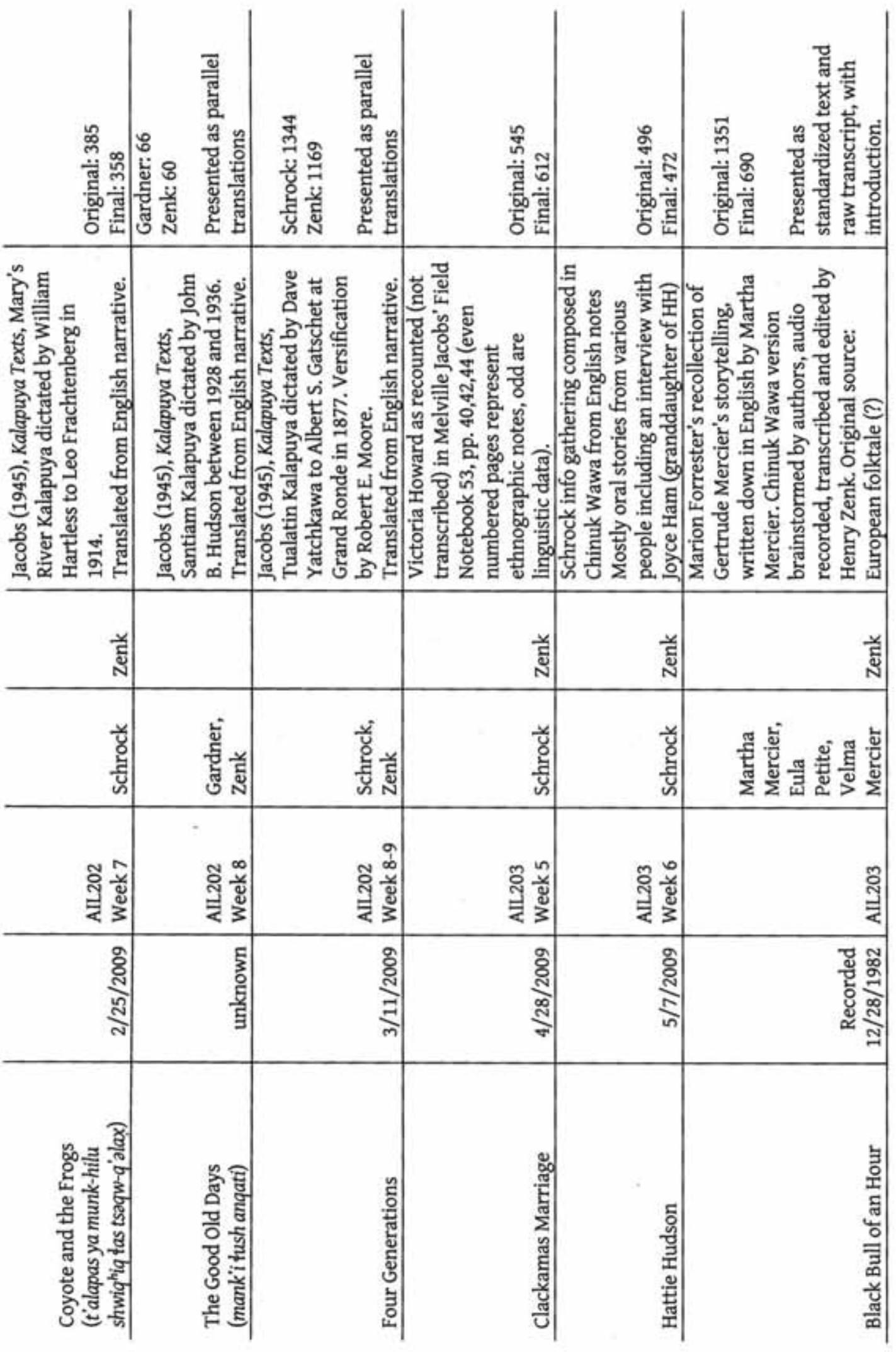


Initial Format

General interviews:

Interviewer describes the research and initiates general discussion:

- How do new texts get developed for the language program?

- What makes texts appropriate for use in language classes?

- Tell me about the process that you use to develop a new text.

- What do you think about when you compose a text? When you edit someone else's composition?

- What resources do you use when you are writing or editing?

- What do you find yourself having to make decisions about when you write or edit? How do you make those decisions?

- What are the trickiest parts of the writing/editing process?

- Do you find that there are areas where you and others disagree?

- What do you think are the "sticking points" of Chinuk Wawa - the areas that still need to be figured out?

- What do you think about the new texts that have been developed and how they've worked out in the university classes?

- What do you think is important for me to consider in doing this research?

- Is there any particular text that you think would be interesting to discuss in detail with me?

\section{Retrospective interviews}

Interviewer chooses a text to discuss with the interviewee. She begins by asking general questions, such as:

- Can you tell me about writing (or editing) this particular text?

- What is the history of this text?

- How was the topic (or source text) selected?

- How did it come to be written?

- Was it designed to address any particular learning objectives? If so, what were they?

- Do you remember making any changes or having to make any tricky decisions while you were writing/editing this text? Was there anything that you remember going back and forth on a lot? How did you finally make your decision?

The interviewer then identifies a certain change or an exemplar of a type of change that she wishes to discuss with the interviewee. She initiates a conversation on the topic by showing the change and asking the following sorts of questions:

- What do you remember about this particular change?

- Do you find that this is a common kind of change for you? 
- Are there times when you think you wouldn't make a change like this?

- When would it be okay not to make this change?

- Is this an important change or kind of change for you? Is the text acceptable without it? Why or why not?

Probing questions may be like the following:

- What kind of change do you feel like this is? Does it have to do with grammar, style...?

- How do you know it sounds better this way? What influenced your decision?

- Tell me about the discussion you and $\mathrm{X}$ had about this change. What was the difference of opinion? Do you feel that it is resolved?

- How do you feel that this text worked in the lesson? Are there any further changes you would make after using this text in class?

\section{Additional Questions Developed from Text Analysis General:}

- How do you develop texts from different sources?

- What kinds of changes do you think get made to texts? Which ones are most frequent?

- Are there any consistent differences that you've noticed between your writing and others' writing?

\section{Regarding vocabulary:}

- What are your thoughts about choosing words when there is no obvious choice?

- What options do you consider when choosing a word?

- Do you notice any preferences that you or others have among these options?

\section{Regarding orthography and hyphenation:}

- What are the factors in deciding how words borrowed from other languages should be transliterated?

- What are your thoughts about hyphenation?

- When should hyphenation be used, and what does it mean to you?

- What rule (if any) do you use to help you decide whether or not to use a hyphen?

- Have your ideas about hyphenation changed over time, and if so, how and why?

- Do you think that hyphenation is a lexical issue, or a grammatical one? 


\section{Regarding grammar:}

- What are your thoughts about uk and ukuk? Do you follow any rule about when to use either?

- What are your thoughts about the different forms of the personal pronouns?

- What is the relationship between overt subject and object NPs and personal pronouns?

- When is it important to use an NP?

- What do you think about auxiliaries: when are they necessary, what do they mean, when are they different from their lexical meanings?

- What are your thoughts about pus: what grammatical and lexical roles does it play?

\section{Regarding narrative strategies:}

- What do you think of as the characteristics of Chinuk Wawa narrative?

- How do those characteristics relate to texts that are written down as opposed to told orally?

- What changes do you think are made in creating a "literary language" that can be read in classes?

- How should the texts be formatted?

- What kinds of information is it important to present in Chinuk Wawa texts?

- What can be omitted or should be left out?

- What are your thoughts about clause-initial alta? 
APPENDIX D: CRANE'S MYTH SELECTIONS

\section{Tracked Changes, Codes, and Comments}

The following is a screenshot from a section of Crane's Myth (in which Heron escapes from the basket in which he is being carried), showing Schrock's text with Zenk's tracked changes in orange. My coding is within brackets in the texts, and all of our comments are in the right margin.

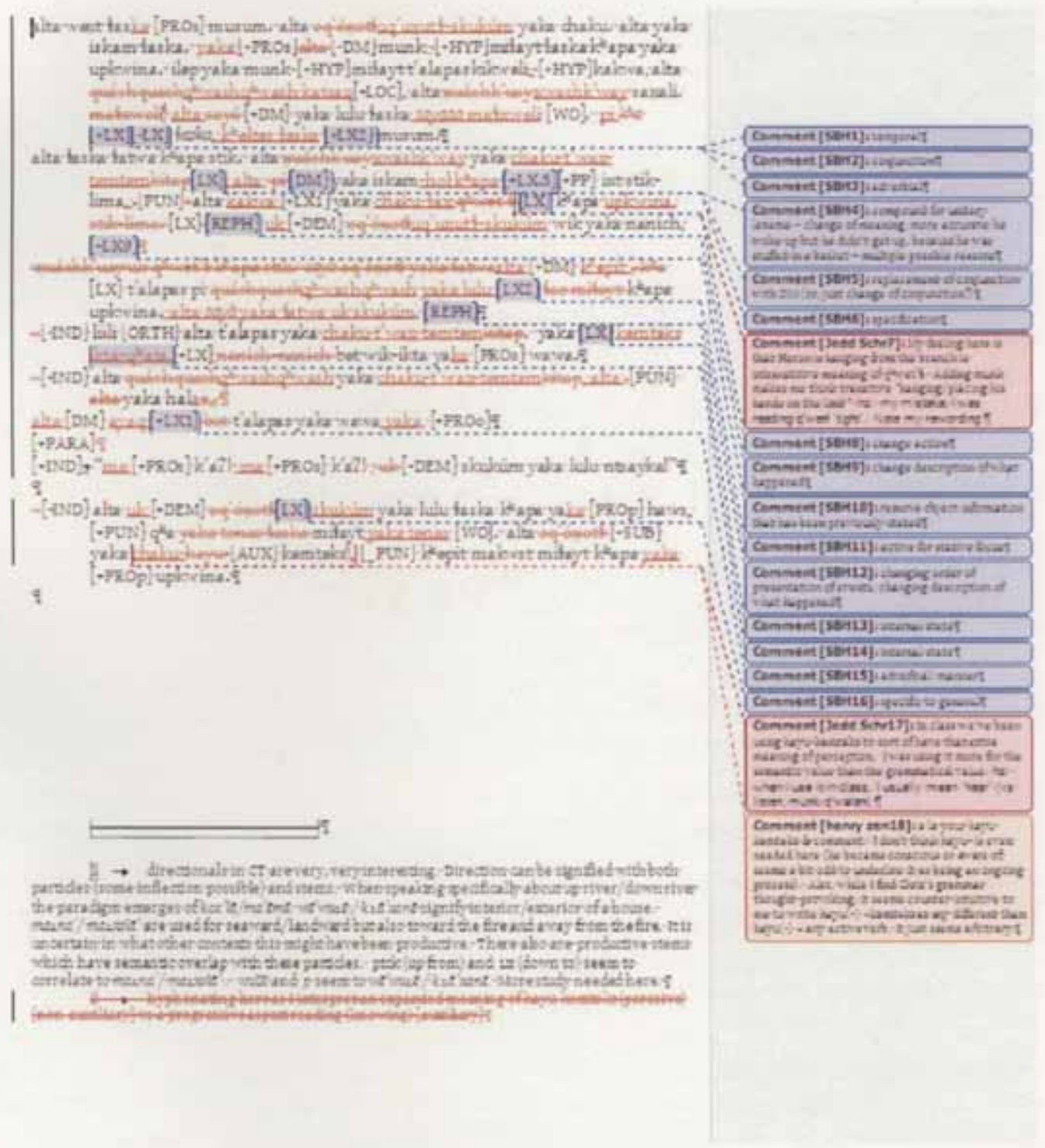


2. Line by line (Chinookan text and English gloss from Boas, 1894, p. 107)

$$
\mathrm{C}=\text { Charles Cultee (transcribed by Boas); } \mathrm{B}=\text { Boas; } \mathrm{S}=\text { Schrock; } \mathrm{Z}=\text { Zenk }
$$

C: A'ta arkj̣̄e'witox ·itx. NōLx Oqjō̄xōt,

B: Now they fell asleep. She came Oq;ō'xōt,

S: alta waxt tas musum. alta oq'óxotł yaka chaku. Now again they slept. Then Oq'óxotł she came.

Z: alta waxt taska musum. alta uq'uxutt-skukúm yaka chaku. Now again they slept. Then uq'uxutt-monster she came.

C: akı.'lgitgax;

B: she put them into [basket]

S: alta munk miłayt taska $k^{h}$ apa yaka upkwina. alta yaka iskam taska. Now makes be-located them PREP [in] her basket. Now she gets them.

Z: yaka munk-miłayt taska $k^{h}$ apa yaka upkwina. alta yaka iskam taska. She puts them PREP [in] her basket. Now she gets them.

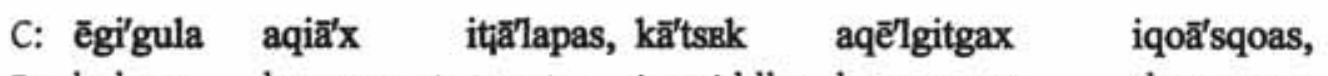

B: below he was put coyote, in middle he was put the crane,

S: ilap yaka munk miłayt t'alapas kikwali kakwa, alta quáshquash, First she makes be-located coyote below thus, then Crane,

Z: ilap yaka munk-miłayt t'alapas kikwali-kakwa, alta $q^{h}$ wash $^{h}{ }^{h}$ wash katsaq, First she puts Coyote below-like, then Crane middle,

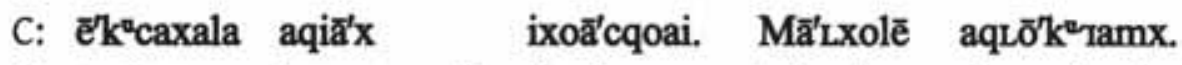

B: on top he was made the heron. Inland she arrived carrying them.

S: alta xuáshk'uay saxali. alta łaska łatwa $\mathrm{k}^{\text {hapa stik. }}$ then Heron above. Then they went PREP [to] forest.

Z: alta xwashk'way saxali. alta taska tatwa $\mathrm{k}^{\text {h }}$ apa stik then Heron above. Then they went PREP [to] forest.

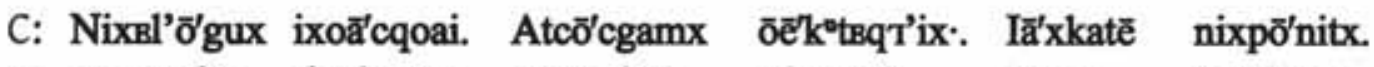

B: He awoke the heron. He took it a branch. There he hung.

S: alta xuáshk'uay yaka kitap pi yaka iskam ixt stik-lima. alta yaka $q^{h}{ }^{w} t^{\prime}$ ' $k^{h}$ apa stik-lima. oq'óxotł wik yaka nanich xuáshk'uay uk $q^{h}{ }^{\text {wet' }} k^{h}$ apa stik.

Then Heron he got-up and he got one branch. Then he hung PREP [from] branch. Oq'oxotł NEG she see Heron that hung PREP [from] tree.

Z: alta xwashk'way yaka chaku-t'wax-tomtom, alta yaka iskam-hol khapa ixt stik-lima, alta kakwa yaka chaku-tax $k^{h}$ apa upkwina. uk uq'uxutt-skukúm wik yaka nanich. Then Heron he woke-up, then he got-hold PREP [of] one branch, then thusly he become-emerged PREP [from] basket. That uq'uxutt-monster NEG she see. 


\section{C: Kulā'yi nō'yamx uqcxē'Lau.}

B: Far she arrived the monster.

S: sayá oq'óxotł yaka łatwa, $\mathrm{k}^{\text {ha }}$ t'alapas pi quáshquash łas miłayt $\mathrm{k}^{\text {hapa }}$ upkwina.

Z: alta $\mathrm{k}^{\mathrm{h}}$ əpit t'alapas pi $\mathrm{q}^{\mathrm{h}}$ wash ${ }^{\mathrm{h}}$ wash yaka lulu $\mathrm{k}^{\mathrm{h}}$ apa upkwina. alta sayá yaka łatwa uk skukúm.

C: Nixkl'ō'gux itā̄lapas. Nē'k·imqac pst nixā'x.

B: He awoke coyote. He looked [? ?] quiet he was.

S: liili alta t'alapas yaka kitap. yaka nanich-nanich bat wik-ikta ya wawa.

Z: lili alta t'alapas yaka chaku-t'wax-təmtəm. yaka kəmtaks ikta-qhata, bat wik-ikta yaka wawa.

C: NixBL'ō'kux iqoă'cqoac.

B: He awoke the crane.

S: alta quáshquash yaka kitap.

Z: alta $q^{\text {h }}$ wash $^{\text {h }}$ wash yaka chaku-t'wax-təmtəm,

\section{C: Atcixвlqülxax.}

B: He shouted.

S: alta yaka hala,

Z: alta yaka hala.

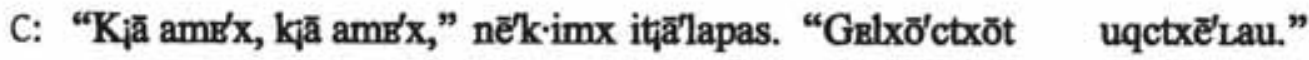

B: "Silent be, silent be," he said coyote. "She carries us the monster."

S: bat t'alapas yaka wawa, "k'a?! k'a?! uk skukúm yaka lulu ntsayka!"

Z: alta ayaq t'alapas yaka wawa yaka, "ma k’a?! ma k’a?! skukúm yaka lulu ntsayka!"

C: Akcō'k ${ }^{\natural}$ Tamx

gō tr'kXaqu gō tga'a

uqctxē'Lau.

B: She carried them two to her house to her children the monster.

S: alta oq'óxotł yaka lulu łaska $k^{\text {hapa }}$ ya haws $\mathrm{q}^{\text {ha }}$ yaka tonas łaska miłayt.

$\mathrm{Z}$ : alta uk skukúm yaka lulu taska $\mathrm{k}^{\text {h }}$ apa yaka haws, $\mathrm{q}^{\text {ha }}$ miłayt yaka tonas.

C: Agiōnā'xuatcgox qix. ē'Xat.

B: She lost him that one.

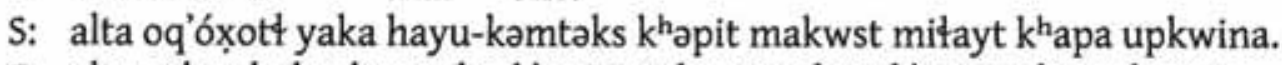

$\mathrm{Z}$ : alta yaka chaku-kəmtəks, $\mathrm{k}^{\mathrm{h}}$ əpit makwst miłayt $\mathrm{k}^{\mathrm{h}}$ apa yaka upkwina. 


\section{APPENDIX E: TEXT IN VERSE FORM}

In order to show an example of Hymes-influenced versification of oral narrative, the following excerpt is included from The Four Generations of Mankind, which was originally dictated in Tualatin Kalapuya by Dave Yatchkawa to Albert S. Gatschet, Grand Ronde, 1877. The line-segmentation of this version was by Robert E. Moore. This copy was transcribed from a manuscript in the personal collection of Henry B. Zenk.

Long ago there were people

There were lots of people

They filled the land.

Everywhere there were many people.

There was not much sickness.

All those who were made,

all those children did become big.

Then they lived a long time.

Then they went, the hunters (were) five people.

One dog did accompany them.

Then five times did they sleep,

In the evening the dog came home.

Then one small girl asked the dog:

"How many were killed?"

The dog did not speak.

For the second time she asked:

"How many were killed?"

Five times she asked.

Then the dog said:

"Five were killed."

Then the world turned upside down.

All the people became stars.

Then there were no people on earth,

there was only the girl

and the dog who made her his wife. 